\title{
S2k-Leitlinie „Akute infektiöse Gastroenteritis im Säuglings-, Kindes- und Jugendalter" - AWMF Registernummer 068-003
}

Leitlinie der Gesellschaft für pädiatrische Gastroenterologie und Ernährung

(GPGE) gemeinsam mit der Deutschen Gesellschaft für Kinder- und Jugendmedizin

(DGKJ), dem Berufsverband der Kinder- und Jugendärzte (BVKJ), der Deutschen

Gesellschaft für pädiatrische Infektiologie (DGPI), der österreichischen Gesellschaft für

Kinder- und Jugendheilkunde (ÖGKJ), der Deutschen Gesellschaft für Gastroenterologie,

Verdauungs- und Stoffwechselstörungen (DGVS), dem Arbeitskreis „Krankenhaus \&

Praxishygiene“ der AWMF und der Deutschen Gesellschaft für Pflegewissenschaft e. V.

(DGPW)

\section{Autoren:}

Carsten Posovszky', Verena Backendorf², Stephan Buderus ${ }^{3}$, Martin Claßen ${ }^{4}$, Hans-jörg Epple ${ }^{5}$, Bernd Gruber ${ }^{6}$, Almuthe C. Hauer ${ }^{7}$, Johannes Hübner ${ }^{8}$, Klaus-Michael Keller ${ }^{9}$, Sibylle Koletzko ${ }^{8}$, Burkhard Lawrenz ${ }^{10}$, Anjona Schmidt-Choudhury ${ }^{11}$, Andreas Stallmach ${ }^{12}$, Ulrich von Both ${ }^{8}$

Institute

1 Klinik für Kinder- und Jugendmedizin, Universitätsklinikum Ulm, Ulm

2 Klinikum Mutterhaus der Borromäerinnen, Trier

3 St. Marienhospital Bonn, Pädiatrie, Bonn

4 Klinik für Kinder- und Jugendmedizin, Klinikum Links der Weser

5 Medizinische Klinik für Gastroenterologie, Infektiologie und Rheumatologie, Charité - Universitätsmedizin Berlin, Campus Benjamin Franklin, Berlin

6 Niels-Stensen-Kliniken, Marienhospital Osnabrück, Osnabrück

7 Universitätsklinik für Kinder- und Jugendheilkunde, Medizinische Universität Graz, Graz, Österreich

8 Dr. von Haunersches Kinderspital, Ludwig-MaximiliansUniversität, München

9 DKD Helios-Klinik Wiesbaden, Wiesbaden

10 Praxis für Kinder- und Jugendmedizin, Arnsberg
11 Klinik für Kinder- und Jugendmedizin der Ruhr-Universität im St.-Josef-Hospital, Bochum

12 Klinik für Innere Medizin IV (Gastroenterologie, Hepatologie und Infektiologie), Universitätsklinikum Jena der Friedrich-Schiller-Universität Jena, Jena

Bibliografie

DOI https://doi.org/10.1055/a-0981-6906

Z Gastroenterol 2019; 57: 1077-1118

(c) Georg Thieme Verlag KG, Stuttgart · New York

ISSN 0044-2771

Korrespondenzadresse

PD Dr. med. Carsten Posovszky

Klinik für Kinder- und Jugendmedizin,

Universitätsklinikum Eythstr. 24, 89075 Ulm

Tel.: ++ 49/731/50057315

Fax: ++ 49/7 31/50 057285

carsten.posovszky@uniklinik-ulm.de 


\begin{tabular}{|c|c|}
\hline Inhaltsverzeichnis & Seite \\
\hline Einleitung & 1078 \\
\hline E-1 Hintergrund & 1078 \\
\hline E-2 Ziele der Leitlinie & 1079 \\
\hline Methodik & 1079 \\
\hline M-1 Versorgungsbereich und Zielgruppen & 1079 \\
\hline $\begin{array}{l}\text { M-2 Zusammensetzung der Leitliniengruppe: } \\
\text { Beteiligung von Interessengruppen }\end{array}$ & 1079 \\
\hline M-3 Beteiligte Gruppierungen und Fachgesellschaften & 1080 \\
\hline $\begin{array}{l}\text { M-4 Redaktionelle Unabhängigkeit und Umgang mit } \\
\text { potenziellen Interessenkonflikten }\end{array}$ & 1080 \\
\hline M-5 Durchführung & 1080 \\
\hline $\begin{array}{l}\text { a) Recherche, Auswahl und Bewertung wissenschaftlicher } \\
\text { Belege (Evidenzbasierung) }\end{array}$ & 1080 \\
\hline $\begin{array}{l}\text { b) Formulierung der Empfehlungen und strukturierte } \\
\text { Konsensfindung }\end{array}$ & 1081 \\
\hline M-6 Externe Begutachtung und Verabschiedung & 1081 \\
\hline M-7 Verbreitung und Implementation & 1081 \\
\hline M-8 Gültigkeitsdauer und Aktualisierung & 1081 \\
\hline Kapitel & 1082 \\
\hline $\begin{array}{l}\text { K-1 Definition, klinisches Bild und Diagnostik der akuten } \\
\text { infektiösen Gastroenteritis im Säuglings- und Kindesalter }\end{array}$ & 1082 \\
\hline $\begin{array}{l}\text { K-2 Management und Behandlung der akuten Gastro- } \\
\text { enteritis im Säuglings-, Kindes- und Jugendalter }\end{array}$ & 1094 \\
\hline $\begin{array}{l}\text { K-3 Prävention, Hygiene und nosokomiale Infektion im } \\
\text { Säuglings- und Kindesalter }\end{array}$ & 1104 \\
\hline Literaturverzeichnis & 1113 \\
\hline
\end{tabular}

\section{ABKÜRZUNGSVERZEICHNIS}

AAD antibiotikaassoziierte Diarrhoe

AGE akute Gastroenteritis

AWMF Arbeitsgemeinschaft der Wissenschaftlichen Medizinischen Fachgesellschaften e. V.

BfR Bundesinstitut für Risikobewertung

BSG Blutkörperchensenkungsgeschwindigkeit

BVKJ Berufsverband der Kinder- und Jugendärzte e. V.

CDAD Clostridoides-difficile-assoziierte Diarrhoe

CDC Centers for Disease Control and Prevention

CDI Clostridoides-difficile-Infektion

CED chronisch-entzündliche Darmerkrankung

CRP C-reaktives Protein

DGHM Deutsche Gesellschaft für Hygiene und Mikrobiologie

DGKH Deutsche Gesellschaft für Krankenhaushygiene e. V.

DGKJ Deutsche Gesellschaft für Kinder- und Jugendmedizin e. V.

DGPI Deutsche Gesellschaft für Pädiatrische Infektiologie e. V.
DGPW Deutsche Gesellschaft für Pflegewissenschaften e. V.

DGVS Deutsche Gesellschaft für Gastroenterologie, Verdauungs- und Stoffwechselerkrankungen e. V.

EAEC enteroaggregative Escherichia coli

EHEC enterohämorrhagische Escherichia coli

EIA enzymgekoppelter Immunadsorptionstest

(ELISA) (engl. Enzyme-Linked Immunosorbent-Assay)

EIEC enteroinvasive Escherichia coli

EPEC enteropathogene Escherichia coli

ETEC enterotoxinbildende Escherichia coli

GPGE Gesellschaft für Pädiatrische Gastroenterologie und Ernährung e. V.

HUS hämolytisch-urämisches Syndrom

IDSA Infectious Diseases Society of America

IfSG Infektionsschutzgesetz

KISS Krankenhaus-Infektions-Surveillance-System des Nationalen Referenzzentrums für Surveillance von noskomialen Infektionen am RKI

KRINKO Kommission für Krankenhaushygiene und Infektionsprävention

LGG Lactobacillus GG

NICE National Institute for Health and Clinical Excellence (UK)

MTS Manchester-Triage-System

ÖGKJ Österreichische Gesellschaft für Kinder- und Jugendheilkunde

ORL orale Rehydrationslösung

ORT orale Rehydrationstherapie

RCT Randomized Controlled Trial

RKI Robert-Koch-Institut

SBS Säure-Basen-Status

SIRS systemisches inflammatorisches ResponseSyndrom

STEC Shigatoxin-produzierende Escherichia coli

STIKO Ständige Impfkommission am RKI

STX Shigatoxin

VRE Vancomycin-resistente Enterokokken

VTEC Verotoxin-produzierende $E$. coli

ZNS Zentralnervensystem

\section{Einleitung}

\section{E-1 Hintergrund}

Die akute infektiöse Gastroenteritis (AGE) ist eines der häufigsten pädiatrischen Krankheitsbilder. In den meisten pädiatrischen Leitlinien wird sie klinisch durch eine verminderte Stuhlkonsistenz und für das Alter erhöhte Stuhlfrequenz definiert, die auch mit Fieber und Erbrechen einhergehen kann [1]. Säuglinge und Kleinkinder sind mit 1 bis 2 Episoden von AGE im Jahr am häufigsten betroffen. Dies zeigt sich epidemiologisch an der höchsten altersspezifischen Inzidenz für AGE im Kindesalter in Deutschland; am häufigsten sind die Norovirus-Infektionen bei unter 5-Jährigen mit 595/100 000 Einwohnern, gefolgt von den Rotavirus-Infek- 
tionen mit ca. 300/100 000, den Campylobacter- (122/100 000) und Salmonellen-Infektionen (69/100 000) bei den 1-Jährigen [2]. Auch Erkrankungen durch enterohämorraghische Escherichia coli (EHEC), die meist mit Durchfall assoziiert sind, treten insbesondere bei Kindern unter 5 Jahren auf [2].

Die AGE im Kindesalter verläuft häufig mild, ist aber mit einer relevanten Hospitalisierungsrate und nicht zu vernachlässigenden Todesraten assoziiert. Mangelnde Flüssigkeitsaufnahme, Elektrolytentgleisung oder zunehmende Dehydration im Rahmen der AGE sind die häufigsten Gründe für stationäre Krankenhausaufenthalte bei Kindern in Deutschland [3]. Die Hospitalisierungsrate bei Rotavirus-Gastroenteritiden liegt bei unter 15-Jährigen mit $57 \%$ im Vergleich beinahe so hoch wie bei über 69-Jährigen (60\%) [2]. Von den ca. 100000 stationären Aufnahmen von Kindern aufgrund einer akuten infektiösen Gastroenteritis in Deutschland werden ca. 25000 durch Rotaviren verursacht [4].

Für einzelne Enteritis-Erreger finden sich auch saisonale Häufungen, wie zum Beispiel für Noroviren im Winter, Rotaviren im Frühjahr und Salmonellen im Sommer, während andere, wie Campylobacter-spp.-Infektionen, sporadisch auftreten [2]. Weiterhin kommt es immer wieder zu akuten Ausbrüchen von Gastroenteritiden, von denen insbesondere Kinder und Jugendliche in Tageseinrichtungen oder Kliniken betroffen sind [2]. Nosokomiale Gastroenteritisausbrüche werden in Deutschland hauptsächlich durch Noro- (76\%) und Rotaviren $(6,4 \%)$ verursacht [2]. Insofern sind entsprechende Hygiene- und Präventionsmaßnahmen für diese Patientengruppe von besonderer Bedeutung. Der deutliche Rückgang der Rotavirus-Gastroenteritis in Deutschland im Jahr 2016 um 32\% gegenüber dem Vorjahr bei unter 2-jährigen Kindern wird der zunehmenden Inanspruchnahme der seit Sommer 2013 von der Ständigen Impfkommission am RKI (STIKO) empfohlenen Impfung für Säuglinge zugeschrieben [2].

Der klinischen Relevanz der AGE im Kindesalter wurde in den letzten Jahren durch die Entwicklung internationaler Leitlinien Rechnung getragen. So haben u. a. 2008 und 2014 die Europäische Gesellschaft für Pädiatrische Gastroenterologie, Hepatologie und Ernährung (ESPGHAN) gemeinsam mit der Europäischen Gesellschaft für infektiöse Erkrankungen (ESID) [5, 6], sowie 2009 das britische National Institute for Health and Clinical Excellence (NICE) [7] Leitlinien für Kinder unter 5 Jahren vorgestellt. Die S2k-Leitlinie „Akute infektiöse Gastroenteritis im Säuglings-, Kindes- und Jugendalter" der Gesellschaft für pädiatrische Gastroenterologie und Ernährung (GPGE) versteht sich als Adaptation und deutschsprachige Ergänzung der genannten Leitlinien. Die aktuellen Publikationen, die nach Veröffentlichung der o.g. Leitlinien erschienen sind, wurden kritisch gewürdigt und haben - soweit sinnvoll - Eingang in die Empfehlungen dieser Leitlinie gefunden.

\section{E-2 Ziele der Leitlinie}

Das Ziel der interdisziplinären S2k-Leitlinie „Akute infektiöse Gastroenteritis im Säuglings-, Kindes- und Jugendalter“ ist es, den aktuellen Kenntnisstand zu klinischem Bild, Diagnostik, Therapie, Prävention und Hygiene der akuten infektiösen Gastroenteritis, einschließlich der nosokomialen gastrointestinalen Infektionen, bei Säuglingen, Kindern und Jugendlichen auf Basis der wissenschaftlichen Evidenz zusammenzufassen, im Experten- konsens zu bewerten und daraus praxisrelevante Empfehlungen abzuleiten. Die Leitlinie soll einen Handlungskorridor für häufige Entscheidungen liefern. Sie soll zudem der evidenzbasierten Fortund Weiterbildung dienen und somit eine Verbesserung der medizinischen Versorgung von Kindern mit akuter Gastroenteritis erreichen. Insbesondere sollen durch die Leitlinie unnötige stationäre Aufnahmen von Kindern mit AGE vermieden und präventive Maßnahmen zur Infektionsvermeidung und -ausbreitung verbessert werden.

Hierzu seien weitere erläuternde Vorbemerkungen vorangestellt.

1. Im Kindesalter spielen infektiöse Darmerkrankungen eine wesentlich größere Rolle als im Erwachsenenalter.

2. Das Krankheitsbild und die Therapie der akuten infektiösen Gastroenteritis unterscheiden sich in wesentlichen Aspekten zwischen Kindern und Erwachsenen. Die S1-Leitlinie „Akute Gastroenteritis im Kindesalter“ der GPGE ist zwischenzeitlich veraltet. Die S2k-Leitlinie „Gastrointestinale Infektionen und Morbus Whipple“ der DGVS (AWMF Register Nr. 021/024) und S1-Handlungsempfehlung „Akuter Durchfall“ der DEGAM (AWMF Register Nr. 053/030) [8] beziehen sich auf erwachsene Patienten. Vor diesem Hintergrund wurde eine separate S2k-Leitlinie für Säuglinge, Kinder und Jugendliche als Ergänzung erstellt.

3. Pädiatrische Leitlinien der European Society for Paediatric Gastroenterology, Hepatology and Nutrition (ESPGHAN) und der European Society of Pediatric Infectious Diseases (ESPID) $[5,6]$ sowie vom National Institute for Health and Care Excellence (NICE) [7], die sich auf unter 5-Jährige beziehen, wurden bei der Leitlinienerstellung berücksichtigt.

4. Die Qualität der wissenschaftlichen Evidenz wird für einige Empfehlungen als nicht hoch eingeschätzt, sodass hier lediglich Expertenmeinungen Grundlage für die Empfehlungen bilden können.

5. Die Gültigkeit der Leitlinie beträgt 5 Jahre. Eine Revision ist für 2024 geplant.

\section{Methodik}

\section{M-1 Versorgungsbereich und Zielgruppen}

Die Leitlinie gilt sowohl für die stationäre als auch für die ambulante Versorgung. Die Empfehlungen richten sich an alle an der Diagnostik und Therapie beteiligten Berufsgruppen (Kinder- und Jugendärzte, Kindergastroenterologen, pädiatrische Infektiologen, gastroenterologische Internisten, Krankenhaushygieniker, Pflegewissenschaftler). Die Leitlinie richtet sich zur Information an Hausärzte, Allgemeinärzte, Internisten, Kinderkrankenpfleger sowie an Betroffene und ihre Eltern.

\section{M-2 Zusammensetzung der Leitliniengruppe: Beteiligung von Interessengruppen}

Die Gesellschaft für pädiatrische Gastroenterologie und Ernährung (GPGE) beauftragte Carsten Posovszky (Ulm) mit der Leitung der Leitlinienerstellung. In Abstimmung mit der GPGE und AWMF wurden die Eckpunkte des Konsentierungsverfahrens festgelegt, 
andere Fachgesellschaften eingeladen und die Mandatsträger den Arbeitsgruppen zugeordnet. Dabei erfolgte die Auswahl der AG-Mitglieder primär nach fachlicher Expertise. Leider konnte die Deutsche Gesellschaft für Allgemeinmedizin und Familienmedizin (DEGAM) aufgrund begrenzter Ressourcen nicht bei dieser Leitlinie mitwirken. Da es sich um ein akutes Krankheitsbild handelt und eine Selbsthilfegruppe nicht existiert, wurde kein Patientenvertreter beteiligt $(\triangleright$ Tab. $\mathbf{M}-\mathbf{2})$.

\section{M-3 Beteiligte Gruppierungen und Fachgesellschaften}

\section{Federführung und Koordination}

Gesellschaft für pädiatrische Gastroenterologie und Ernährung e. V. (GPGE)

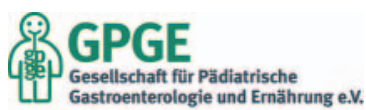

\section{Mitarbeit}

Arbeitskreis „Krankenhaus \& Praxishygiene“ der AWMF

Berufsverband der Kinder- und Jugendärzte e. V. (BVKJ)

Deutsche Gesellschaft für Kinder- und Jugendmedizin e. V. (DGKJ)

Deutsche Gesellschaft für pädiatrische Infektiologie e. V. (DGPI)

Deutsche Gesellschaft für Pflegewissenschaft e. V. (DGPW)

Deutsche Gesellschaft für Gastroenterologie, Verdauungs- und Stoffwechselkrankheiten e. V. (DGVS)

Österreichische Gesellschaft für Kinder- und Jugendheilkunde (ÖGKJ)

\section{M-4 Redaktionelle Unabhängigkeit und Umgang mit Interessenkonflikten}

Die Leitlinie wurde finanziert von der GPGE, der DGKJ und dem Lions Club Dillingen. Vertreter der pharmazeutischen Industrie wurden nicht am Prozess der Leitlinienentwicklung beteiligt, um Neutralität und Unabhängigkeit zu wahren.

Vor dem Hintergrund der zunehmenden Bedeutung von Leitlinien zur Diagnostik und Therapie von Erkrankungen werden potenzielle Interessenkonflikte der an der Leitlinie mitarbeitenden Personen immer wichtiger. Interessenkonflikte sind als Situationen definiert, die ein Risiko beinhalten, dass das professionelle Urteilsvermögen, welches sich auf ein primäres Interesse bezieht, durch sekundäre (persönliche) Interessen unangemessen beeinflusst wird. Sekundäre Interessen, die mit dem primären Interesse der evidenzbasierten Leitlinienerstellung in Konflikt geraten können, sind zum Beispiel materielle Interessen, wie das Interesse an der Aufrechterhaltung einer Beziehung zu einem pharmazeutischen Unternehmen. Zu den immateriellen Interessen gehören ggf. die mandatierende Organisation (z. B. Fachgesellschaften), der Arbeitgeber und der wissenschaftliche Schwerpunkt der betroffenen Person. Ebenso können soziale oder intellektuelle Interessen als sekundäre Interessen zu einem Interessenkonflikt führen. Bezüglich potenzieller Interessenkonflikte bei den Teilnehmern der S2k-Leitlinienkonferenz „Akute infektiöse Gastroenteritis im Säuglings-, Kindes- und Jugendalter“ sei an dieser Stelle kurz zusammenge-
- Tab. M-2 Mitarbeiter der Leitlinie.

Mitarbeiter der Leitlinie

\begin{tabular}{|c|c|c|}
\hline $\begin{array}{l}\text { AG } 1 \text { Definition, } \\
\text { klinisches Bild und } \\
\text { Diagnostik der } \\
\text { akuten infektiösen } \\
\text { Gastroenteritis im } \\
\text { Säuglings-, Kindes- } \\
\text { und Jugendalter }\end{array}$ & K.-M. Keller (DGKJ) & $\begin{array}{l}\text { B. Lawrenz (BVKJ, } \\
\text { Arnsberg), U. von Both } \\
\text { (DGPI, München), } \\
\text { H.-J. Epple (DGVS, } \\
\text { Berlin), A.C. Hauer } \\
\text { (GPGE, ÖGKJ, Graz), } \\
\text { C. Posovszky (Ulm) }\end{array}$ \\
\hline $\begin{array}{l}\text { AG } 2 \text { Management } \\
\text { der akuten Gastro- } \\
\text { enteritis }\end{array}$ & $\begin{array}{l}\text { S. Buderus (GPGE, } \\
\text { Bonn) }\end{array}$ & $\begin{array}{l}\text { A. Schmidt-Choudury } \\
\text { (Bochum), M. Claßen } \\
\text { (Bremen), B. Lawrenz } \\
\text { (BVKJ, Arnsberg), } \\
\text { C. Posovszky (Ulm) }\end{array}$ \\
\hline $\begin{array}{l}\text { AG } 3 \text { Prävention und } \\
\text { Hygiene ambulant } \\
\text { erworbener und } \\
\text { nosokomialer akuter } \\
\text { Gastroenteritis im } \\
\text { Säuglings-, Kindes- } \\
\text { und Jugendalter }\end{array}$ & $\begin{array}{l}\text { Gruber (Arbeitskreis } \\
\text { Krankenhaus- und } \\
\text { Praxishygiene), } \\
\text { C. Posovszky (Ulm) }\end{array}$ & $\begin{array}{l}\text { V. Backendorf } \\
\text { (DGPW), J. Hübner } \\
\text { (DGPI, München), } \\
\text { A. Stallmach (DGVS, } \\
\text { Jena), S. Koletzko } \\
\text { (München) }\end{array}$ \\
\hline AWMF & $\begin{array}{l}\text { I. Kopp, M. Nothacker } \\
\text { (Marburg/Lahn), } \\
\text { A. Moss (Ulm) }\end{array}$ & \\
\hline
\end{tabular}

fasst, dass vor Beginn der Leitlinien-Konferenz alle Teilnehmer ihre potenziellen Interessenkonflikte (siehe ausführliche Tabelle im Leitlinienreport) schriftlich mithilfe eines Formblattes der AWMF (Version 2010), das direkte, finanzielle und indirekte Interessen umfasst, offengelegt haben. Diese Interessenkonflikte wurden auf der Leitlinienkonferenz unter Moderation der AWMF (vertreten durch M. Nothacker) offen diskutiert und es wurde einstimmig beschlossen, dass sich Personen mit thematisch relevanten, moderaten Interessenkonflikten (d. h. Patentbesitz, Mitgliedschaft in einem Advisory Board eines thematisch relevanten Medikaments bzw. eines relevanten pharmazeutischen Unternehmens und Aktienbesitz > $10000 €$ ) bei der Abstimmung von Empfehlungen, die von diesen Interessenkonflikten berührt werden könnten, enthalten. Es wurden Stimmenthaltungen für einzelne Teilnehmer zu den Themen Impfung, orale Rehydrationslösungen und Probiotika festgehalten (siehe Leitlinienreport). Gelegentliche Honorare für Vortrags- oder Schulungstätigkeiten wurden als geringfügiger Interessenkonflikt gewertet und führten nicht zu Stimmenthaltungen.

\section{M-5 Durchführung}

\section{a) Recherche, Auswahl und Bewertung wissenschaftlicher Belege (Evidenzbasierung)}

Es erfolgte eine systematische Literaturrecherche. Auf Grundlage von Stichwörtern erfolgte im April 2016 und Juli 2017 eine Literatursuche nach „MeSH-terms“ in PubMed (Einschränkungen: human, die letzten 5 oder 10 Jahre; keine Editorials, historische Artikel, Kommentare oder Fallberichte). Die gefundenen Artikel wurden aufgrund von Abstract und Titel bewertet und entweder 
- Tab. M-3 Literatursuche.

\begin{tabular}{|l|l|l|}
\hline Literatursuche & Einschränkung & gefundene Artikel \\
\hline „acute gastroenteritis children“ & human; Trials 10 years & 998 \\
\hline & human; Reviews 5 years & 660 \\
\hline And „nosocomial“ & human; 10 years & 182 \\
\hline And „guidelines“ & 10 years & 36 \\
\hline And „prevention“ & Review 10 years & \\
\hline
\end{tabular}

in das Literaturverzeichnis aufgenommen oder verworfen. Die Details dieser Literatursuche sind in $\mathbf{T a b}$. $\mathbf{M}-\mathbf{3}$ dargestellt. Außerdem wurden alle Teilnehmer der Arbeitsgruppen gebeten, zusätzliche relevante Literatur hinzuzufügen. Die so gefundene Literatur wurde allen Teilnehmern über eine Online-Plattform zur Verfügung gestellt.

Eine systematische Evidenzbewertung der so gefundenen Literatur nach vorher festgelegten Regeln erfolgte nicht.

\section{b) Formulierung der Empfehlungen und strukturierte Konsensfindung}

Die Arbeitsgruppenleiter wurden gebeten, einen Fragenkatalog möglichst klinisch orientierter Fragen zu erstellen. Auf Basis der Diskussion in den Arbeitsgruppen erfolgte die Ausarbeitung der Empfehlungen durch die Arbeitsgruppenleiter. Im Rahmen einer 2-tägigen Leitlinienkonferenz vom 06.-07.07.2017 wurden diese Empfehlungen im nominalen Gruppenprozess diskutiert, überarbeitet und abgestimmt. Das Abstimmungsergebnis wurde protokolliert. Zusätzlich wurden im Nachgang noch einzelne Empfehlungen überarbeitet und im Rahmen von Delphi-Abstimmungen online abgestimmt. Die Konsensusstärken sind in > Tab. M-4 dargestellt.

Nach der Leitlinienkonferenz wurden die einzelnen Empfehlungen von den Arbeitsgruppen mit Kommentaren und Literaturverweisen versehen. Bei allen Handlungsempfehlungen ist die Stärke der Empfehlung anhand der Formulierung ersichtlich. Die Formulierungen und Bedeutungen der Empfehlungsstärken sind in - Tab. M-5 dargelegt. In allen Kommentaren wurden die Empfehlungen mit der jeweils zugrunde liegenden Literatur verknüpft und ggf. die Empfehlung aus Sicht der Leitliniengruppe begründet. Evidenzgrade wurden in dieser S2k-Leitlinie nicht vergeben. In manchen Fragen, die für die Versorgung wichtig sind, aber nicht explizit in Studien untersucht wurden, beruht die Empfehlungsstärke auf der Expertenmeinung und wird dementsprechend als Statement kenntlich gemacht. Außerdem wurden für die Versorgung wichtige Definitionen in der Leitliniengruppe abgestimmt ( $\triangleright$ Tab. M-6).

\section{M-6 Externe Begutachtung und Verabschiedung}

Die Leitlinie wurde allen beteiligten Fachgesellschaften zur Stellungnahme vorgelegt und von den jeweiligen Vorständen verabschiedet. Die endgültige Finalisierung erfolgte nach formaler Sichtung auf die Kriterien einer S2k-Leitlinie durch die AWMF.
\ Tab. M-4 Konsensusstärke.

Konsensusstärke

\begin{tabular}{l|l}
\hline $\begin{array}{l}\text { starker Konsens } \\
\text { Konsens }\end{array}$ & Zustimmung von >95\% der Teilnehmer \\
\hline $\begin{array}{l}\text { mehrheitliche } \\
\text { Zustimmung }\end{array}$ & Zustimmung von > 75-95\% der Teilnehmer \\
\hline kein Konsens & Zustimmung von weniger als $50 \%$ der Teilnehmer \\
\hline
\end{tabular}

- Tab. M-5 Empfehlungsstärken.

$$
\text { Empfehlungsstärken }
$$

\begin{tabular}{|l|c|}
\hline starke Empfehlung & „soll“ \\
\hline Empfehlung & „sollte“ \\
\hline Empfehlung offen & „kann“ \\
\hline
\end{tabular}

negative Empfehlungen werden entsprechend formuliert („soll nicht“, „sollte nicht")

\section{M-7 Verbreitung und Implementierung}

Die Leitlinie wird auf der Homepage der GPGE (http://www.gpge.eu/) und der AWMF (http://www.awmf.de/) zum freien Download zur Verfügung gestellt. Geplant ist eine Publikation der Kernaussagen der Leitlinie in der „Monatsschrift für Kinderheilkunde“ in deutscher Sprache. Zusätzlich soll eine Kurzversion im „Deutschen Ärzteblatt“ in deutscher und englischer Sprache und in den „Leitlinien Kinderund Jugendmedizin" der DGKJ publiziert werden.

\section{M-8 Gültigkeitsdauer und Aktualisierungsverfahren}

Die Gültigkeit der Leitlinie beträgt 5 Jahre. Eine Aktualisierung ist für Mai 2024 vorgesehen und wird über die GPGE-Geschäftsstelle koordiniert werden. Eine Überarbeitung der Leitlinie bei veränderter Datenlage erfolgt gegebenenfalls auch früher. 
- Tab. M-6 Zeitplan der Leitlinie.

\begin{tabular}{|c|c|}
\hline April 2016 & Anmeldung der Leitlinie bei der AWMF \\
\hline bis September 2016 & $\begin{array}{l}\text { Zusammenstellung der Arbeitsgruppen: } \\
\text { Auswahl, Anfragen, Zu-/Absagen (Gruppen } \\
\text { und Teilnehmer siehe Punkt M-2) und } \\
\text { Anfrage bei den anderen unterstützenden } \\
\text { Fachgesellschaften (siehe Punkt M-3) }\end{array}$ \\
\hline bis Juni 2017 & Entwurf der Statements \\
\hline bis Juni 2017 & $\begin{array}{l}\text { Sichtung und Kommentierung der } \\
\text { Statements }\end{array}$ \\
\hline bis Anfang Juli 2017 & Überarbeitung der Statements \\
\hline 06.-07.07.2017 & 2-tägige Konsensuskonferenz in Ulm \\
\hline bis Oktober 2018 & Erstellung aller Kommentare \\
\hline bis Dezember 2018 & $\begin{array}{l}\text { Verabschiedung der Statements mit Kom- } \\
\text { mentaren über Online-Plattform (Delphi) }\end{array}$ \\
\hline bis Februar 2019 & $\begin{array}{l}\text { Fertigstellung des Manuskripts durch } \\
\text { Einarbeitung der Literatur und Ergänzung } \\
\text { des Methodenteils }\end{array}$ \\
\hline bis Ende April 2019 & $\begin{array}{l}\text { Begutachtung durch die beteiligten } \\
\text { Fachgesellschaften }\end{array}$ \\
\hline
\end{tabular}

\section{Kapitel}

\section{Kapitel I: Definition, klinisches Bild und Diagnostik der akuten infektiösen Gastroenteritis im Säuglings- und Kindesalter}

AG Leiter: K.-M. Keller, Wiesbaden

AG Mitglieder: A.-C. Hauer, Graz; C. Posovszky, Ulm, H.-J. Epple, Berlin; U. von Both, München; B. Lawrenz, Arnsberg

\section{I.1 Klinische Diagnose}

\section{I.1.1 DEFINITION}

\section{Klinische Leitsymptome einer akuten Gastroenteritis (AGE)}

Die Leitsymptome einer AGE im Kindes- und Jugendalter sind plötzliche Minderung der Stuhlkonsistenz und Steigerung der Stuhlfrequenz (>3-mal/die oder mindestens 2 Stühle mehr als die für das Kind übliche Anzahl von Stühlen) mit oder ohne Erbrechen bzw. Fieber.

Konsensstärke: $100 \%$, starker Konsens

Die physiologische Stuhlfrequenz und -konsistenz unterliegt großen Schwankungen, je nach Alter und Ernährung. Gestillte Neugeborene und Säuglinge haben in der Regel flüssige bis breiige Stühle mit allerdings sehr divergierender Frequenz (zwischen 1 -mal in 1 bis 2 Wochen und bis zu 10 Stühlen am Tag, meist nach jeder Stillmahlzeit). Nicht gestillte Säuglinge haben seltener und eher breiige Stühle (1-3-mal/Tag), Kleinkinder über 4 Jahre breiige bis geformte Stühle. Die Spannbreite liegt hier zwischen
- Tab.l-1 Definitionen.

\begin{tabular}{|l|l|}
\hline Durchfall/Diarrhoe & $\begin{array}{l}\text { Abgang von zu flüssigem Stuhl unabhängig } \\
\text { von der Ätiologie }\end{array}$ \\
\hline akute Diarrhoe & $\begin{array}{l}\text { akut einsetzend, Dauer maximal 2 Wochen, } \\
\text { meist infektiös, toxisch }\end{array}$ \\
\hline prolongierte Diarrhoe & $\begin{array}{l}\text { Dauer von mehr als 7 bis 14 Tage, meist } \\
\text { infektiös }\end{array}$ \\
\hline $\begin{array}{l}\text { Chronischer Durchfall/ } \\
\text { Diarrhoe }\end{array}$ & $\begin{array}{l}\text { Durchfall über mehr als 14 Tage unabhängig } \\
\text { von der Ätiologie (kongenital, erworben, } \\
\text { funktionell) }\end{array}$ \\
\hline persistierende Diarrhoe & $\begin{array}{l}\text { infektiöse Durchfallerkrankung über mehr } \\
\text { als 14 Tage }\end{array}$ \\
\hline
\end{tabular}

3-mal am Tag bis zu 2-3-mal pro Woche. Größere Kinder, Jugendliche und Erwachsene haben durchschnittlich zwischen 2-mal pro Woche bis zu 2-mal am Tag geformte Stühle [9]. Bei einer Gastroenteritis kommt es zu einer plötzlichen Minderung der Stuhlkonsistenz mit Steigerung der individuellen Stuhlfrequenz, die zusätzlich von Erbrechen begleitet sein kann ( $\triangleright$ Tab. l-1).

Die RKI-Definition nosokomialer Infektionen des Gastrointestinaltraktes geht aus epidemiologischen Gründen über diese Definition hinaus (siehe auch III.4.1) [10]. Alternativ zur klinischen Symptomatik der akut einsetzenden Diarrhoe wird in der KISSDefinition auch die Kombination von Krankheitssymptomen (wie Fieber $>38^{\circ} \mathrm{C}$, Übelkeit, Erbrechen, Abdominal- oder Kopfschmerz ohne andere erkennbare Ursachen) oder der Erregernachweis zur Diagnose einer Gastroenteritis mit einbezogen.

\section{I.1.2 DEFINITION}

Verlauf einer AGE, persistierende Diarrhoe

Das Erbrechen dauert typischerweise 1-3 Tage, während die Durchfälle üblicherweise 5-7 Tage, in manchen Fällen auch bis zu 2 Wochen andauern können. Bei der persistierenden Diarrhoe beträgt die Durchfalldauer definitionsgemäß mehr als 2 Wochen.

Konsensstärke: $100 \%$, starker Konsens

Im Gegensatz zur kürzer andauernden AGE wird eine Durchfalldauer von mehr als 14 Tagen bei Kindern und Jugendlichen als chronische bzw. persistierende Diarrhoe definiert ( $\downarrow$ Tab. I-1) $[11,12]$. Diese tritt in Entwicklungsländern häufig im Anschluss an eine akute Gastroenteritis durch Parasiten, aber auch durch Viren und Bakterien auf. Die Risikofaktoren für eine persistierende Diarrhoe in diesen Regionen sind Kalorien- und Proteinmalnutrition, mangelnde Muttermilchernährung, Mangel an Vitamin A und Zink sowie zugrunde liegende systemische Infektionen wie AIDS und Malaria [13-15]. In einer deutschen retrospektiven Studie waren AGE durch Rotavirus-Infektionen bei hospitalisierten Kindern häufiger mit schwereren und länger dauernden Durchfallerkrankungen assoziiert als AGE durch Noro- oder Adenoviren [3]. AGE durch Salmonellen können ebenfalls sehr protrahiert verlaufen [3]. Länger verlaufende chronische Diarrhoen in 
Entwicklungsländern kommen vor allem nach AGE im jungen Säuglingsalter (<6 Monate) vor [16]. Ferner ist frühes Abstillen vor allem in Entwicklungsländern ein Risikofaktor für prolongierte Verläufe einer AGE [17].

\section{I.1.3 STATEMENT}

Wenn weitere Symptome hinzukommen oder Erbrechen bzw. Diarrhoe über die genannten Zeiträume hinaus anhalten, sollen andere Erkrankungen in Betracht gezogen werden. Konsensstärke: $100 \%$, starker Konsens

Besonders bei Säuglingen und Kleinkindern können die für AGE typischen Symptome wie Durchfall und Erbrechen auch als Begleitsymptome einer schweren Infektion, z. B. im Rahmen einer Sepsis, einer Pneumonie, einer Meningitis usw., oder auch einer intestinalen Obstruktion bei Volvulus oder bei einem Stoffwechseldefekt auftreten. Deshalb sollen vor allem bei den im Folgenden genannten zusätzlichen Symptomen andere Erkrankungen in Betracht gezogen werden:

Eine Temperaturerhöhung von $>38^{\circ} \mathrm{C}$ bei jungen Säuglingen bis 3 Monate oder Temperaturen $>39^{\circ} \mathrm{C}$ bei älteren Kindern kann Manifestation z. B. einer hochfieberhaften Pyelonephritis aufgrund einer Harntransportstörung oder eines vesikoureteralen Refluxes sein. Kurzatmigkeit und/oder Tachypnoe müssen an die Möglichkeit einer zugrunde liegenden Pneumonie denken lassen. Nackensteifigkeit, vorgewölbte Fontanelle oder gestörtes Bewusstsein sind Zeichen einer Meningoenzephalitis. Blutigschleimige Stühle, galliges Erbrechen oder schwere oder lokalisierbare Abdominalschmerzen mit Abwehrspannung können Zeichen einer intestinalen Obstruktion sein, wie z. B. bei Invagination, Volvulus, Stenosen, Perforation etc.

„Red flags“ für eine AGE sind assoziiert mit den Manifestationen der Dehydration (s.u.). Chronische Durchfälle können gutartig sein (z. B. „toddler's diarrhea“ im Sinne unspezifischer Durchfälle des Kleinkindes oder „Erbsen-Karotten-Syndrom“) oder reflektieren eine schwerwiegendere Grunderkrankung mit Malabsorption, Entzündung oder kongenitalen Stoffwechselstörungen. Warnhinweise für chronische Durchfälle sind: Positive Familienanamnese, Beginn in der Neonatalperiode oder nach Nahrungswechsel, Reisen in Hochrisikogebiete für Durchfallerreger, starker Gewichtsverlust, Wachstumsstillstand, Uhrglasnägel, großer Appetit, aber schlechte Gewichtszunahme, Appetitlosigkeit, Fieber, Steatorrhoe, Hämatochezie, extraintestinale Begleitsymptome sowie spezielle Nahrungsdefizite mit Malabsorption [18].

\section{I.1.4 STATEMENT}

Bei Verdacht auf AGE soll nach weiteren Fällen in der Umgebung, Auslandsreisen, Tierkontakt und Aufnahme potenziell kontaminierter (infektiöser) Nahrungsmittel und Getränke gefragt werden.

Konsensstärke: $100 \%$, starker Konsens
Ergibt die Anamnese Hinweise für Rohmilchkonsum, muss eine Infektion mit Campylobacter, Salmonellen, Listerien und EHEC bedacht werden. Zelten am Fluss und Trinken von ungekochtem Wasser kann eine Lamblien-Infektion bedingen. Der Konsum von Speisen, die aus rohen Eiern hergestellt werden (wie z. B. Kartoffelsalat mit Mayonnaise), können insbesondere bei Wärme eine bakterielle AGE zur Folge haben.

Die Umgebungsanamnese ist bei AGE durch Viren häufig positiv. Laut einer Literaturumfrage in Westeuropa haben Rotavirus-Gastroenteritiden eine Inzidenz von bis zu 5 Fällen pro 100 Personenjahre (siehe auch III.1.2). Aufgrund hoher Hospitalisierungsraten ist die nosokomiale Übertragung sehr hoch [19] (Kapitel III.1.2). Die AGE durch Noroviren, bislang an zweiter Stelle, holt in Ländern mit hoher Rotavirus-Impfrate auf [20, 21]. Aktuelle Daten aus dem infektionsepidemiologischen Jahrbuch des Robert-Koch-Instituts (RKI) für 2016 belegen, dass $76 \%$ aller nosokomialen Infektionen Norovirus-bedingt sind, Rotaviren machen nur noch 6,4\% aus [2]. Aus Schulen und Kindertagesstätten werden Ausbrüche an Norovirus-Infektionen berichtet [22, 23]. Noroviren sind ferner der häufigste Auslöser von Reisedurchfällen [24].

Obwohl die Häufigkeit bakterieller AGE durch Salmonellen oder Campylobacter abgenommen hat, lohnt sich die Frage nach Konsum von rohem bzw. nicht garem Fleisch, Milch oder Eiern. Laut RKI-Jahrbuch 2017 wurden für das Jahr 2016 insgesamt 915 potenziell lebensmittelausgelöste Infektionen gemeldet (ein Rückgang von ca. 7 \% im Vergleich zu 2015), in 477 Fällen wurde Campylobacter jejuni als Erreger angegeben (gleichbleibend zum Vorjahr), in 216 Fällen wurden Salmonella ssp. Angegeben (ein Rückgang von 16\% im Vergleich zum Vorjahr) [2]. 1068 Patienten waren durch 328 explizit lebensmittelbedingte Ausbrüche erkrankt; hier wurden am häufigsten Fleisch oder Fleischprodukte gefolgt von Milch und Milchprodukten sowie Ei und Eiprodukten als Infektionsvehikel genannt [2]. Andere Getränke als Milch sind selten Lebensmittelvehikel für Campylobacter spp., G. Lamblia oder Salmonella spp. [2].

Laut IfSG muss der Nachweis von Noro- und Rotavirus-Infektionen sowie Infektionen mit Salmonellen, Shigellen und Yersinien vom Labor an das RKI gemeldet werden [2]. Infektionen durch Lamblien und Campylobacter müssen sogar namentlich dem RKI gemeldet werden. Bei Cholera, HUS und Typhus haben behandelnder Arzt und das Labor eine Meldepflicht. Dies gilt für Deutschland, Österreich und auch für die Schweiz (siehe auch Kapitel III.2.5).

\section{I.1.5 STATEMENT}

Aus differenzialdiagnostischen Gründen sollte im Rahmen der Anamneseerhebung auch nach dem Konsum von Diarrhoeauslösenden Nahrungsmitteln bzw. Getränken gefragt werden. Konsensstärke: $100 \%$, starker Konsens

Apfelsaftkonsum oder Smoothies aus Fruktose-reichen Obstsorten wie Mango, Wassermelone, Birne und Apfel können bei manchen Menschen durchfällige Stühle und Blähungen auslösen. Dem Krankheitsbild liegt wahrscheinlich eine verminderte Expres- 
sion von GLUT5-Transportern zugrunde, was bei ca. 5 \% der Bevölkerung zur intestinalen Fruktose-Malabsorption führen kann [25]. Bei Kleinkindern kann es durch übermäßigen Genuss entsprechender Säfte und Limonaden schnell zu einer Fruktose-Überladung mit Malabsorption und osmotischer Diarrhoe kommen. Auch übermäßiger Obstkonsum bei gleichzeitiger Wasserzufuhr oder in Kombination mit Xylit- oder Sorbit-haltigen Süßigkeiten (insbesondere in zuckerfreien Kaugummis) kommen als Ursache für Durchfälle in Betracht. In ähnlicher Weise führt die Fehlverdauung von Laktose bei nicht bekannter primärer oder sekundärer Laktoseintoleranz zu osmotischen Durchfällen, Bauchschmerz, Übelkeit und Erbrechen. Die adulte Hypolaktasie kommt bei ca. $21 \%$ der Deutschen vor, bei mediterraner oder asiatischer Herkunft steigt der Prozentsatz auf 80-100\% [26].

\section{I.2 Epidemiologie}

\section{I.2.1 DEFINITION \\ Häufigkeit}

Die Häufigkeit von AGE bei Kindern < 3 Jahren liegt in Europa bei 0,5-2 Episoden pro Kind und Jahr.

Konsensstärke: $100 \%$, starker Konsens

\section{I.2.2 DEFINITION}

\section{Ursache}

Die meisten Fälle von AGE treten im Kleinkindesalter auf und werden durch Viren verursacht.

Konsensstärke: $100 \%$, starker Konsens

Weltweit sterben ca. 10,6 Millionen Kinder pro Jahr vor ihrem 5. Geburtstag [27]. Die Ursache hierfür war 2003 in ca. $20 \%$ (1,87 Mio.) der Fälle eine AGE [27, 28]. Von den jährlich 9,4 Mio. Fällen an AGE in England werden 1,5 Mio. dem Primärarzt vorgestellt. $70 \%$ der Fälle mit AGE sind viraler Genese. RotavirusInfektionen machen bislang in Europa mehr als $50 \%$ der Hospitalisierungen wegen AGE aus und etwa 1 Drittel der Notfallvorstellungen [27]. In den letzten Jahren übersteigen laut RKI Norovirus-Infektionen die Rotavirus-bedingten Durchfallerkrankungen, möglicherweise als Folge der zunehmenden Immunisierung der Säuglinge gegen Rotaviren [2]. Dennoch sind die Rotaviren auch nach Einführung der Rotavirus-Impfung die am häufigsten nachgewiesenen infektiösen Erreger einer schweren akuten GE, insbesondere bei Kindern unter 5 Jahren, gefolgt von Norovirus Gll und Adenovirus 40/41 [29, 30] (siehe auch 2.5).

Daten eines nationalen laborbasierten Überwachungssystems zeigen, dass die Infektion mit Rota- oder Noroviren bei Kindern in holländischen Tageseinrichtungen signifikant mit saisonal gehäufter GE assoziiert ist [31]. Auch das RKI meldet für Deutschland einen saisonalen Gipfel der gemeldeten AGE durch Rotaviren für die Saison 2014/2015 im April, gefolgt von einem Tal mit weniger Meldungen. Ab der 42.-51. Kalenderwoche zeichnete sich der nächste Gipfel ab. Für Noroviren wird ein Gipfel in der 5. sowie in der 51. Kalenderwoche angegeben, also hauptsächlich die Herbst- und Wintermonate für die beiden häufigsten viralen AGE [2].

\section{I.2.3 EMPFEHLUNG}

Die bakterielle AGE ist deutlich seltener und kommt eher bei Kindern ab 2 Jahren vor. Bei blutiger Diarrhoe mit Fieber sollte primär an eine bakterielle Genese gedacht werden. Konsensstärke: $100 \%$, starker Konsens

Eine systematische Analyse aus 60 Studien zur regionalen Verteilung (Entwicklungsländer vs. Industrienationen) von für Kinder bedeutsamen Durchfallerregern ergab, dass die akut auftretende blutige Diarrhoe in der Regel Symptom einer Infektion mit Campylobacter spp., Salmonella spp., Shigella, enterohaemorrhagischen E. coli oder Entamoeba histolytica ist. In Industrienationen sind Infektionen mit Campylobacter und Salmonella die häufigsten [32]. Darüber hinaus ließ sich anhand einer prospektiv durchgeführten Populationsstudie in Nordwestdeutschland in $35 \%$ bei AGE ein Erreger nachweisen und zeigen, dass bei nur 6,65\% der an AGE erkrankten Kinder enteropathogene Bakterien ursächlich waren, während bei 17,75\% Viren nachgewiesen wurden. Von den bakteriellen Erregern wurde Salmonella am häufigsten isoliert und in jedem der Fälle als krankheitsrelevant eingestuft. Es ergab sich eine Inzidenz bakterieller AGE von 162/100 000 Einwohnern, wobei v. a. Kinder zwischen 0-14 Jahren betroffen waren. Zusätzlich fiel eine typische saisonale Häufung für Salmonellen-Infektionen von Mai bis Oktober auf [33].

Im Rahmen des spanischen Netzwerks für pädiatrische Erstversorgung wurden 729 Fälle akuter bakterieller Gastroenteritis, die während eines Jahres diagnostiziert worden waren, weiteren mikrobiologischen Analysen unterzogen: Die mit Abstand am häufigsten ermittelten bakteriellen Erreger waren Campylobacter und nicht thyphoide Salmonella spp.: Campylobacter wurde in $59,9 \%$ isoliert, v. a. bei Kindern < 3 Jahren und in ländlichen Regionen, und Salmonella in 31,8\%, gefolgt von Aeromonas (2,7\%) und Yersinia (2,4\%) [34]. Ein Rückgang der Infektionen mit Salmonella spp. findet sich auch in Deutschland und England [2, 35]. Nur bei 1,5\% der Patienten waren mehrere Erreger ursächlich. 70 \% der Infektionen beruhten auf direktem Kontakt [34], wobei Geflügel als gut belegte Infektionsquelle für Campylobacter- oder Salmonella-Infektionen gilt [2, 36, 37].

\section{I.2.4 STATEMENT}

Die nosokomiale AGE wird meist durch virale Erreger hervorgerufen.

Konsensstärke: $100 \%$, starker Konsens

Welche Bedeutung nosokomiale AGE durch Rotaviren haben, geht aus einer Metaanalyse von insgesamt 20 qualitativ hochwertigen Beobachtungsstudien hospitalisierter Kinder in Europa und Nord- 
amerika hervor: Die zusammengefasste unbereinigte Inzidenz nosokomialer Rotavirus-Infektionen betrug 2,9 (95\%-KI:1,6-4,4)/ 100 Krankenhausaufenthalte, mit der höchsten Inzidenz bei Kindern <2 Jahren, v. a. während der Wintermonate (8,1; $95 \%$-KI: 6,4-9,9/100 Krankenhausaufenthalte). Die für das gesamte Jahr abgeglichene Inzidenz betrug für Kinder < 5 Jahren 0,7 (95\%-KI: $0,0-1,8)$ und ansonsten 0,4 (95\%-KI: 0,1-2,1)/100 Krankenhausaufenthalte [38]. Dem RKI wurden $70 \%$ der Ausbrüche mit jeweils 5 oder mehr Erkrankungen mit Angaben zu Ort oder Umfeld des Ausbruchsgeschehens gemeldet. Demnach ereigneten sich $47 \%$ der Ausbrüche an AGE durch Rotaviren in Kindergärten, $29 \%$ in Pflege- und Altenheimen und nur 8,1\% in Krankenhäusern sowie $2 \%$ in Haushalten [2]. Noroviren wurden in Industrienationen ebenfalls als Erreger nosokomialer Infektionen nachgewiesen, insbesondere bei Kindern. Dies ist aber im Vergleich weniger gut mit Zahlen belegt [39]. Laut RKI lagen für $68 \%$ der übermittelten Ausbrüche ( $n=17980$, ca. $20 \%$ aller Erkrankungen) Angaben zum Ort oder Umfeld des Ausbruchsgeschehens vor. Ein Großteil dieser Ausbrüche betraf Krankenhäuser (38\%), Alten- und Pflegeeinrichtungen (21\%), Kinderbetreuungseinrichtungen (13\%) sowie private Haushalte (11\%). Da nicht alle Fälle einer AGE virologisch untersucht werden und nur bestätigte Norovirus- Gastroenteritiden an das RKI gemeldet werden, ist von einer massiven Unterschätzung der AGE-Fälle durch Noroviren auszugehen [2].

\section{I.3 Faktoren für schwere oder chronische Durchfälle}

Chronische Durchfälle werden als Persistenz von ungeformten Stühlen, meist auch mit erhöhter Stuhlfrequenz, über mindestens 14 Tage unabhängig von ihrer Ätiologie bezeichnet [40, 41]. Unter den häufigsten Ätiologien von chronischen Durchfällen finden sich auch infektiöse Auslöser; dies wird dann als „persistierende“ Diarrhoe bezeichnet $[40,41]$. Eine AGE, deren Verlauf länger als erwartet ist, wird häufig auch als „prolongierte“ Diarrhoe bezeichnet (Dauer 7 bis 14 Tage) ( mit schwerer Dehydration, Lethargie, Fieber, Hospitalisierung, Enzephalitis oder prolongierter AGE wird als schwer bezeichnet [6].

\section{I.3.1 STATEMENT}

Rotavirus-Enteritiden im Kindesalter ( $<5$ Jahre) sind häufig mit einem schweren Verlauf assoziiert.

Konsensstärke: $100 \%$, starker Konsens

Die Schwere einer Gastroenteritis steht in direktem Zusammenhang mit der Ätiologie, wobei die Rotaviren als das für Kinder unter 5 Jahren weltweit schwerwiegendste infektiöse Agens gelten und eine Rotavirus-Enteritis häufig mit Dehydration, schwerem Verlauf und Hospitalisierung assoziiert ist [6, 42]. Die von der WHO und dem Center for Disease Control (CDC) eingeführte Rotavirus-Surveillance zeigt, dass weltweit 20 bis $73 \%$ und in Europa 26 bis $45 \%$ der AGE durch Rotaviren verursacht werden und diese in allen Regionen hauptverantwortlich für schwere Verläufe und Hospitalisierung sind [42].

Rotaviren führten in einer retrospektiven deutschen Studie am häufigsten zur Hospitalisierung [3]. Außerdem wurden in der
Erhebungseinheit für seltene pädiatrische Erkrankungen in Deutschland (ESPED) in 2 Jahren 101 Fälle von schweren Verläufen durch Rotavirus-Infektion berichtet, bei denen eine intensivmedizinische Versorgung, Hyponatriämie (<125 mmol/l), Hypernatriämie (> 155 mmol/l), Enzephalopathie oder Rotavirus-assoziierte Mortalität vorlag [43].

Epidemiologisch wird durch die Einführung der Rotavirus-Impfung seit 2008 ein Rückgang der gemeldeten Rotavirus-Infektionen verzeichnet [2].

\section{I.3.2 STATEMENT}

Bei persistierender infektiöser AGE werden häufig Rotaviren, seltener andere Viren, bakterielle Erreger und Protozoen isoliert.

Konsensstärke: $90 \%$, Konsens

Chronische bzw. persistierende Verläufe einer AGE betreffen meist Säuglinge und kommen häufiger in Schwellen- und Entwicklungsländern vor [44]. Dort werden vor allem bei Säuglingen und Kleinkindern hohe Mortalitätsraten von 32 bis $62 \%$ berichtet [45]. Die Ursachen der persistierenden Diarrhoe sind sowohl bezogen auf definierte Bevölkerungsgruppen als auch auf individueller Ebene wenig untersucht. Es wird derzeit eine multifaktorielle Genese angenommen. Abgesehen von Malnutrition, jungem Alter, mangelndem Stillen und inadäquatem Antibiotikaeinsatz sind neben Rotaviren v. a. Cryptosporidium, Giardia lamblia und enteroaggregative Escherichia coli (EAEC) mit persistierender Diarrhoe assoziiert [46].

\section{I.3.3 EMPFEHLUNG}

Bei Säuglingen soll auf schwere Dehydration und persistierende Verläufe der AGE, insbesondere bei Rotavirus-Infektionen, geachtet werden.

Konsensstärke: $100 \%$, Starker Konsens

Das Risiko für schwere oder persistierende Durchfallerkrankungen wird in Europa im ersten Lebensjahr, insbesondere in den ersten 6 Lebensmonaten oder bei einem Gewicht unter $8 \mathrm{~kg}$, als besonders hoch eingestuft $[6,7,47]$. So wird auch bei einer infektiösen Durchfallerkrankung in den ersten beiden Lebensmonaten eine stationäre Aufnahme empfohlen [48]. Aufgrund von Beobachtungsstudien werden Rotavirus-Infektionen als besonders schwer verlaufend eingeschätzt [49]. Das Alter der an Rotavirus-Infektion erkrankten Kinder mit schwerer Dehydration (> 10\% des Körpergewichts) lag in einer prospektiven ESPED-Studie (Erhebungsstudie für seltene pädiatrische Erkrankungen in Deutschland) im Median bei 8 Monaten und damit signifikant niedriger als bei moderater oder leichter Dehydration [43]. Intensivmedizinische Behandlungsbedürftigkeit ist ebenfalls mit einem medianen Alter von 7 Monaten signifikant niedriger als bei nicht intensivpflichtigen Rotavirus-Erkrankten (Median 12,5 Monate) [43]. Ein Trend 
zu schwerer Hypernatriämie findet sich zusätzlich in dieser Altersgruppe (medianes Alter 8 Monate).

\section{I.3.4 STATEMENT}

Kinder mit einer angeborenen oder erworbenen Immundefizienz haben ein höheres Risiko für schwere und persistierende Verläufe von GE.

Konsensstärke: $100 \%$, starker Konsens

Patienten, die an einer angeborenen oder erworbenen Immunschwäche leiden, haben ein hohes Risiko, an einer infektiösen Durchfallerkrankung durch Viren, Bakterien oder Protozoen mit schwerem und chronischem Verlauf zu erkranken [50-53]. Einerseits bestehen häufig durch eine bereits vorhandene Enteropathie oder Mangelernährung Risikofaktoren für einen schweren Verlauf, und andererseits ist die Elimination der Erreger durch die gestörte Immunantwort beeinträchtigt [50]. Das Erregerspektrum unterscheidet sich dabei deutlich von Patienten mit intaktem Immunsystem und es finden sich häufig opportunistische Erreger als Ursache [51]. Weiterhin kann eine Lebendimpfung mit Rotaviren bei Säuglingen mit schwerem kombiniertem Immundefekt (SCID) zu einer persistierenden lebensbedrohlichen systemischen Infektion führen [54, 55]. Bei schweren oder persistierenden Verläufen oder atypischen Erregern einer AGE im Kindesalter soll deshalb an angeborene primäre Immundefekte gedacht werden und eine immunologische Basisdiagnostik (mikroskopisch differenziertes Blutbild, Bestimmung von IgG, IgA, IgM und IgE) sowie die Konsultation eines Immunologen erfolgen [56, 57]. Die Therapie beinhaltet je nach Immundefekt neben antimikrobieller Therapie auch Immunglobulin-Gaben bis hin zur hämatopoetischen Stammzelltransplantation [56].

\section{I.3.5 STATEMENT}

Bei Patienten mit schweren Verläufen einer GE soll an eine Clostridoides-difficile (Clostridium-difficile-) -Infektion (CDI) gedacht werden. Insbesondere Patienten mit Grunderkrankungen, wie z. B. chronisch entzündlichen Darmerkrankungen, onkologischen Erkrankungen, nach Stammzelltransplantation oder solider Organtransplantation, haben ein erhöhtes Risiko für eine CDI.

Konsensstärke: $92 \%$, Konsens

2015 wurde von Lawson und Rainey basierend auf phänotypischen, chemotaxonomischen und phylogenetischen Untersuchungen vorgeschlagen, den Terminus Clostridoides difficile für Clostridium difficile zu verwenden, welchem wir in dieser Leitlinie folgen [58]. Der primäre Risikofaktor für eine Clostridoides-difficile-Infektion (CDI) ist die Gabe von Antibiotika [59, 60] (siehe Kapitel III.4.4). In den USA findet sich ein zunehmender Trend von CDI bei hospitalisierten Kindern, insbesondere Patienten mit mehreren Erkrankun- gen [60-62]. Das Risiko an CDI zu erkranken ist dabei für Patienten mit CED besonders hoch (Odds-Ratio 11,42) [60,61] und erhöht das Kolektomie- und Mortalitätsrisiko [63, 64]. Weiterhin findet sich eine CDI signifikant häufiger bei Patienten mit onkologischen Erkrankungen, nach Stammzelltransplantation oder solider Organtransplantation [59, 60]. Zusätzlich gibt es Fallberichte zu schweren Verläufen einer CDI bei Patienten mit Mukoviszidose [65, 66] und bei Morbus Hirschsprung [67].

Neben diesen speziellen Situationen erkranken Kinder aber auch außerhalb des Krankenhauses häufiger an einer CDI als Erwachsene [68]. In dieser Studie erleiden nicht vorerkrankte Kinder sogar häufiger schwere und rezidivierende Verläufe als Kinder mit im Krankenhaus erworbener CDI [69].

\section{I.3.6 STATEMENT}

Malnutrition und Koinfektion mit mehreren Erregern sind Risikofaktoren für schwere und/oder persistierende Verläufe einer GE.

Konsensstärke: $90 \%$, Konsens

Malnutrition ist in Entwicklungsländern ein Risikofaktor für persistierende infektiöse Durchfallerkrankungen, aber auch deren Folgen [13-15]. Unterernährung, Nährstoffmangel, gastrointestinale Infektionen, Schädigung der Darmschleimhaut und in der Folge Malabsorption von Nährstoffen führen zu einem Teufelskreis, der mit einer hohen Morbidität und Mortalität einhergeht (Link: WHO factsheet) [15]. Retrospektive Studien zeigen, dass Infektionen mit mehreren Erregern schwere Verläufe nehmen [70, 71]. Die Prävalenz von Koinfektionen lag bei diesen Studien aus Italien und China bei 18 und 20\%, häufig wurden Rota- und Noroviren, aber auch C. diff. nachgewiesen. In Entwicklungsländern finden sich noch höhere Prävalenzen mit bis zu 34\% [72]. Besonders hohe Prävalenzen finden sich hierbei bei Kindern unter 2 Jahren [72].

\section{I.3.7 STATEMENT}

Kinder- und Jugendliche in Gemeinschaftseinrichtungen haben ein erhöhtes Risiko für AGE.

Konsensstärke: $100 \%$, starker Konsens

Zirkulierende virale und parasitäre Infektionen in Tageseinrichtungen tragen zur erhöhten saisonalen Morbidität unter den Kindern bei [31]. In einer niederländischen Surveillance-Studie wurde gezeigt, dass in $78 \%$ der Stuhlproben pathologische Erreger nachgewiesen werden konnten, wobei $95 \%$ der Stuhlproben von asymptomatischen Kindern stammten [73]. Der Besuch einer Tageseinrichtung erhöht das Risiko insbesondere an Rotaviren, Noroviren, Gardia lamblia, Astroviren oder Campylobacter zu erkranken [31, 74]. 


\section{I.4 Komplikationen}

\section{I.4.1 STATEMENT}

Hauptkomplikationen der AGE sind Dehydration mit Hypovolämie sowie Störungen des Säurebasen- und Elektrolythaushalts. Bei Verdacht auf eine infektiöse GE soll eine ausreichende Flüssigkeitssubstitution erfolgen.

Konsensstärke: $100 \%$, starker Konsens

Die Schwere der AGE ist abhängig von der Ätiologie und betrifft häufiger Kinder unter 5 Jahren [27, 75]. 2 Drittel der schweren Verläufe werden durch virale Erreger, insbesondere Rotaviren, hervorgerufen (siehe I.3.2) [49]. Die Hauptkomplikation ist dabei die Dehydration [49]. Die AGE führt durch flüssige Stühle, Erbrechen und vermehrte Transpiration bei Fieber zu Wasser- und Elektrolytverlusten (Natrium, Phosphat, Chlorid, Bikarbonat). Dehydration mit Hypovolämie und Störungen des Säure-Basen- und Elektrolythaushalts sind, wenn diese Flüssigkeitsverluste nicht ersetzt werden, die Folge der AGE.

\section{I.4.2 STATEMENT}

Besonders dehydrationsgefährdet sind Säuglinge und Kleinkinder < 2 Jahren, Kinder und Jugendliche nach ausgedehnten Darmresektionen und solche mit Immundefizienz, Diabetes mellitus, Stoffwechseldefekten oder Malnutrition.

Konsensstärke: $100 \%$, starker Konsens

Säuglinge und Kleinkinder bis zum 2. Geburtstag haben im Verhältnis zu ihrem Körpergewicht einen höheren Flüssigkeitsumsatz (je nach Alter 100 bis 160 ml pro kg Körpergewicht) als ältere Kinder (je nach Alter 40 bis $100 \mathrm{ml}$ pro kg Körpergewicht) [9]. Daher kommt es bei Störung der Flüssigkeitsaufnahme durch Erbrechen und vermehrten Verlusten infolge von Durchfall und erhöhter Perspiration bei Fieber schneller zur Dehydration mit Hypovolämie und Störungen des Säure-Basen-Haushalts als bei älteren Kindern [43].

Kinder und Jugendliche mit Darmresektionen und Kinder mit Immundefizienz haben ein erhöhtes Risiko für einen schweren oder protrahierten Verlauf einer Gastroenteritis [6, 50-52, 57].

Bei Diabetes mellitus und anderen Stoffwechselstörungen kann durch eine AGE eine Stoffwechselentgleisung hervorgerufen werden; Patienten mit Diabetes mellitus zeigen bei Entgleisungen durch den osmotischen Wasserlust infolge der Glukosurie eine Dehydration und durch den Insulinmangel eine Azidose, die die Dehydration und Azidose durch AGE verschlimmern.

Bei Unterernährung sind ebenfalls gehäuft schwere Verläufe beschrieben, insbesondere in wenig entwickelten tropischen Ländern [14].

\section{I.4.3 STATEMENT}

Krampfanfälle oder Enzephalopathie treten am häufigsten bei viraler AGE auf, können aber auch durch bakterielle Infektionen verursacht werden.

Konsensstärke: $92 \%$, Konsens

Benigne Krampfanfälle ohne Fieber wurden bei viralen Gastroenteritiden beobachtet, insbesondere bei Rota- und Norovirus-Infektionen [6], aber auch bei bakteriellen Infektionen, insbesondere mit Nachweis einer Bakteriämie [6]. Eine Enzephalopathie lag in der ESPED-Erhebung bei 58 von 84 Kindern (69\%) mit schwerer AGE durch Rotaviren vor [43]. Hiervon waren 44 somnolent und 23 hatten Krampfanfälle. Die Krampfanfälle traten meist fieberassoziiert auf und waren bei 6 Kindern mit schwerer Hyper(>155 mmol/l) oder Hyponatriämie (<125 mmol/l) verbunden. Bei 14 (24\%) der 58 Patienten fand sich ein pathologisches Enzephalogramm (EEG). In 1 Fall wurden auch Rotaviren im Liquor nachgewiesen ( $>$ Tab. I-2).

\section{I.4.4 STATEMENT}

Bei bestimmten bakteriellen AGE (z. B. durch Yersinien, EHEC, Campylobacter, Salmonellen) kann es zu weiteren erregerspezifischen Komplikationen wie Sepsis, Krampfanfällen, Nierenversagen sowie mikroangiopathischen (z. B. HUS, TTP), rheumatischen und neurologischen Folgeerkrankungen (z. B. Guillain-Barre-Syndrom, reaktive Arthritis) kommen.

Konsensstärke: $90 \%$, Konsens

\section{I.5 Klinische Evaluation und Einschätzung der Schwere der GE}

\section{I.5.1 Klinische Evaluation}

\section{I.5.1.1 EMPFEHLUNG}

Es soll klinisch festgestellt werden, ob das Kind vital gefährdet ist. Zeichen dafür sind:

Eingeschränktes Bewusstsein, kaltschweißige Haut, extrem eingesunkene Augen (ggf. Fontanelle), trockene Schleimhäute (Zunge), fehlende Tränen, schlaffer Muskeltonus, $\geq 10 \%$ Verlust des Körpergewichts, verlängerte kapilläre Füllungszeit (>3 Sekunden), Tachypnoe/Azidose-Atmung, Tachykardie sowie Anurie.

Konsensstärke: $90 \%$, Konsens

Die ESPGHAN-Leitlinie gibt eine schwache Empfehlung für die Verwendung eines klinischen Dehydrations-Scores (Clinical Dehydration-Score, CDS) [6]. Dieser wurde ab 2008 in mehreren Studien an Kindern im Alter von 1 bis 36 Monaten validiert [77-79]. In diesem Score wird für Bewusstseinseinschränkungen bis zum Koma, kalte und/oder schweißige Haut, extrem eingesunkene Augen und schlaffen Muskeltonus die jeweils höchste Punktzahl 
- Tab. I-2 Die typischen Komplikationen und Folgeerkrankungen bakterieller AGE sind nachfolgend tabellarisch aufgelistet (Erreger in alphabetischer Reihenfolge) [76].

\section{Erreger}

Campylobacter spp.

Clostridium spp.

\section{Komplikationen}

Cholezystitis, Vaskulitis, Erythema nodosum, Perikarditis, Myokarditis

septische Arthritis, Weichteilinfektionen

Peritonitis

Endokarditis, Meningitis

Bakteriämien

Abort

hämolytische Anämie

reaktive Arthritis, Reiter-Syndrom

IgA-Nephropathie, Glomerulonephritis

Guillain-Barré-Syndrom, Miller-Fisher-Syndrom

pseudomembranöse Kolitis, ggf. mit toxischem Megakolon und/oder Darmperforation

Enteritis necroticans

EHEC

Listerien

Salmonella spp. hämorrhagische Kolitis

hämolytisch-urämisches Syndrom (HUS)

thrombotisch-thrombozytopenische Purpura (TTP)

Meningitis, Meningoenzephalitis, Hirnabszess, Sepsis, Endokarditis, Hepatitis, Leberabszess, Endophthalmitis, Lymphadenitis

\section{Bakteriämie}

fokale Infektionen: Osteomyelitis Hirnabszesse und Meningitis Pneumonien und Pleuraempyeme Nierenabszesse Endo-/Perikarditis eitrige Arthritis

Besiedlung von endovasalem Plastikmaterial

prolongierte oder rezidivierende Bakteriämie

reaktive Arthritis

Erythema nodosum

toxisches Megakolon mit Darmperforation

Rektumprolaps

atypische Verläufe

Enzephalopathie mit Kopfschmerzen, Lethargie,

Verwirrtheit und Krampfanfällen

Sepsis

Bronchopneumonie, Myokarditis

hämolytisch-urämisches Syndrom

disseminierte intravasale Gerinnung, Multiorganversagen

reaktive Arthritis, Reiter- Syndrom

\section{Besonderheiten}

selten

selten

insbesondere bei Peritonealdialyse

Neugeborene

Neugeborene, Immundefizienz

sehr selten, durch Campylobacter fetus

$3 \%$, insbesondere bei HLA-B27- Nachweis

0,06-0,1 \% häufig AK gegen GM1-Gangliosid

durch Clostridoides difficile, meist 4-10 Tage nach Antibiotikatherapie, selten bis 10 Wochen danach oder schon während der Antibiotikatherapie

durch Clostridium perfringens Typ C, Ileus, Darmperforation, gastrointestinale Massenblutung Tetraplegie, Bulbärparalyse septisch-toxisches Herz- Kreislauf-Versagen, Letalität 15-25\% nicht selten, alle Altersgruppen

5-15\% der Kinder bis 6 Jahre mit EHEC- Infektion, seltener bei älteren Menschen, Niereninsuffizienz in 2/3 der Fälle, bei $10-30 \%$ terminal

eher bei älteren Patienten ${ }^{65}$

sehr selten, eher bei Immundefizienz oder Implantaten (Gelenke, Herzklappen etc.)

bei jungen Säuglingen $10 \%$, sonst 5-6\%

bei $10 \%$ der Fälle mit Bakteriämie, besonders bei Sichelzellkrankheit, bei Neugeborenen, Säuglingen und Immundefizienten

zentralvenöse Katheter; Kunststoffmaterial nach Herz- und Gefäßoperationen

bei chronischer Bilharziose (Infektion der Schistosomen (S. mansoni) mit Salmonellen und somit einer Escape-Option gegenüber der Antibiotikatherapie)

selten in der ersten Lebensdekade, häufiger bei

HLA-B27-Positiven

bei Kleinkindern

bei Neugeborenen und jungen Säuglingen, erhöhte Letalität

häufiger bei Säuglingen und Kleinkindern, seltener bei älteren Kindern, kann letal verlaufen, Pathogenese ungeklärt selten, eher bei Malnutrition, meist S.-dysenteriae-1-assoziiert

meist durch S. dysenteriae 1

vor allem im Zusammenhang mit S.-flexneri-Infektionen und HLA-B27

Glomerulonephritis 
- Tab. I-2 (Fortsetzung)

\begin{tabular}{|c|c|c|}
\hline Erreger & Komplikationen & Besonderheiten \\
\hline \multirow[t]{2}{*}{ Staphylococcus aureus } & Lebensmittelintoxikation & $\begin{array}{l}\text { meist Enterotoxin-A-bis E-assoziiert (Enterotoxine werden } \\
\text { von } 30 \% \text { aller S.-aureus-Stämme gebildet) }\end{array}$ \\
\hline & toxisches Schock- Syndrom (TSS) & $\begin{array}{l}\text { durch TSS-Toxin-1-bildende S. aureus, selten, eher bei } \\
\text { jüngeren Erwachsenen, nur bei fehlenden Antikörpern gegen } \\
\text { TSST-1 (im späteren Erwachsenenalter meist vorhanden), } \\
\text { Gastroenteritis möglich, aber nicht obligat }\end{array}$ \\
\hline \multirow[t]{6}{*}{ Yersinien } & intestinale Blutung, Invagination, Ileumperforation & \\
\hline & Bakteriämie & bei Säuglingen < 3 Monate bis zu $30 \%$ \\
\hline & Sepsis mit Leber- und Milz-Abszessen & $\begin{array}{l}\text { sehr selten, eher bei Eisenüberladung mit und ohne } \\
\text { Chelat-Therapie }\end{array}$ \\
\hline & Kawasaki-ähnliche Symptome & bei Kleinkindern \\
\hline & $\begin{array}{l}\text { Erythema nodosum, Uveitis anterior, tubulo- interstitielle } \\
\text { Nephritis, Glomerulonephritis, hämolytische Anämie }\end{array}$ & häufiger bei Adoleszenten \\
\hline & reaktive Arthritis & $\begin{array}{l}\text { häufiger bei HLA-B27-positiven Kindern ab } 6 \text { Jahren, } \\
\text { Übergang in chronische juvenile Spondylarthritis möglich }\end{array}$ \\
\hline
\end{tabular}

vergeben. Trotz mehrerer Evaluationsstudien wird die Evidenz für diesen Score von den LL-Autoren insgesamt als niedrig eingestuft.

Entsprechend der ESPGHAN-Leitlinie wird der prozentuale Gewichtsverlust als bester Maßstab für die Schwere der Dehydration angegeben; ein Gewichtsverlust von mehr als $9 \%$ wird in der Leitlinie als Indikator einer schweren Dehydration mit Notwendigkeit der Hospitalisation und parenteralen Flüssigkeitszufuhr angesehen. Obwohl diesen Angaben nur schwache bis moderate Evidenz zugrunde liegt, wird von den LL-Autoren eine starke Empfehlung dazu ausgesprochen; die Anwendung des Kriteriums Gewichtsverlust ist im klinischen Alltag allerdings ohnehin dadurch limitiert, dass nur selten sichere Informationen über das Gewicht vor Beginn der AGE vorliegen [80]. Der modifizierte Vesikari-Score kann auch ohne Angabe von Gewichtsverlust aus Dauer von Durchfall und Erbrechen, Fieber, zukünftiger medizinischer Vorstellung und Behandlung ermittelt werden. Dieser Score mit 7 Unterpunkten wurde zwischenzeitlich für Kinder von 3 bis 48 Monaten evaluiert und erlaubt die Einschätzung der Schwere im ambulanten Setting, er sollte aber in weiteren klinischen Studien geprüft werden [81].

Eine über 3 Sekunden verlängerte kapilläre Füllungszeit ist bei Kindern laut der Metaanalyse von Fleming et al. ein spezifisches klinisches Zeichen, das als „red flag“ genutzt werden kann; leider ist es nur wenig sensitiv, sodass eine normale kapilläre Füllungszeit nicht allein als Indikator eines guten Kreislaufzustandes des Patienten verwendet werden soll [82]. Digital-videografische Methoden sind zur Verbesserung der Objektivierbarkeit dieses klinischen Zeichens entwickelt worden, jedoch noch nicht ausreichend validiert [83].

Eine vertiefte und beschleunigte Atmung („Kußmaul-Atmung“ oder „Azidose-Atmung“) als Zeichen der respiratorischen Kompensation einer ausgeprägten metabolischen Azidose wurde erstmals 1874 von Kußmaul beschrieben und ist inzwischen ein bekanntes und anerkanntes klinisches Zeichen. Eine solche Azidose tritt zum Beispiel bei einer ausgeprägten Dehydration auf.
Die Tachykardie ist ein wenig spezifisches, aber sensitives Zeichen für eine Hypovolämie mit niedrigem Blutdruck und drohendem hypovolämischem Schock.

Eine mangelnde Urinproduktion wird von der ESPHGAN-Leitlinie als einfach von Eltern zu erfragendes Zeichen eines Volumenmangels angegeben [6]; bei Säuglingen und Kleinkindern mit den heute üblichen stark flüssigkeitsbindenden Fertigwindeln ist es jedoch manchmal schwierig zu beurteilen. Berichten die Eltern jedoch über normale Urinproduktion, kann dies als zuverlässiges Zeichen gegen eine schwere Dehydration und somit gegen eine vitale Bedrohung gewertet werden [6]. Eine Anurie kann hingegen auf ein drohendes prärenales Nierenversagen hinweisen.

\section{I.5.1.2 EMPFEHLUNG}

Aufgrund eines erhöhten Komplikationsrisikos soll eine Arztvorstellung erfolgen bei:

Allen Säuglingen (<12 Monate), persistierendem Erbrechen, Trinkverweigerung länger als $4 \mathrm{~h}$, großvolumigen Durchfällen, Vorliegen einer schweren Grunderkrankung (siehe Kommentar), Lethargie, hohem Fieber, blutigem Durchfall sowie starken Bauchschmerzen.

Konsensstärke: $100 \%$, starker Konsens

Bei Säuglingen kommt es aufgrund ihres höheren Wasserumsatzes bei mangelnder Flüssigkeitszufuhr oder Flüssigkeitsverlusten infolge von Erbrechen, Diarrhoe und Fieber naturgemäß schneller zur bedrohlichen Dehydration als bei älteren Kindern. Bei persistierendem Erbrechen und anhaltender Trinkverweigerung können Flüssigkeitsverluste nicht enteral ausgeglichen werden. Bei anhaltenden und großvolumigen Durchfällen und/oder hohem Fieber sind die Flüssigkeitsverluste höher, sodass sie möglicherweise nicht enteral ausgeglichen werden. Lethargie ist ein klinisches Zeichen für eine schwere Dehydration (vgl. I.5.1.1). 
Bei blutigem Durchfall und starken Bauchschmerzen müssen andere möglicherweise für die Symptomatik ursächliche Erkrankungen, wie zum Beispiel eine Invagination oder ein Volvulus, ausgeschlossen werden.

Bei schweren Grunderkrankungen wie Diabetes mellitus oder anderen Stoffwechselstörungen kann die AGE zu einer behandlungsbedürftigen Stoffwechselentgleisung führen, bei Immundefizienz (angeboren oder als Therapiefolge) ist das Risiko für protrahierte und schwerere Verläufe erhöht (siehe I.4.2) [6]. Kinder mit chronischen Erkrankungen wie chronisch entzündlichen Darmerkrankungen (CED) und onkologischen Grunderkrankungen haben ein erhöhtes Risiko für schwere und protrahierte GE durch Clostridoides difficile und andere opportunistische Erreger [6]. Kinder und Jugendliche mit neurologischen Grunderkrankungen haben häufiger hypernatriämische Dehydrationen als Kinder ohne Grunderkrankungen [84].

Daher soll in allen diesen Situationen die Beurteilung des Therapiebedarfs nicht indirekt über die Angaben von Laien (Eltern oder Betreuer des erkrankten Kindes), sondern direkt durch einen in der Untersuchung und Behandlung von Kindern erfahrenen Arzt erfolgen, um die Situation mit ausreichender Sicherheit einschätzen und das notwendige Vorgehen planen zu können.

\section{I.5.1.3 STATEMENT}

Klinische Zeichen einer hypernatriämischen Dehydration können sein: Unruhige, ungezielte Bewegungen, erhöhter Muskeltonus, gesteigerte Muskeleigenreflexe, Krampfanfälle sowie Schläfrigkeit bis hin zum Koma.

Konsensstärke: $100 \%$, starker Konsens

Eine signifikante Hypernatriämie $\left(\mathrm{Na}^{+} \geqq 150 \mathrm{mmol} / \mathrm{l}\right)$ ist bei Kindern und Jugendlichen im Alter von 2 Wochen bis 17 Jahren sehr selten und betraf in einer retrospektiven schottischen Studie 1 von 2288 Krankenhausaufnahmen [84]. Laut dieser Studie ist die häufigste Ursache die Dehydration infolge von AGE oder systemischen Infektionen. Insbesondere bei AGE durch Rotaviren findet sich signifikant häufiger eine Hypernatriämie [85].

In entwickelten Ländern kommt eine hypertone Dehydration bei Gastroenteritis fast nur bei Säuglingen vor. Dies kann durch 2 Mechanismen erklärt werden: Die Kohlenhydrate der Milch werden bei schwerer Gastroenteritis nicht resorbiert, sind im Kolon osmotisch aktiv und entziehen dem Extrazellularraum Wasser. Dem mit entstehender Hypernatriämie einhergehenden starken Durstgefühl kann bei älteren Kindern mit verstärkter Flüssigkeitsaufnahme begegnet werden; diese Möglichkeit ist bei kleinen Säuglingen naturgemäß begrenzt.

Klinisch finden sich dann frühzeitig eine teigige Haut, teils sogar mit Ödemen statt mit vermindertem Hautturgor, und zerebrale Symptome wie Unruhe, Irritabilität und Krampfanfälle, bei zunehmender Hypernatriämie und Dehydration auch Bewusstseinsstörungen [86]. Erst spät entstehen Symptome der Hypovolämie wie Blutdruckabfall und Tachykardie. Aus diesem Grund und wegen der Maskierung des verminderten Hautturgors durch das teigige Hautbild wird der Schweregrad der Dehydration bei gleichzeitiger Hypernatriämie klinisch häufig unterschätzt.

In Entwicklungsländern kommt die hypertone Dehydration auch bei älteren Säuglingen und Kleinkindern häufiger vor (vielleicht, weil dort die Möglichkeiten zur Wasseraufnahme bei Durstgefühl begrenzt sind); als einziges verwertbares klinisches Zeichen für eine Hypernatriämie bei Diarrhoe wurden Krampfanfälle und Dehydration identifiziert [86].

\section{I.5.1.4 STATEMENT}

Zur Klärung der Frage, ob eine unkomplizierte GE vorliegt oder das Kind einem Arzt vorgestellt werden muss, kann eine telefonische Einschätzung geeignet sein.

Konsensstärke: $90 \%$, starker Konsens

In Europa ist die AGE eher mild und selbstlimitierend, die klinische Situation kann sich aber auch schnell verschlechtern. Entscheidend ist daher auch die Verlässlichkeit einer Familie, um eine AGE zu Hause durch telefonische Beratung zu betreuen. Ferner muss eine orale Rehydrationslösung zu Hause verfügbar sein [6].

In der ESPGHAN-Leitlinie wird im Rahmen einer Telefonberatung bei AGE empfohlen, spezifische, einfache und verständliche Fragen zu stellen.

Die Leitliniengruppe schlägt hierfür folgende Fragen vor:

- Wie alt ist das Kind?

- Welche Risikofaktoren und Vorerkrankungen liegen vor? (z. B. ehemaliges Frühgeborenes?)

- Wie lange ist das Kind schon krank? Seit wieviel Stunden Durchfall und seit wieviel Stunden Erbrechen?

- Hat es Fieber und was war die höchste gemessene Temperatur?

- Wie viele durchfällige Stühle und wie viele Male Erbrechen hatte das Kind in den letzten $24 \mathrm{~h}$ ?

- Trinkt das Kind noch?

- Scheidet das Kind noch Urin aus?

- Wie wach ist das Kind, gibt es Verhaltensauffälligkeiten?

- Welche Behandlungsmaßnahmen wurden durchgeführt (Antiemetika, ORL)?

Die Empfehlungen aus Konsensus-basierten Leitlinien zur Vorstellung beim Arzt sind uneinheitlich [87]. Bei folgenden Warnhinweisen („,red flags“) soll eine Vorstellung beim Arzt erfolgen:

- Alter $<3$ Monate oder Gewicht $<8 \mathrm{~kg}$

- Fieber $>38^{\circ} \mathrm{C}$ für kleine Säuglinge ( $<3$ Monate), $>39^{\circ} \mathrm{C}$ für größere Kinder (3-36 Monate)

- schwere Grunderkrankung, wie z. B. Diabetes mellitus, Nierenerkrankung

- fortwährendes Erbrechen

- große und häufige Durchfälle

- blutige Durchfälle

- Durchfälle > 7 d Dauer

- Zeichen für eine Dehydration 
- Tab. I-3 CDS für Kinder von 0-8 Jahren.

\begin{tabular}{|l|l|l|l|}
\hline klinische Befunde & $\mathbf{0}$ & $\mathbf{1}$ & $\mathbf{2}$ \\
\hline allgemeines Erscheinungsbild & normal & $\begin{array}{l}\text { durstig, unruhig oder lethargisch, aber } \\
\text { irritabel, wenn berührt }\end{array}$ & taumelig, kaltschweißig, komatös \\
\hline Augen & normal & leicht eingesunken & extrem eingesunken \\
\hline Schleimhäute, Zunge & feucht & klebrig & trocken \\
\hline Tränen & vorhanden & wenig Tränen & keine Tränen \\
\hline $0=$ keine Dehydration; $1-4=$ leichte bis milde Dehydration; $5-8=$ moderat bis schwere Dehydration. & \\
\hline
\end{tabular}

- Unfähigkeit der Eltern, ORL zu verabreichen, oder Kind toleriert ORL nicht

- undurchsichtige Umgebungsbedingungen (nicht einzuschätzende soziale Bedingungen...)

Für die einzelnen „red flags“ gibt es wenig Evidenz, auch wenn jeweils starke Empfehlungen für ihre Beachtung gegeben werden [87].

\section{I.5.2 Wie wird die Dehydration erhoben?}

\section{I.5.2.1 STATEMENT}

Die wichtigsten klinischen Zeichen für eine mittelgradige Dehydration sind:

5-9\% Gewichtsverlust, verlängerte kapilläre Füllungszeit (>2 Sek.), reduzierter Hautturgor, „klebrige“ Schleimhäute, verminderte Tränenbildung, leicht eingesunkene Augen, vertiefte Atmung, Irritabilität, Fieber und reduzierte Urinproduktion.

Konsensstärke: $100 \%$, starker Konsens

Die Erfassung des Schweregrads einer Dehydration ist essenzielle Basis für eine geeignete Behandlung [6]. Die hierfür empfohlenen klinischen Zeichen unterscheiden sich dabei in den jeweiligen Leitlinien [87]. Als bester Maßstab für den Grad der Dehydration wird immer wieder der Gewichtsverlust in Prozent des Gewichts unmittelbar vor der Erkrankung genannt, welcher sich leider meist nicht ermitteln lässt, da das unmittelbar zuvor gemessene Gewicht nur selten bekannt ist (siehe I.5.1.1) [6]. Bei den klinischen Zeichen zur Dehydration wie Tachykardie, Pulsqualität, Atmung, eingesunkene Augen, Tränenproduktion, trockene Schleimhäute, Hautturgor, kapilläre Füllungszeit und Temperatur der Extremitäten finden sich die größten Übereinstimmungen zwischen den Leitlinien [87].

Elterliche Angaben von Dehydrationssymptomen sind meist unspezifisch und daher ungeeignet; die Urinproduktion wird deshalb nur in 4 von 8 Leitlinien erhoben [87]. Allerdings macht eine normale Urinproduktion eine Dehydration eher unwahrscheinlich.
Aus Daten in Entwicklungsländern kann abgeleitet werden, dass Kinder mit häufigen großvolumigen Stühlen und Erbrechen ein höheres Risiko haben.

\section{I.5.2.2 EMPFEHLUNG \\ Klinischer Dehydrations-Score (CDS):}

Zur Feststellung des Dehydrationsgrades sollte der klinische Dehydrations-Score (CDS) eingesetzt werden.

Konsensstärke: $80 \%$, Konsens

In der ESPGHAN-Leitlinie wird konstatiert, dass es keinen idealen einzelnen Standard-Score zur Evaluation des Dehydrationsgrades gibt (siehe I.5.1.1) [6]. Empfohlen wird häufig der CDS-Score, weil er am einfachsten und leichtesten einzusetzen und mittlerweile in einigen Studien validiert ist, v. a. bezüglich einer Notwendigkeit intravenöser Rehydration, Gewichtszunahme, notwendiger Labortests und stationärem Aufnahmebedarf ( $\triangleright$ Tab. I-3) [77-79, 88]. Der CDS hat gemäß der Übersichtsarbeit von Falszewska et al. bei Kindern von 1 bis 36 Monaten mit AGE eine gute diagnostische Trennschärfe, eine moderate und schwere Dehydration zu erkennen (positive „likelihood-ratio“ 5,2-6,6), lediglich die Wahrscheinlichkeit diese auszuschließen ist begrenzt (negative likelihood-ratio 0,4-0,55) [89]. Deshalb wird der Einsatz des CDS in Kombination mit anderen Kriterien auch in der ESPGHAN-LL empfohlen [6, 90].

Sehr aufschlussreich und interessant ist eine prospektive Studie aus den Niederlanden, die zum Ziel hatte, prognostische Risikofaktoren für ein Versagen der oralen Rehydration zu finden: Bei 167 von 802 vorher gesunden Säuglingen und Kleinkindern mit AGE (21\%) kam es zu einem solchen Versagen, d. h. zur sekundären Notwendigkeit einer Rehydration über eine Magensonde, Wiedervorstellung oder stationäre Aufnahme wegen persistierender Probleme der AGE. Risikofaktoren waren ein dringlicher initialer Handlungsbedarf festgestellt nach Manchester-Triage-System (MTS), ein hoher klinischer Dehydrations-Score sowie eine verzögerte Rekapillarisierungszeit [91]. 
- Tab. I-4 Epidemiologische und klinische Fakten für die häufigsten Ursachen viraler AGE bei Kindern [92, 93].

\begin{tabular}{|c|c|c|c|c|c|c|c|}
\hline Virus & Hauptsaison & Inkubationszeit & Transmission & Alter & Dauer & $\begin{array}{l}\text { Laktose- } \\
\text { intoleranz }\end{array}$ & $\begin{array}{l}\text { Weitere } \\
\text { Besonderheiten }\end{array}$ \\
\hline Rotavirus & $\begin{array}{l}\text { Herbst/ } \\
\text { Winter }\end{array}$ & $2-3 d$ & fäkal-oral, Erbrechen & $\begin{array}{l}6-24 \\
\text { Monate }\end{array}$ & $5-7 d$ & ja & $\begin{array}{l}\text { Verursacht schwere } \\
\text { Durchfälle }\end{array}$ \\
\hline Norovirus & ganzes Jahr & $12-48 \mathrm{~h}$ & $\begin{array}{l}\text { fäkal-oral, Wasser, } \\
\text { Meeresfisch, } \\
\text { Nahrungsmittel, } \\
\text { Erbrechen }\end{array}$ & $\begin{array}{l}\text { jedes } \\
\text { Alter }\end{array}$ & $1-4 d$ & nein & $\begin{array}{l}\text { Erbrechen führend, } \\
\text { verursacht die meisten } \\
\text { nichtbakteriellen AGEs }\end{array}$ \\
\hline Astrovirus & Winter & $4-5 d$ & fäkal-oral, Wasser & $\begin{array}{l}\text { jedes } \\
\text { Alter }\end{array}$ & $5-6 d$ & Ja & endemisch, epidemisch \\
\hline $\begin{array}{l}\text { enterische } \\
\text { Adeno-Viren } \\
\text { (Typ 40/41) }\end{array}$ & Sommer & $3-10 d$ & fäkal-oral & Kinder & $6-9 d$ & Ja & endemisch \\
\hline
\end{tabular}

\section{I.5.3 Gibt es klinische Befunde, die für eine bakterielle oder virale Ätiologie der GE sprechen?}

\section{STATEMENT}

Hohes Fieber, blutige Stühle und starke Bauchschmerzen sprechen eher für eine bakterielle Infektion. Erbrechen und respiratorische Symptome sprechen eher für eine virale Genese der AGE.

Konsensstärke: $100 \%$, starker Konsens

Es gibt keinen klinischen Befund, der sicher zwischen viraler und bakterieller AGE unterscheiden kann. Eine virale AGE geht aber häufiger als eine bakterielle AGE mit respiratorischen Symptomen und länger andauerndem Erbrechen einher [3]. Bei AGE durch Noroviren sticht die Häufigkeit des Erbrechens, u. U. auch ohne Durchfall, hervor [3]. Kinder mit AGE durch Rotaviren haben häufigeres und höheres Fieber, Dehydration und Elektrolytstörungen als jene ohne Rotavirus-Nachweis [85]. Ein klinisches „Kolitis-Bild“ mit vielen, blutig-schleimigen Durchfällen von geringer Menge, Bauchschmerzen und hohem Fieber spricht eher für eine bakterielle Genese der AGE [6] ( Tab. I-4).

\section{I.6 Diagnostik}

\section{I.6.1 Erregerdiagnostik}

\section{I.6.1.1 STATEMENT}

Die Diagnose einer AGE soll klinisch gestellt werden. Eine routinemäßige Erregerdiagnostik soll nicht erfolgen.

Konsensstärke: $90 \%$, Konsens

Mikrobiologische Stuhluntersuchungen sind für die allermeisten Fälle einer akuten AGE nicht hilfreich, da die Ergebnisse keine Bedeutung für die Behandlung haben $[6,53]$. Die meisten Verläufe sind selbstlimitierend und die diagnostische Ausbeute ist bei umfangreichem Erregerspektrum eingeschränkt. Ausnahmen sind schwere Grunderkrankungen, wie z. B. Immundefekt, onkologische Erkrankung oder chronisch-entzündliche Darmerkrankung, schweres Krankheitsbild, blutige Durchfälle, lange andauernde Krankheitsverläufe oder Ausbrüche an AGE in Gemeinschaftseinrichtungen, Krankenhäusern, Pflegeeinrichtungen etc. (siehe I.6.1.2).

\section{I.6.1.2 STATEMENT}

Eine Erregerdiagnostik sollte in folgenden Situationen erfolgen:

- Vorliegen relevanter Komorbiditäten

- Patienten mit Immundefizienz

- blutige Diarrhoe

- schweres Krankheitsbild

- Diarrhoe-bedingte Hospitalisierung

- Verdacht auf eine Häufung, bei der ein epidemiologischer Zusammenhang vermutet werden kann

- vor Einleitung einer antibiotischen Therapie

- bei nosokomialer Diarrhoe

Konsensstärke: $100 \%$, starker Konsens

Bei obigen Konstellationen ist eine Erregerdiagnostik sinnvoll, weil sich hieraus Maßnahmen zur Infektionsprävention und Therapie ergeben könnten $[6,53,87]$. Aus hygienischer Sicht kann eine Kohortenbildung in Kliniken oder Pflegeeinrichtungen erforderlich sein (siehe Kapitel III.2.3) oder eine antimikrobielle Behandlung bei Immundefekt, onkologisch erkrankten Kindern oder jenen mit chronisch- entzündlicher Darmerkrankung notwendig werden. Gehäufte nosokomiale Erkrankungen an AGE müssen laut IfSG an das Gesundheitsamt gemeldet werden (siehe Kapitel III.2.5). Je nach Einrichtung (Altenheim, Krankenhaus, Intensivstationen, Gemeinschaftsküche, Restaurant etc.) hat dies weitreichende Konsequenzen bezüglich Hygienekontrollen oder der Unterbrechung des Betriebs.

Außerdem wird eine Erregerdiagnostik im Rahmen der Differenzialdiagnose protrahierter Durchfälle (> 7 Tage) zur Unter- 
scheidung einer infektiösen AGE und chronisch-entzündlicher Darmerkrankung empfohlen [64].

\section{I.6.1.3 STATEMENT}

Eine Differenzierung zwischen bakterieller und viraler AGE ist für die initiale Therapie nicht entscheidend. Die Bestimmung systemischer (CrP, Procalcitonin) oder fäkaler Inflammationsmarker (Calprotectin, Laktoferrin) mit dem Ziel, eine bakterielle Ursache für eine AGE wahrscheinlicher zu machen, soll nicht routinemäßig erfolgen.

Konsensstärke: $100 \%$, starker Konsens

Laboruntersuchungen werden bei immunkompetenten Kindern älter als 12 Monate, die an AGE erkrankt sind, nicht routinemäßig benötigt, da sie für die Behandlung mit ORL und eine frühe Realimentation nicht entscheidend sind [6, 87]. Dennoch kann bei Vorliegen von Risikofaktoren wie unter I.5.1.2 und I.5.1.4 beschrieben oder Konstellationen wie unter I.6.1.2, moderater Dehydration im CDS, verzögerter Kapillarfüllung, Versagen der ORL und notwendiger Rehydration über Magensonde bzw. Infusionen oder unklarer Differenzialdiagnose die Bestimmung der Serumelektrolyte, Blutgase, CRP und Blutbild indiziert sein $[3,87]$. Eine qualitativ gute Evidenz hierzu fehlt jedoch.

\section{I.6.1.4 STATEMENT}

Eine EHEC-Infektion soll bei Patienten mit typischer/entsprechender Symptomatik (Trias aus mikroangiopathischer hämolytischer Anämie, Thrombozytopenie und akuter Nierenfunktionseinschränkung) ausgeschlossen werden.

Konsensstärke: $100 \%$, starker Konsens

Eine EHEC-Infektion soll bei jeder AGE im Kindesalter differenzialdiagnostisch berücksichtigt werden. Begleitsymptome sind Übelkeit, Erbrechen, zunehmende Bauchschmerzen und selten Fieber. Bei 10-20\% der Erkrankten entwickelt sich eine hämorrhagische Kolitis. Gefürchtet ist vor allem das hämolytisch-urämische Syndrom (HUS). Als HUS wird das Zusammentreffen der Symptome Hämolyse, Thrombopenie und Erhöhung der Retentionswerte (Kreatinin bzw. Harnstoff) in Verbindung mit einer Oligurie bzw. einer Anurie bezeichnet. Bei entsprechender Klinik soll laut S1-Leitlinie der DEGAM für Erwachsene sofort eine Klinikeinweisung erfolgen [94]. Das HUS ist die häufigste Ursache für ein akutes Nierenversagen im Kindesalter. Daher soll auch bei Kindern und Jugendlichen mit Verdacht auf HUS eine stationäre Abklärung und ggf. Therapie erfolgen. Der Häufigkeitsgipfel liegt im frühen Kleinkindesalter (1-4 Jahre). Die Krankheit ist jedoch nicht auf das Kindesalter begrenzt, sie kann in jedem Alter vorkommen [53]. Die häufigste Variante, das infektionsassoziierte HUS, zeigt eine jahreszeitliche Schwankung mit der höchsten Inzidenz in den Sommermonaten. Dieser Form des HUS geht eine Diarrhoe voraus (sog. D+-HUS). In den letzten Jahren scheint die Häufigkeit des D+-HUS weltweit zuzunehmen. Mittlerweile wurden Ende- mien in fast allen Erdteilen berichtet. Das infektionsassoziierte HUS tritt 1-12 Tage (Median 4 Tage) nach Infektion auf. Als Prodromi werden bei fast allen Patienten (70-95\%) wässrige Durchfälle und bei 2/3 der Fälle blutiger Durchfall berichtet. Fieber, Erbrechen, abdominelle Schmerzen und zerebrale Symptome sind bei ca. 1/3 der Patienten zum Zeitpunkt der Diagnosestellung vorhanden. Bei etwa 20-25\% finden sich Zeichen eines Infektes der oberen Luftwege. Die zerebralen Symptome reichen von Somnolenz über Krampfanfälle bis hin zum Koma. Der durchfallbedingte Flüssigkeitsverlust begünstigt zerebrale Symptome.

Die typische Laborkonstellation zeigt eine Leukozytose > $20000 /$ $\mu \mathrm{l}$ in $40 \%$, Thrombozytopenie $<50000 / \mu \mathrm{l}$ in $50 \%$ und $<20000 / \mu \mathrm{l}$ in $5 \%$, Anämie mit $\mathrm{Hb}<10 \mathrm{~g} / \mathrm{dl}$ in $70 \%$, LDH-Erhöhung $>2000 \mathrm{U} / \mathrm{l}$ in $90 \%$ und Kreatininwerte $>2,5 \mathrm{mg} / \mathrm{dl}$ in $75 \%$. Typische Fragmentozyten im Blutausstrich im Zusammenhang mit der klinischen Symptomatik sichern die Diagnose. Die mikrobiologische Diagnostik auf EHEC ist komplex. Zur notwendigen und sinnvollen Kombination der verschiedenen Testverfahren wird auf die Empfehlungen des RKI und BfR verwiesen (link: www.rki.de/...). Nach § 6 Abs. 1 Nr. 1 des IfSG besteht bereits bei Krankheitsverdacht sowie bei Erkrankung und Tod an enteropathischem hämolytisch-urämischen Syndrom (HUS) eine namentliche Meldepflicht. Ferner ist jeder EHECNachweis, soweit er auf eine akute Infektion hinweist, meldepflichtig.

\section{I.6.1.5 STATEMENT}

Bei Patienten mit Diarrhoe und einem erhöhten Risiko für eine C.-difficile-Infektion (z. B. Kinder mit chronisch-entzündlicher Darmerkrankung, M. Hirschsprung, ältere Kinder mit Antibiotikatherapie) soll zeitnah eine sensitive Diagnostik auf Toxinbildende $\mathrm{C}$. difficile erfolgen.

Konsensstärke: $100 \%$, starker Konsens

Bei Patienten mit Verdacht auf eine nosokomiale Diarrhoe oder ambulante AGE mit Risikofaktoren soll eine zeitnahe Diagnostik auf Clostridoides difficile durchgeführt werden [53]. Als wichtigster Risikofaktor gilt eine durch Antibiotika hervorgerufene Störung des intestinalen Mikrobioms (so genannte Dysbiose) [53].

CDI sind die Hauptursache für antibiotikaassoziierte Durchfälle oder pseudomembranöse Kolitis. Die Inzidenz von antibiotikaassoziierten Durchfällen ist bei Kindern $<2$ Jahren mit $18 \%$ besonders hoch [95]. Bei Neugeborenen und jungen Säuglingen sind asymptomatische Träger von toxigenen oder nicht toxigenen Clostridien beschrieben [96], aber auch Assoziationen zu Infektionen, insbesondere der nekrotisierenden Enterokolitis (NEC). Entscheidende Determinante für den Nachweis von Clostridien im Darm von Frühgeborenen ist die Zeitdauer des Aufenthalts auf der Intensivstation [97]. Trotz der hohen Rate asymptomatischer Träger von C. difficile bei Säuglingen kann C. difficile eine Ursache für eine besonders schwer verlaufende Kolitis bei M. Hirschsprung sein [67].

Exazerbationen chronisch-entzündlicher Darmerkrankungen sind auch im Kindesalter mit CDI assoziiert [64, 98-100]. 
Tests auf $C$. difficile sollten nur bei symptomatischen Patienten mit klinisch signifikanten wässrigen Durchfällen erfolgen, wenn es Verdacht auf eine CDI gibt oder prädisponierende Faktoren dafür vorliegen. Bei Säuglingen sollten Tests auf $C$. diff. nur bei M. Hirschsprung oder anderen Motilitätsstörungen, bei älteren Kindern nur nach Ausschluss gängiger anderer Durchfallursachen, bei Risikofaktoren (Antibiotikagebrauch, insbesondere Breitspektrum-Antibiotika) oder prädisponierenden Grunderkrankungen, wie Immundefekten, chronisch- entzündlichen Darmerkrankungen, Mukoviszidose, M. Hirschsprung, Z. n. Darmchirurgie etc., durchgeführt werden.

Die Labortestung für eine CDI beinhaltet den Nachweis von C.-difficile-Toxin(en) oder Toxin-bildenden C.-difficile-Bakterien im Stuhl [101]. Die derzeit verfügbaren Assays können zwischen Kolonisation und Infektion nicht unterscheiden. Stuhl- Enzymimmuno-Assays auf Toxin A und/oder B sind preiswert, aber nicht besonders sensitiv. Empfohlen wird eine PCR-Methode (NAAT = nuclear acid amplification testing) oder eine 2-Schritt-Diagnostik in Form eines GDH-Assays, gefolgt von einem NAAT, wenn der GDH-Test positiv ist [102, 103].

\section{I.6.2 Klinische Chemie}

\section{STATEMENT}

Bei Kindern mit intravenösem Rehydrationsbedarf soll die Bestimmung von Natrium, Kalium, Kreatinin, Harnstoff, SBS (kapillär oder venös), Blutzucker und Blutbild erfolgen. Konsensstärke: $100 \%$, starker Konsens

Trotz geringer Evidenz wird empfohlen, bei Kindern, die eine intravenöse Rehydration benötigen, eine Laborbestimmung der Serumelektrolyte durchzuführen, da insbesondere die Natriumspiegel die Rehydration beeinflussen [6]. Erhöhte Laborwerte für Natrium, Kalium, Glukose, Kreatinin und Harnstoff korrelierten in einer Studie sehr gut mit dem Ausmaß der Dehydration [104]. Die Höhe des Harnstoffwertes korrelierte auch in einer anderen Studie sehr gut mit Gewichtsänderungen und dem Schweregrad der Dehydration [105, 106]. Außerdem hat sich die Bestimmung des Bikarbonats in Studien als nützlich erwiesen, um zwischen dem Grad der Dehydration zu diskriminieren [106, 107].

Praktisch, einfach, preiswert und schnell verfügbar ist die Bestimmung der Blutgase mit Elektrolyten, $\mathrm{Hb}$ und Blutzucker aus venösem Blut bei Infusionsanlage. Bei schwer krankem Kind kann hierbei auch eine Blutkultur abgenommen werden. Eine zusätzliche Analyse des Kreatinins und Blutbildes kann wichtige Hinweise dafür liefern, ob möglicherweise eine EHEC-Infektion vorliegen könnte und die Gefahr eines HUS droht (siehe I.6.1.4).

\section{I.6.3 Weiterführende Diagnostik}

\section{STATEMENT}

Eine weiterführende endoskopische oder radiologische Diagnostik soll bei AGE nicht erfolgen, es sei denn, es liegt ein schwerer Krankheitsverlauf vor, der differenzialdiagnostisch oder hinsichtlich einer Komplikation abgeklärt werden soll.

Konsensstärke: $90 \%$, Konsens

Eine weiterführende apparative Diagnostik ist bei AGE im Kindesalter zunächst nicht erforderlich. Wird anamnestisch oder klinisch - vor allem bei Kleinkindern (<2 Jahre) - jedoch eine walzenförmige Resistenz getastet oder eine Invagination vermutet, ist die Durchführung einer Abdomen-Sonografie indiziert. Es besteht eine klare Assoziation zwischen respiratorischen und intestinalen Virusinfekten und einer Invagination [108, 109], aber auch bei bakterieller Enteritis können Invaginationen auftreten [110]. Bei Verdacht auf eine Perforation nach einer Invagination ist eine Röntgenaufnahme des Abdomens im Stehen oder in Seitenlage indiziert. Bei Invaginationen ist ein konservativer Repositionsversuch mit Luft (Röntgendurchleuchtung erforderlich) oder Flüssigkeit (sonografische Kontrolle) die Therapie der 1. Wahl beim therapeutischen Vorgehen $[111,112]$. Die konservative Erfolgsrate war bei der sonografisch-kontrollierten hydrostatischen Reposition mit $96,8 \%$ signifikant der radiologischen Reposition mit Luft $(83,9 \%)$ in einem RCT überlegen [113].

Endoskopisch-histologische Untersuchungen sind speziellen Fragestellungen vorbehalten, wie z. B. M. Crohn/Colitis ulcerose oder Mukoviszidose und Verdacht auf pseudomembranöse Kolitis durch C. difficile, insbesondere bei klinisch- dringlichen Situationen und mikrobiologisch negativen Stuhlbefunden [102, 103] (s. o. und I.6.1.5). Die Frage einer fehlenden Erholung nach einer infektiösen AGE kann den Verdacht auf eine zugrunde liegende CED aufkommen lassen. Diese klinische Konstellation muss dann zu weiterer Diagnostik inkl. Endoskopie z. A. einer CED führen [53].

\section{Kapitel II: Management und Behandlung der akuten Gastroenteritis im Säuglings-, Kindes- und Jugendalter (AG 2)}

AG-Leiter: S. Buderus, Bonn

AG-Mitglieder: M. Classen, Bremen; B. Lawrenz B., Arnsberg; C. Posovszky, Ulm; A. Schmidt-Choudhury, Bochum;

\section{II.1 Orale Rehydrationstherapie}

\section{II.1.1 EMPFEHLUNG}

Bei AGE ohne Dehydration soll die gewohnte altersentsprechende Ernährung angeboten werden.

Konsensstärke: $100 \%$, starker Konsens 


\section{II.1.2 EMPFEHLUNG}

Als Standardtherapie der Dehydration bei akuter Gastroenteritis soll eine orale Rehydration mit einer Glukose-Elektrolytlösung (Natrium 60 mmol/l, Glukose 74-111 mmol/l) oder Polymer- basierten Elektrolytlösung rasch begonnen werden. Diese sind effektiv und sicher.

Konsensstärke: $100 \%$, starker Konsens

Weltweit haben sich orale Rehydrationslösungen (ORL) aufgrund ihrer Wirksamkeit und grundsätzlich einfachen Anwendbarkeit zur Therapie der AGE durchgesetzt. Eine aktuelle Analyse von 15 Leitlinien, die von Organisationen wie der WHO oder der ESPGHAN bzw. in Ländern wie Kenia, Malaysia oder Großbritannien und Kanada erstellt wurden, belegt diese globale Priorität der ORL für die Therapie der AGE [1]. Die Misserfolgsrate („failure rate") der oralen Rehydrationstherapie (ORT) wird in Studien, Metaanalysen und Leitlinien zwischen $4 \%[5,114]$ und $16,2 \%$ bis $25 \%$ angegeben $[91,115,116]$. Zwischen $75 \%$ und $96 \%$ der Säuglinge und Kinder mit leichter bis mittelschwerer Dehydration können also erfolgreich oral rehydriert werden.

ORT ist nebenwirkungsärmer als intravenöse Rehydration. Die schmerzhafte Venenpunktion entfällt und es besteht kein Risiko für eine Phlebitis oder ein Paravasat [117]. Es kommt seltener zu schweren Komplikationen wie Krampfanfällen oder gar Todesfällen. Sie verhindert häufig eine stationäre Aufnahme und hierdurch das Risiko für nosokomiale Infektionen. Jedoch wurde bei ORT eine im Vergleich zur intravenösen Rehydration höhere lleus-Rate berichtet [117]. Die Dauer des Krankenhausaufenthalts ist bei ORT gleich lang bzw. tendenziell kürzer und es gibt keine Unterschiede hinsichtlich des Auftretens von Hypo- oder Hypernatriämien, der Durchfalldauer bzw. der angestrebten Gewichtsentwicklung [5, 114, 117, 118].

Zumeist werden im deutschen Sprachraum ORL auf Glukose-Basis verwendet; es gibt jedoch einige wenige Produkte, deren Kohlenhydrat-Gehalt auf Polymerbasis in Form von Reis, Karotte oder deren Kombination beruht. Die Autoren einer aktuellen CochraneAnalyse schlussfolgern einen leichten Vorteil dieser polymeren Produkte gegenüber den hypotonen ORL ( $\leq 270 \mathrm{mOsm} / \mathrm{l})$ [119].

\section{II.1.3 EMPFEHLUNG}

Koffeinhaltige Getränke, Limonaden oder Fruchtsäfte sollten bei Dehydration nicht zur oralen Rehydration verwendet werden. Konsensstärke: $100 \%$, starker Konsens

Die empfohlenen ORL enthalten Natrium und Glukose in einer physiologisch optimalen Kombination und Konzentration (,hypoosmolar“) für eine bessere intestinale Resorption von Wasser $[120,121]$. Auf diese Weise werden die Verluste von Elektrolyten, Flüssigkeit und Energie ausgeglichen. Die in Deutschland, Österreich, der Schweiz und anderen Ländern verfügbaren und handelsüblichen ORL enthalten außerdem Kalium, Chlorid und eine basische Puffersubstanz (zumeist Zitrat), um die häufig bestehende metabolische Azidose auszugleichen.

Cola oder Apfelsaft entsprechen diesen Anforderungen und Empfehlungen für die Zusammensetzung einer wirksamen ORL nicht: Sie enthalten zu wenig Natrium, zum Teil sehr viel Zucker, sie sind hyper-osmolar oder aufgrund variabler Verdünnung diesbezüglich nicht standardisiert, und der Basengehalt ist stark variabel [122]. Allerdings haben sie den Vorteil, dass sie geschmacklich besser von den Patienten akzeptiert werden. Bemerkenswert ist daher die Studie von Freedman et al., bei der tatsächlich unter kontrollierten Bedingungen verdünnter Apfelsaft (mit $50 \%$ Wasser verdünnt) zur Rehydration im Vergleich zu einer der empfohlenen Standard-ORL eingesetzt wurde [115]. In der Behandlungsgruppe mit Apfelsaft fanden sich weniger Therapieversager mit der Notwendigkeit zur intravenösen Rehydration; dieser Anteil war höher, je älter die Kinder waren. Einschränkend erwähnen aber die Autoren selbst, dass die Ergebnisse von dieser ersten Studie, die ganz überwiegend (68\%) an Kindern ohne relevante Dehydrationszeichen durchgeführt wurde, nicht ohne weiteres auf die Behandlung von kränkeren und deutlich dehydrierteren Kinder übertragen werden können. In diesem Sinne wurde die Studie auch kürzlich im Deutschen Ärzteblatt kommentiert [115]. Es sind also weitere kontrollierte Studien notwendig, bevor bei entsprechendem Wirksamkeitsnachweis eine Empfehlung zu verdünntem Apfelsaft zur Rehydration gegeben werden kann. Andere Bemühungen gehen dahin, ORL in der beschriebenen, empfohlenen Zusammensetzung geschmacklich zu verbessern. So konnte gezeigt werden, dass ein hypotones, zinkhaltiges, orales Rehydrationsgel die Akzeptanz bei Kindern verbessert [123]. Das Produkt ist jedoch derzeit im deutschen Sprachraum nicht erhältlich.

\section{II.1.4 EMPFEHLUNG}

Bei Dehydration mit Erbrechen soll eine orale Rehydration dennoch versucht werden. Eine Zufuhr von $5 \mathrm{ml}$ einer oralen Rehydrationslösung (ORL) alle 1-2 Minuten mittels Löffel oder Spritze, idealerweise durch eine Bezugsperson, ist meist effektiv. Konsensstärke: $90 \%$, Konsens

\section{II.1.5 EMPFEHLUNG}

Eine nasogastrale Sonde sollte zur enteralen Rehydration gelegt werden, wenn eine orale Rehydration mittels häufigen Trinkens oder Löffelns kleiner Mengen einer oralen Rehydrationslösung (ORL) nicht gelingt.

Konsensstärke: $100 \%$, starker Konsens

\section{II.1.6 EMPFEHLUNG}

Die enterale (orale oder nasogastrale) Rehydration sollte mit einer Geschwindigkeit von 40-50 ml/kg über 4 Stunden erfolgen (schnelle Rehydration), alternativ kann eine langsamere Vorgehensweise über 24 Stunden Anwendung finden.

Konsensstärke: $100 \%$, starker Konsens 


\section{II.1.7 EMPFEHLUNG:}

Laufende Verluste sollen zusätzlich ersetzt werden: Pro Erbrechen oder wässrigem Stuhl mit $10 \mathrm{ml} / \mathrm{kg} \mathrm{KG}$ und pro $1{ }^{\circ} \mathrm{C}$ Temperaturerhöhung über $37,0^{\circ} \mathrm{C}$ mit $10 \mathrm{ml} / \mathrm{kg} \mathrm{KG} / 24 \mathrm{~h}$. Konsensstärke: $100 \%$, starker Konsens

Erbrechen ist kein Symptom, das per se eine intravenöse Flüssigkeitstherapie notwendig macht. Die detaillierte und praxisorientierte Darstellung der oralen Rehydration im ausführlichen Bericht des Centers for Disease Control (CDC) belegt die Wirksamkeit der oben beschriebenen Vorgehensweise auch bei Kindern [124]. Sollte das häufige Anbieten von Flüssigkeit aus der Flasche oder vom Löffel nicht möglich sein, wird eine kontinuierliche Rehydration über eine nasogastrale Sonde empfohlen. In einer Studie konnte gezeigt werden, dass die schnelle nasogastrale Rehydration ebenso sicher und effektiv ist wie die intravenöse Therapie [125].

Metaanalysen bestätigen die Gleichwertigkeit der ORT und der intravenösen Rehydration bei der Behandlung dehydrierter Kinder [114, 126]. Diese Empfehlungen und Beurteilungen sind auch Bestandteil der evidenzbasierten Leitlinie der ESPGHAN zur akuten Gastroenteritis von 2008 und ihrer Aktualisierung 2014 [5, 6]. Die Mengenangaben zur Flüssigkeitstherapie basieren auf Flüssigkeitsdefiziten, die bei leichter bis mäßiger Dehydration im Rahmen einer AGE bestehen und in den Studien verwendet wurden, die dieser Leitlinie zugrunde liegen. Es ist darauf zu achten, dass laufende Verluste mit zusätzlichen ORL-Gaben ersetzt werden, um stets das tatsächliche Volumen-Defizit während der Rehydrationsphase zu ersetzen. Die schnelle Rehydration über 4 Stunden ist praktikabel und besonders geeignet, den Erfolg der ORT im ambulanten Setting, zum Beispiel durch Wiedereinbestellung in die Praxis, zu überprüfen, oder im prästationären Setting zu entscheiden, ob doch eine vollstationäre Versorgung notwendig ist. Studiendaten belegen, dass die ORT gegenüber der intravenösen Rehydration schneller in der Notaufnahme begonnen wird und nach 4 Stunden weniger Kinder der ORT-Gruppe eine stationäre Aufnahme benötigen (30,6\% im Vergleich zu 48,7\%) [127]. Einen Algorithmus zum Vorgehen bei Dehydration finden Sie in der Anlage der Leitlinie (Anlage 1).

\section{II.2 Intravenöse Rehydrationstherapie}

Die Empfehlungen zur intravenösen Rehydration basieren im Wesentlichen auf den Empfehlungen der ESPGHAN und der britischen NICE-Guideline zur Therapie der akuten Gastroenteritis $[6,7]$.

\section{II.2.1 EMPFEHLUNG}

Eine intravenöse Rehydration soll erfolgen:

- bei Scheitern einer oralen oder nasogastralen Rehydration,

- bei Schockzustand,

- bei schwerer Dehydration >9\%KG (insbesondere, wenn neurologische Symptome bestehen oder eine schwere
Azidose ( $\mathrm{pH}<7,25$; $\mathrm{BE}<-15 \mathrm{mmol} / \mathrm{l})$ oder Hypo- oder Hypernatriämie vorliegt) sowie

- bei Symptomen eines Ileus und galligem Erbrechen.

Konsensstärke: $100 \%$, starker Konsens

Diese Indikationen für eine intravenöse Flüssigkeitstherapie werden in den Leitlinien der verschiedenen Länder bzw. Organisationen nahezu uniform angegeben [1]. Das Vorgehen unterscheidet sich jedoch insbesondere bei der Feststellung des Scheiterns der ORT. In einigen Länder wird nach Scheitern von Trinken oder Löffeln der ORL vor Beginn einer intravenösen Therapie noch ein Versuch mittels nasogastraler Sondierung gemacht [1]. Dieses Vorgehen wird in Deutschland und Österreich bisher noch nicht flächendeckend umgesetzt und sollte häufiger erwogen werden, um eine intravenöse Therapie zu verhindern (siehe II.1.5; Algorithmus Anlage 1). Entsprechend personell ausgestattete Versorgungsstrukturen und finanzielle Anreize hierfür sollten etabliert werden, um diesen Zustand zu verbessern.

\section{II.2.2 EMPFEHLUNG}

Folgende Patienten mit der klinischen Diagnose einer Gastroenteritis sollen stationär behandelt werden:

- bei Schock/schwere Azidose

- bei schwerer Dehydration (Gewichtsverlust $\geq 9 \%$ )

- bei gescheiterter oraler Rehydration

- bei ausgeprägter Hyponatriämie ( $\mathrm{Na}+<130 \mathrm{mmol} / \mathrm{l})$ bzw. ausgeprägter Hypernatriämie ( $\mathrm{Na}+>150 \mathrm{mmol} / \mathrm{l})$

- bei neurologischen Symptomen (Lethargie/Koma)

- bei nicht gesicherter adäquater ambulanter Umsetzung der Rehydration durch Betreuungsperson/en

- bei schwerer (chronischer) Grunderkrankung (z. B. onkologischer Erkrankung, Immundefizienz, Diabetes und anderen Stoffwechselstörungen)

- bei Malnutrition und/oder Gedeihstörung

- bei Hinweis auf Ileus oder intestinale Transportstörung (z. B. Invagination)

- bei Säuglingen < $3500 \mathrm{~g}$ oder jünger als 2 Monate

- bei anhaltend blutiger Diarrhoe

Konsensstärke: $100 \%$, starker Konsens

Das Scheitern der ORT war in einer niederländischen Studie mit einer hohen Versorgungs-Dringlichkeitsstufe nach ManchesterTriage-System (MTS), einer verlängerten Kapillarfüllungszeit sowie einem hohen Dehydrationsgrad assoziiert [91]. Es handelt sich dabei also um klinisch schwer kranke Patienten.

Dementsprechend sollen Patienten aufgrund der Schwere oder besonderen Symptomatik ihrer Erkrankung stationär behandelt werden. Dies betrifft zum Beispiel Patienten mit einer primär schweren Dehydration, nach erfolgloser oraler bzw. nasogastraler Rehydrationstherapie oder mit Symptomen, bei denen eine differenzialdiagnostische Abklärung der Gastroenteritis zeitnah erfor- 
derlich ist, wie zum Beispiel bei Ileus oder Sepsis. Ebenso sollen Patienten mit Risikofaktoren für einen schweren oder komplizierten Verlauf, wie junge oder kleine Säuglinge und Patienten mit vorbestehender Grunderkrankung bzw. Mangelernährung, stationär versorgt werden [6]. Diese Patienten benötigen in der Regel neben der Rehydrationstherapie eine engmaschige klinische und laborchemische, teilweise auch intensivmedizinische Überwachung durch Pflege und ärztliches Personal und erweiterte Diagnostik mit Bildgebung.

\section{II.2.3 EMPFEHLUNG}

Bei Schock sollen initial $20-40 \mathrm{ml} / \mathrm{kg}$ KG isotone Kochsalzlösung (alternativ Ringer-Lösung) über 15-30 Minuten verabreicht werden.

Intensivmedizinisch erfahrene Pädiater sollen hinzugezogen werden.

Konsensstärke: $100 \%$, starker Konsens

\section{II.2.4 EMPFEHLUNG}

Bei persistierendem Schock soll darüber hinaus nach anderen Ursachen gesucht werden.

Konsensstärke: $100 \%$, starker Konsens

\section{II.2.5 EMPFEHLUNG}

Die intravenöse Rehydration bei schwerer Dehydration ohne Schock sollte mit einer schnellen Phase von 20 ml/kg KG isotoner Kochsalzlösung (alternativ Ringer-Lösung) über 2 bis 4 Stunden begonnen werden.

Konsensstärke: $100 \%$, starker Konsens

\section{II.2.6 EMPFEHLUNG}

Patienten mit AGE und schwerer Hyper- ( $\geq 150 \mathrm{mmol} / \mathrm{l})$ bzw. Hyponatriämie $(<130 \mathrm{mmol} / \mathrm{l})$ sollen intensivmedizinisch überwacht und behandelt werden.

Konsensstärke: $100 \%$, starker Konsens

Eine aktuelle Studie aus Indien bestätigt nochmals, dass isotone Kochsalzlösung auch bei schwerer Dehydration der Ringer-Lösung gleichwertig und somit aufgrund der generellen Verfügbarkeit und Kosten zu bevorzugen ist [128].

Eine schnelle intravenöse Rehydration kann über 2 bis 4 Stunden mit $20 \mathrm{ml} / \mathrm{kg} / \mathrm{h}$ erfolgen, um dann mit einer intravenösen $\mathrm{Er}$ haltungstherapie bzw. oraler Rehydration fortgesetzt zu werden [6]. Eine ultrarasche intravenöse Rehydration mit $60 \mathrm{ml} / \mathrm{kg} / \mathrm{h}$ bietet dagegen bei hämodynamisch stabilen Patienten keinen Vorteil und ist darüber hinaus mit einer längeren Hospitalisierung assoziiert $[129,130]$.
Das Vorgehen bei Kindern mit schwerer AGE und Schock soll frühzeitig auch gemeinsam mit intensivmedizinisch erfahrenen Pädiatern abgestimmt werden. Bei Schock wird nach der ESPGHAN-Leitlinie die Gabe von Ringer-Lösung bei niedriger Evidenz bevorzugt [6].

Eine hypernatriämische Dehydration (sogenannte „Toxikose“ bzw. „hypertone Dehydration“) ist selten, die Häufigkeit wird mit $<1 \%$ bis $4 \%$ aller AGE-Fälle angegeben [6]. Die klinische Beurteilung ist hierbei erschwert, da der ausgeprägte Flüssigkeitsmangel den Patienten klinisch im Vergleich zu „normoton“ dehydrierten nicht anzusehen ist. Oft handelt es sich um junge Säuglinge, zumeist jünger als 6 Monate, mit Tachypnoe und teigig wirkender Haut. Komplizierend können neurologische Symptome wie erhöhter Muskeltonus, Hyperreflexie, aber auch Krampfanfälle und Bewusstseinsstörungen bis zum Koma auftreten. Das Ziel der Rehydrationstherapie ist ein Ausgleich des Flüssigkeitsdefizits durch Volumensubstitution mit einhergehender langsamer Reduktion des Serum-Natriumspiegels über ungefähr 48 Stunden [6]. Die initiale Volumengabe von $0,9 \% \mathrm{NaCl}$-Lösung zur Rehydration erscheint sicher, da trotz der Hypernatriämie ein Defizit des Gesamtkörpernatriums besteht [131]. Zusätzlich zum Erhaltungsbedarf werden bei milder Dehydration $50 \mathrm{ml} / \mathrm{kg}$ und bei schwerer Dehydration $100 \mathrm{ml} / \mathrm{kg}$ über $24 \mathrm{~h}$ verabreicht und enterale Verluste ersetzt [132]. Zur Überwachung sind häufige Kontrollen des PlasmaNatriums indiziert, die „Absinkrate“ sollte etwa 0,5-0,6 mmol/l/h betragen $[6,132]$. In schweren Fällen kann die Dauer der Rehydration bis zu 48 Stunden betragen, wenn zum Beispiel bei Aufnahme ein Serum-Natrium von $165 \mathrm{mmol} / \mathrm{l}$ vorlag.

Die wesentliche Komplikation einer hyponatriämischen Dehydration ist die Entwicklung einer hyponatriämischen Enzephalopathie mit Hirnödem, erhöhtem Hirndruck, gestörter Perfusion und selten auch Hirnstammeinklemmung [86, 133]. Aufgrund der Verwendung von hypotonen intravenösen Rehydrationslösungen kann es auch iatrogen während der Behandlung zur Hyponatriämie kommen [134] (siehe II.2.8). Bei einer AGE wird bereits aufgrund des Volumendefizits und Erbrechens vermehrt antidiuretisches Hormon (ADH) gebildet, sodass hypotone Lösungen bei AGE nicht geeignet sind und zur Prävention der Hyponatriämie $0,9 \%$ ige $\mathrm{NaCl}$-Lösung verwendet werden soll $[133,135]$. Die klinischen Symptome können unspezifisch sein und mit Übelkeit und Erbrechen nicht von den üblichen Symptomen der AGE unterscheidbar sein, aber bis hin zu Bewusstseinsstörungen und Krampfanfällen reichen [86]. In seltenen Fällen können Herzrhythmusstörungen oder auch ein neurogenes Lungenödem auftreten. Wie bei der hypertonen Dehydration soll auch bei der hypotonen Dehydration die Geschwindigkeit der Normalisierung der SerumNatriumkonzentration etwa bei $0,5 \mathrm{mmol} / \mathrm{l} / \mathrm{h}$ liegen. Bei einer schweren Hyponatriämie mit den Zeichen einer Enzephalopathie wird folgendes Vorgehen empfohlen [135, 136]: Zunächst über 10 Minuten Gabe von 2 ml/kg KG 3 \%ige NaCl-Lösung (maximal $100 \mathrm{ml}$ ). Abhängig von den Symptomen kann der Bolus bis zur klinischen Besserung 1-2-mal wiederholt werden. Ziel in dieser Phase ist der Anstieg des Serum-Natriums um 5-6 mmol// in den ersten 1-2 Stunden. 


\section{II.2.7 EMPFEHLUNG}

Die intravenöse Rehydration im Verlauf soll abhängig von den Elektrolyt-Befunden und dem Alter des Kindes mit 2/3- oder Vollelektrolytlösungen, in der Regel mit $5 \%$-Glukose, erfolgen. Konsensstärke: $100 \%$, starker Konsens

\section{II.2.8 EMPFEHLUNG}

Hypotone intravenöse Lösungen (Natrium-Gehalt $<75 \mathrm{mmol}$ / I) und Halbelektrolytlösungen sollen wegen der Gefahr der Hyponatriämie nicht eingesetzt werden.

Konsensstärke: $100 \%$, starker Konsens

Die Entwicklung einer Hyponatriämie ist eine mögliche und relevante Komplikation der intravenösen Rehydration [134]. Die Verwendung einer Halbelektrolytlösung führte in einer prospektiv randomisierten Studie bei Kindern in den ersten 4 Stunden der Rehydration sowohl bei $13 \%$ der Kinder, die bei Aufnahme bereits hyponatriäm waren, als auch bei $51 \%$ der Kinder mit zunächst normalem Serum-Natrium signifikant häufiger zu einem Abfall des Serum-Natriums von $\geq 2$ mmol/l [137]. Dieser signifikante Effekt wurde bei Verwendung von isotoner Infusionslösung weder bei den hyponatriämen Kindern noch bei den isoton dehydrierten Kindern nachgewiesen [137]. Eine weitere prospektiv randomisierte Studie zeigte weder für die Verwendung von Ringer-Laktat noch einer $0,9 \%$ igen $\mathrm{NaCl}$-Lösung bei schwer dehydrierten Kindern eine Entwicklung von Hyper- oder Hyponatriämien [128]. Daher haben die unter II.2.8 beschriebenen Lösungen keinen Stellenwert mehr und sollen durch Vollelektrolyt- bzw. 2/3-Elektrolytlösungen (siehe Kapitel II.2.7.) ersetzt werden. Die Metaanalyse von Wang zur Erhaltungstherapie zeigt, dass das Risiko für eine Hyponatriämie bei hypotoner Infusionslösung um den Faktor 2,24 und für eine schwere Hyponatriämie um den Faktor 5,29 gegenüber isotoner Infusionslösung erhöht ist. Dem gegenüber bestand kein erhöhtes Risiko eine Hypernatriämie zu entwickeln [138].

\section{II.2.9 STATEMENT \\ Der Flüssigkeitserhaltungsbedarf für 24 Stunden kann nach der Holiday-Segar-Formel abgeschätzt werden: $100 \mathrm{ml} / \mathrm{kg} \mathrm{KG}$ bei einem Körpergewicht $\leq 10 \mathrm{~kg} .1000 \mathrm{ml}$ plus $50 \mathrm{ml} / \mathrm{kg}$ KG bis zu einem Gewicht von $20 \mathrm{~kg}$. Ab $20 \mathrm{~kg}$ Körpergewicht $1500 \mathrm{ml}$ plus $20 \mathrm{ml} / \mathrm{kg}$ für jedes Kilogramm über 20 kg Körper- gewicht. \\ Konsensstärke: $100 \%$, starker Konsens}

Sofern die Rehydration langsam über $24 \mathrm{~h}$ erfolgt und die Kinder länger im Krankenhaus verweilen, ist nicht nur der Verlust durch die AGE, sondern auch der physiologische Flüssigkeitsbedarf zu ersetzen. Diese Empfehlung stellt eine mögliche, aber besonders
- Tab. Il-1 Kalkulation des Erhaltungsbedarfs nach der HolidaySegar-Methode.

\begin{tabular}{|l|l|l|}
\hline Gewicht & Flüssigkeitsbedarf & $\begin{array}{l}\text { Zwischen- } \\
\text { summe }\end{array}$ \\
\hline \begin{tabular}{l|l|} 
für die ersten \\
$10 \mathrm{~kg} \mathrm{KG}$
\end{tabular} & $100 \mathrm{ml} / \mathrm{kg} \mathrm{KG} / \mathrm{d}$ & $\begin{array}{l}\text { bei } 10 \mathrm{~kg}: \\
1000 \mathrm{ml} / \mathrm{d}\end{array}$ \\
\hline $\begin{array}{l}\text { für die zweiten } \\
10 \mathrm{~kg} \mathrm{KG}\end{array}$ & $50 \mathrm{ml} / \mathrm{kg} \mathrm{KG} / \mathrm{d}$ & $\begin{array}{l}\text { bei } 20 \mathrm{~kg}: \\
1500 \mathrm{ml} / \mathrm{d}\end{array}$ \\
\hline ab dem 20.kg KG & $20 \mathrm{ml} / \mathrm{kg} \mathrm{KG} / \mathrm{d}$ & ab $20 \mathrm{~kg}:$ \\
& & $1500 \mathrm{ml} / \mathrm{d}+\ldots$ \\
\hline
\end{tabular}

einfache und weit verbreitete Methode dar, um die Berechnung des Erhaltungsbedarfs nach dem initialen Ausgleich des Flüssigkeitsdefizits vorzunehmen [139] ( Tab. II-1).

\section{II.2.10 EMPFEHLUNG}

Neben diesem Erhaltungsbedarf (siehe II.2.9) sollen die bestehenden Defizite und die laufenden Verluste durch Durchfall und/oder Erbrechen berücksichtigt und ersetzt werden (Berechnung siehe II.1.7).

Konsensstärke: $100 \%$, starker Konsens

\section{II.2.11 EMPFEHLUNG}

Eine Hypokaliämie sollte erst ab Einsetzen der Urinproduktion ausgeglichen werden.

Konsensstärke: $90 \%$, Konsens

Bei erniedrigtem Serumkalium sollte die Kaliumkonzentration der Infusionslösung nach Einsetzen der Diurese auf einen Kaliumgehalt von $20 \mathrm{mmol} / \mathrm{l}$ ergänzt werden. Trotz normaler Serum-Kaliumwerte haben dehydrierte Patienten oft ein Defizit des Gesamtkörperkaliums. Insbesondere bei länger dauernder Gastroenteritis kommt es zu einem Verlust von Kalium aus den Zellen. Bei Rehydration und Azidose-Ausgleich wird Kalium wieder nach intrazellulär verlagert und es entsteht eine potenziell gefährliche Hypokaliämie im Extrazellularraum (EZR). Der Kaliumbedarf ist bei Kindern mit Gastroenteritis also in der Regel erhöht. Die NICE-Guideline weist explizit darauf hin, dass bei Kindern, die intravenös rehydriert werden, der Kaliumspiegel gemessen und im Verlauf kontrolliert werden sollte.

\section{II.2.12 STATEMENT}

Abhängig vom Schweregrad der Dehydration kann die intravenöse Rehydration über 4 bis 24 Stunden erfolgen.

Konsensstärke: $100 \%$, starker Konsens 


\section{II.2.13 STATEMENT}

Während der laufenden intravenösen Rehydration soll immer wieder auch versucht werden, die orale Rehydration zu beginnen. Tolerierte Mengen der oralen bzw. enteralen Rehydration sollen für die Flüssigkeitsbilanz berücksichtigt werden. Konsensstärke: $100 \%$, starker Konsens

\section{II.2.14 STATEMENT}

Eine Reevaluation des Patienten soll innerhalb von 4 Stunden erfolgen:

- klinische Einschätzung (CDS-Score, Bewusstseinszustand, Ödeme),

- Gewicht,

- Urinproduktion und

- Laborkontrollen entsprechend der Ausgangsbefunde und des Schweregrads der Erkrankung.

Konsensstärke: $100 \%$, starker Konsens

Traditionell wurde die intravenöse Rehydration langsam durchgeführt und führte zu längeren stationären Aufenthalten. Entsprechend den WHO-Empfehlungen sollte die akute Dehydration mittels schneller Infusion ausgeglichen werden, sodass normalerweise bei Kleinkindern nach 3 bis 4 Stunden und bei älteren Kindern nach 1 bis 2 Stunden mit ORL schluckweise begonnen werden kann [28]. Studien belegen keinen Vorteil einer ultraraschen $(60 \mathrm{ml} / \mathrm{kg} / \mathrm{h})$ intravenösen Rehydration gegenüber der schnellen $(20 \mathrm{ml} / \mathrm{kg} / \mathrm{h})$ Rehydration $[129,130]$. Die Autoren empfehlen eine Rehydration mit $20 \mathrm{ml} / \mathrm{kg} / \mathrm{h}$ über 1 bis 4 Stunden gefolgt von oraler Hydrierung bzw. Gabe von Flüssigkeit zur Erhaltung [129]. Ein evidenzbasiertes standardisiertes Protokoll zur intravenösen Rehydration liegt für Kinder jedoch nicht vor [6]. Somit wird ein individualisiertes Vorgehen mit engmaschigen Reevaluationen während der intravenösen Rehydration empfohlen [7, 28]. Die intravenöse Rehydration soll die Elektrolyt- und Säure-Basen-Veränderungen schneller korrigieren, die renale und intestinale Perfusion verbessern und dadurch eine frühere enterale Ernährung begünstigen. Der Krankenhausaufenthalt ist bei Kindern, die eine orale Rehydration erhalten, kürzer, weshalb eine orale Rehydration zu bevorzugen ist [114, 117].

\section{II.3 Supplementäre und medikamentöse Therapie bei akuter infektiöser Gastroenteritis}

\section{II.3.1 EMPFEHLUNG}

Der Einsatz bestimmter Probiotika in Ergänzung zur Rehydration kann erwogen werden.

Konsensstärke: $100 \%$, starker Konsens (bei Abstimmung mit und ohne die Teilnehmer mit Interessenkonflikt)
Zahlreiche Probiotika wurden in Zusammenhang mit AGE untersucht. Postulierte Effekte sind einerseits eine Verkürzung der Erkrankungsdauer und Minderung der Schwere der Erkrankung, andererseits eine Minderung der Ansteckungsfähigkeit für die Umgebung der Patienten. In der britischen Leitlinie (NICE) wird trotz des möglichen Nutzens der Probiotika aufgrund der unzureichenden Qualität der Studien und ihrer Heterogenität auch im Hinblick auf die untersuchten verschiedenen Probiotika keine Therapieempfehlung für Kleinkinder abgegeben [7]. Die Autoren der evidenzbasierten Leitlinie der ESPGHAN erwägen trotz der geringen Evidenzqualität den Einsatz von „effektiven“ Probiotika [6]. Lactobacillus GG (LGG) und Saccharomyces (S.) boulardii können die Dauer eines Krankenhausaufenthalts um etwas weniger als 1 Tag verkürzen [6]. Ergänzend hat die ESPGHAN ein evidenzbasiertes Positionspaper zur Verwendung von Probiotika bei akuter Gastroenteritis publiziert [140]. Dementsprechend werden trotz geringer Evidenzqualität LGG (Dosis $>10^{10} \mathrm{CFU} /$ Tag) und S. boulardii (250-750 mg/Tag) zusätzlich zur Rehydration in der Therapie empfohlen. Außerdem wird eine Therapie mit L. reuteri DSM 17938 ( $10^{8}$ bis $4 \times 10^{8} \mathrm{CFU} / \mathrm{Tag}$ ) und Hitze-inaktivierter L. acidophilus LB eingeschränkt auf der Basis sehr schwacher Evidenz in Erwägung gezogen. Eine neue systematische Metaanalyse zu L. reuteri ergab nun eine breitere, aber immer noch heterogene Studien- und Datenlage [141]. L. reuteri verkürzt die Durchfalldauer um 1 Tag, verhindert jedoch bei präventiver Verwendung keine Hospitalinfektionen und der präventive Effekt bei gesunden Kindern außerhalb des Krankenhauses ist ebenfalls unklar. Entsprechend hat die ESPGHAN-Leitlinie empfohlen, den Einsatz der oben genannten Probiotika bei hospitalisierten Kindern mit akuter Gastroenteritis zu erwägen. Allerdings zeigten nun 2 große randomisierte Studien ( $\mathrm{n}=971$ bzw. $\mathrm{n}=886$ ) mit L. rhamnosus GG bzw. L. rhamnosus GG in Kombination mit L. helveticus R0052 bei moderater oder schwerer AGE im Kleinkindesalter keinen signifikanten Unterschied hinsichtlich der Durchfalldauer, der Dauer des Erbrechens oder der Übertragung auf Haushaltsmitglieder gegenüber Placebo [142, 143].

Für andere Probiotika gibt es bisher keine ausreichende Datenlage für entsprechende Empfehlungen [48].

\section{II.3.2 EMPFEHLUNG}

Antiemetika sollen nicht zur Therapie der akuten Gastroenteritis verwendet werden

Konsensstärke: $100 \%$, starker Konsens

Es gibt deutliche Hinweise, dass Ondansetron die Rate erfolgreicher oraler Rehydration verbessern und die Notwendigkeit von intravenöser Flüssigkeitstherapie reduzieren kann. Verschiedene Studien sowie eine Metaanalyse [144] belegen, dass die Rate des Erbrechens und die Notwendigkeit einer Hospitalisierung etwa halbiert werden kann. Obwohl in Studien die Effektivität nachgewiesen wurde, besteht für den Einsatz bei Kleinkindern große Zurückhaltung. Ondansetron wird deshalb in einem aktuellen Therapiealgorithmus nicht berücksichtigt $[48,145]$. 
In einer doppelblinden randomisierten kontrollierten Studie aus Italien wurde die 1-malige orale Gabe von Ondansetron, Domperidon oder Placebo bei Kindern mit einem aufgrund von Erbrechen gescheiterten ersten Rehydrationsversuch verglichen [146]. Eine nachfolgende intravenöse Flüssigkeitstherapie war bei 11,8\% der Patienten in der Ondansetron- und 25,2\% der Domperidonbzw. 28,8\% der Placebo-Gruppe erforderlich (signifikanter Unterschied zugunsten Ondansetron, Domperidon kein Vorteil gegenüber Placebo). Interessanterweise war der Unterschied hinsichtlich der Notwendigkeit einer Krankenhausaufnahme bereits geringer ( $8,4 \%$ O. versus 16,9\% P.; $\mathrm{p}=0,05)$. Durchfall während der Zeit im Aufnahmebereich hatten 27,7\% der Patienten, die Ondansetron bekamen, aber nur 16,9\% der Placebo-Behandelten $(p=0,05 \%)$. Durchfall ist eine typische Nebenwirkung des Medikaments, sodass dies gerade gegen eine Verwendung bei Kindern mit AGE spricht, da diese neben dem Erbrechen unter häufigen Diarrhoen leiden.

Weiterhin wird die Sicherheit der Anwendung von Ondansetron aufgrund kardialer Nebenwirkungen kritisch bewertet. 2012 und 2013 wurde in Deutschland ein „Rote- Hand-Brief“ des Herstellers des Originalpräparats veröffentlicht mit dem Hinweis auf QTc-Zeit-Verlängerungen vor allem bei älteren Patienten, die das Medikament intravenös erhielten (Link: BfArM Odansetron). Dort wird darauf verwiesen, dass insbesondere Patienten mit Elektrolytstörungen ein erhöhtes Risiko hierfür aufwiesen, sodass empfohlen wird, eine Hypokaliämie oder Hypomagnesiämie vor Einsatz von Ondansetron zu korrigieren. Die FDA hat aus ähnlichen Beweggründen 2011 empfohlen, vor der Verwendung von Ondansetron ein EKG zu schreiben (MedWatch: The FDA Safety Information and Adverse Event Reporting Program. Zofran (ondansetron): Drug Safety Communication-Risk of Abnormal Heart Rhythms, Posted 09/15/2011).

Die ESPGHAN hat sich 2014 unter Hinweis auf die mögliche Wirksamkeit, aber das Fehlen des Belegs der Sicherheit auch gegen eine Empfehlung zur Verwendung von Ondansetron ausgesprochen [6]; diese Gesamtbeurteilung trifft auch für die NICEGuideline zu [7]. Demgegenüber wird die Substanz in Kanada und Australien in den jeweiligen Leitlinien auch für Kinder empfohlen. Diese Empfehlungen werden durch eine aktuelle pädiatrische Studie an 134 Kindern von 6 Monaten bis 18 Jahren, die wegen Erbrechens, Übelkeit oder Trinkverweigerung bei Gastroenteritis Ondansetron intravenös erhielten, unterstützt. Hierbei fanden sich nach Gabe von $0,15 \mathrm{mg} / \mathrm{kg}$ Ondansetron nach 15 , 30, 45 und 60 Minuten keine relevanten Verlängerungen der QTc-Zeit im EKG [147].

Dennoch besitzt Ondansetron keine Zulassung für die Indikation „Erbrechen bei AGE“ in Deutschland und Österreich. Somit handelt es sich bei der Verabreichung im Rahmen einer AGE um einen aufklärungspflichtigen „off-label-use“.

Traditionell wird in Deutschland als Antiemetikum auch Dimenhydrinat verwendet, welches in einer Studie die Rate an Erbrechen signifikant reduzierte, aber zu keiner signifikanten Reduktion der Krankenhausaufnahmerate führte [148]. Die Autoren bewerteten den Nutzen als gering, da sich keine Verbesserung der Rehydrationsrate und des klinischen Outcomes gegenüber Placebo ergab. Der sedierende Effekt des Dimenhydrinats erschwert auch die orale Flüssigkeitszufuhr. Weiterhin besitzt auch Dimenhydrinat für Kinder ein relevantes toxikologisches Potenzial. Aufgrund der Meldung von 39 Fällen schwerwiegender Nebenwirkungen, darunter 5 Todesfälle bei Kindern im Alter von 29 Tagen bis 3 Jahren, hat das BfArM (Bundesinstitut für Arzneimittel und Medizinprodukte) am 09.08.2017 beschlossen, die Fachinformationen anzupassen und neben einer Dosisbeschränkung $(5 \mathrm{mg} / \mathrm{kg} / \mathrm{d})$ auch Warnhinweise und Vorsichtsmaßnahmen aufzunehmen. Demnach soll die Substanz explizit nicht mehr bei einer banalen AGE verabreicht werden (Link: BfArM Dimenhydrinat).

\section{II.3.3 EMPFEHLUNG}

Racecadotril kann zur Therapie bei AGE erwogen werden. Konsensstärke: $100 \%$, starker Konsens

Racecadotril wirkt antisekretorisch, soll den Flüssigkeitsverlust durch die Diarrhoe vermindern und zusammen mit der Rehydration zu einem besseren und schnelleren Therapieergebnis führen. Das Medikament erhält in den verschiedenen Leitlinien teils eine starke Empfehlung (Lateinamerika), teils auch eine Ablehnung (NICE und Kanada) [1]. Dies beruht auf einer insgesamt heterogenen Studienlage mit eingeschränkter Datenqualität, die auch weiterhin nach einer Metaanalyse von insgesamt 7 RCTs besteht [149]. Im Vergleich zu Placebo treten keine vermehrten Nebenwirkungen auf und das Präparat wird als sicher eingestuft. Die Wirksamkeit wird durch eine Reduktion der Gesamtdurchfalldauer von ca. 53 Stunden belegt. Insofern kann Racecadotril auch weiterhin zur Therapie der AGE erwogen werden [6]. Es ist jedoch in der Schweiz nicht verfügbar.

\section{II.3.4 EMPFEHLUNG}

Loperamid soll bei AGE nicht eingesetzt werden.

Konsensstärke: $100 \%$, starker Konsens

Loperamid wird weltweit in den Leitlinien aufgrund seines Risikoprofils und der Studienlage bei Kindern nicht $[6,145]$ oder nur sehr eingeschränkt empfohlen [1]. Eine Metaanalyse der Studiendaten ergibt für die Substanz eine Verkürzung der Durchfalldauer von 0,8 Tagen und insgesamt geringere Stuhlhäufigkeit nach 24 Stunden [150]. Jedoch kam es bei 9 von 927 behandelten Kindern zu schweren Nebenwirkungen wie Ileus, Bewusstseinsstörungen oder Tod, die nicht bei den 764 mit Placebo behandelten Kindern auftraten. Die von diesen schweren Nebenwirkungen betroffenen Kinder waren jünger als 3 Jahre. Trotz der gezeigten Wirksamkeit sollte die Substanz also nicht bei Säuglingen und Kleinkindern oder bei Kindern mit schwerer Dehydration bzw. blutigen Durchfällen eingesetzt werden [1, 150]. Aufgrund der therapeutischen Alternativen besteht auch keine Notwendigkeit, dieses Medikament bei älteren Kindern zu verwenden, da grundsätzlich auch die alleinige Rehydration effektiv ist. 


\section{II.3.5 Antibiotika}

\section{II.3.5.1 EMPFEHLUNG}

Bei AGE soll in der Regel keine antibiotische Therapie erfolgen. Konsensstärke: $100 \%$, starker Konsens

Es gibt keine Evidenz, die einen signifikanten Nutzen einer primären antibiotischen Therapie bei der unkomplizierten infektiösen Gastroenteritis von gesunden, nicht immunsupprimierten Kindern nachweist; deshalb wird eine regelhafte antibiotische Therapie nicht empfohlen [6, 7]. Der Verlauf der AGE ist bei Kindern ohne zugrunde liegende Erkrankung in der Regel unabhängig von der Ätiologie selbstlimitierend, und die Kinder erholen sich für gewöhnlich nach einigen Tagen ohne spezifische antimikrobielle Therapie. Bei sehr kranken Kindern mit dysenterischen Beschwerden (akute und starke Bauchschmerzen mit blutigen Stühlen), Fieber mit erhöhten systemischen Entzündungsparametern oder vorliegenden Risikofaktoren und vermuteter bakterieller Genese kann eine empirische Antibiotikabehandlung erwogen werden (siehe nachfolgende Empfehlungen) [151]. Darüber hinaus sollten die bei einer Auslandsanamnese entsprechenden Empfehlungen berücksichtigt werden [7, 152].

\section{II.3.5.2 EMPFEHLUNG}

Bei Patienten mit funktionell relevanter Immundefizienz oder Verdacht auf Sepsis sollte geeignetes Material für eine mikrobiologische Diagnostik asserviert werden. Danach kann eine empirische antibiotische Therapie begonnen werden. Konsensstärke: $100 \%$, starker Konsens

Eine antibiotische Therapie wird bei einer systemischen Infektion oder schwerer extraintestinaler Manifestation einer bakteriellen Infektion empfohlen [6, 7, 151]. Ebenso ist bei Patienten mit angeborener oder erworbener Immundefizienz eine antibiotische Therapie gerechtfertigt (siehe 2.5) [7, 151]. In all diesen Fällen ist nach Asservierung von geeignetem Material eine intravenöse Therapie zu bevorzugen, insbesondere bei Säuglingen und Kleinkindern. Die empirische antibiotische Therapie richtet sich nach dem Vorkommen der Erreger und deren Resistenzlage [151]. Je nach klinischer Symptomatik und möglichen bakteriellen Erregern werden Azithromycin, Ciprofloxacin, Ceftriaxon, Co-Trimoxazol, Rifaximin, Metronidazol oder Vancomycin eingesetzt [151]. Diese Therapie sollte mit den zuständigen Mikrobiologen bzw. Hygienikern entsprechend der regionalen Situation festgelegt werden.

\section{II.3.5.3 EMPFEHLUNG}

Eine antibiotische Therapie der AGE soll nur bei spezifischen pathogenen Erregern oder in spezifischen klinischen Situationen erfolgen:

- Shigellen-Infektionen,

- Infektionen mit Vibrio cholerae,
- Salmonellen-Infektionen bei Risikopatienten (Neugeborene und Säuglinge $<3$ Monate, Patienten mit Immundefizienz, chronisch entzündliche Darmerkrankungen), Bakteriämie und

- Infektionen durch Toxin-bildende C. difficile.

Konsensstärke: $100 \%$, starker Konsens

Die Shigellose ist eine akute invasive enterische Infektion mit flüssigen und teils blutigen Durchfällen, die durch 4 verschiedene Shigella-Bakterienspezies verursacht wird. Shigella dysenteriae Typ 1 bildet ein Toxin (Shiga-Toxin), das für die sehr schweren und teils auch fatalen Erkrankungsverläufe verantwortlich ist. Es löst vor allem in Entwicklungsländern häufig große lokale Epidemien aus [153]. Die antibiotische Therapie der Shigellose kann die Fieberund Diarrhoedauer sowie die Dauer der Keimausscheidung und somit die Infektiosität reduzieren [6, 151, 154]. Somit kann die Keimübertragung vor allem in Kindergärten, Krankenhäusern und anderen Gemeinschaftseinrichtungen verringert werden, da die Menschen die einzigen Überträger der Shigellen sind [151]. Eine frühzeitige und wirksame antibiotische Therapie einer Shigella-dysenteriae-Typ-1-Infektion verringert die Stuhlkonzentration an Shiga-Toxin und könnte das Risiko der Shigella-assoziierten Komplikationen (z. B. HUS) reduzieren [155]. Allerdings steigt die Rate der antibiotikaresistenten Shigellen-Stämme weltweit an, weshalb eine Resistenzbestimmung erfolgen sollte [6]. Die WHO empfiehlt eine Erstlinientherapie mit Ciprofloxacin und Pivmecillinam und eine Zweitlinienbehandlung mit Ceftriaxon und Azithromycin [153]. Aufgrund der Resistenzlage wird von der ESPGHAN in Europa derzeit eine 5-tägige orale Erstlinienbehandlung mit Azithromycin oder alternativ eine intravenöse Behandlung mit Ceftriaxon empfohlen ( $\vee$ Tab. II-2) [6, 156].

Bei Nachweis von Vibrio cholerae soll eine AGE bei dehydrierten Kindern antibiotisch therapiert werden $[6,7]$. Sie verkürzt die Dauer der klinischen Symptomatik und den Flüssigkeitsverlust signifikant, indem die weitere Bildung von Cholera-Toxin verhindert und die weitere Transmission des Erregers reduziert wird [157]. Die WHO-Empfehlung aus dem Jahr 2005 sieht bei Kindern eine Therapie mit 4-mal täglich $12,5 \mathrm{mg} / \mathrm{kg}$ Erythromycin für 4 Tage vor. Eine 1-malige Gabe von 20 mg/kg KG Azithromycin erscheint jedoch mit einem klinischen Ansprechen bei 94,5\% in den ersten 24 Stunden und $100 \%$ Elimination der Ausscheidung von Vibrio cholerae als gleichwertig [158]. Insofern wird derzeit Azithromycin als Erstlinienbehandlung und Erythromycin als Zweitlinientherapie empfohlen ( $\triangleright$ Tab. II-2) [65].

Im Gegensatz hierzu findet sich bei den nicht typhoiden Salmonellen-Infektionen kein Nutzen einer antibiotischen Therapie, weder bezüglich der Symptome noch der Vermeidung von Komplikationen [151]. Eine primäre antibiotische Therapie der Salmonellen-Enteritis hat keinen Einfluss auf die Fieberdauer bei primär Gesunden, dagegen steigt das Risiko einer Dauerausscheidung [159]. Die antibiotische Therapie wird jedoch bei Säuglingen und Neonaten, Patienten mit angeborener oder erworbener Immundefizienz oder relevanter pharmakologischer Immunsuppression, Patienten mit funktioneller oder anatomischer Asplenie und bei Achlorhydrie empfohlen [6, 151]. Das Risiko einer Salmonellen- 
- Tab. II-2 Antiinfektiöse Therapie bei nachgewiesener bakterieller oder parasitärer AGE.

\begin{tabular}{|c|c|c|}
\hline Erreger & Antibiotika & Anmerkung \\
\hline Campylobacter jejuni & Azithromycin $10 \mathrm{mg} / \mathrm{kg} \mathrm{KG} / \mathrm{d}$ für 3 Tage & $\begin{array}{l}\text { bei schwerer Infektion und Beginn der } \\
\text { Therapie innerhalb der ersten } 3 \text { Tage oder } \\
\text { Bakteriämie }\end{array}$ \\
\hline Clostridium difficile & $\begin{array}{l}\text { Metronidazol } 30 \mathrm{mg} / \mathrm{kg} \mathrm{KG} / \text { in } 3 \mathrm{ED} \text {, bei Metronidazol-Resistenz } \\
\text { Vancomycin } 40 \mathrm{mg} / \mathrm{kg} \mathrm{KG} / \mathrm{d} \text { oral in } 4 \mathrm{ED}\end{array}$ & $\begin{array}{l}\text { bei nachgewiesener schwerer Enteritis } \\
\text { und bei Immunsuppression }\end{array}$ \\
\hline ETEC & $\begin{array}{l}\text { Azithromycin } 10 \mathrm{mg} / \mathrm{kg} \text { KG/d für } 3 \text { Tage, Cotrimoxazol 6-12 mg } \\
\text { TMP/kg KG/d in } 2 \mathrm{ED} \text {, } \\
\text { Rifaximin > } 12 \text { Jahre } 600 \mathrm{mg} / \mathrm{d} \text { für } 3 \text { Tage }\end{array}$ & $\begin{array}{l}\text { schwere Infektion, Reisediarrhoe, in } \\
\text { ausgewählten Fällen CAVE-Resistenzen }\end{array}$ \\
\hline Entamoeba histolytica & $\begin{array}{l}\text { Metronidazol 15-30 mg/kg KG/d in } 3 \text { ED, Paomomycin (Humatin) } \\
25-35 \mathrm{mg} / \mathrm{kg} \mathrm{KG/d} \mathrm{in} 3 \text { ED für } 7 \text { Tage }\end{array}$ & gesicherte Infektion, zügige Behandlung \\
\hline Salmonella enteritidis & Ceftriaxon 50-100 mg/kg KG/d, Azithromycin 10 mg/kg KG/d & $\begin{array}{l}\text { nur bei Neonaten und Säuglingen oder } \\
\text { septischen Verläufen, bei Immundefekt }\end{array}$ \\
\hline Salmonella typhii & Cephalosporine der 3. Generation & gesicherte Infektion \\
\hline Shigella dysenterica & $\begin{array}{l}\text { Azithromycin ( } 12 \mathrm{mg} / \mathrm{kg} \mathrm{KG} \mathrm{Tag} \mathrm{1,} \mathrm{dann} 6 \mathrm{mg} / \mathrm{kg} \mathrm{KG} \mathrm{für} 4 \text { Tage) } \\
\text { oral, i.v. Ceftriaxon } 50 \mathrm{mg} / \mathrm{kg} \text { KG für } 2-5 \text { Tage }\end{array}$ & $\begin{array}{l}\text { gesicherte Infektion, verringert } \\
\text { Komplikationen, CAVE-Resistenzen }\end{array}$ \\
\hline STEC/EHEC & keine Therapie & \\
\hline Vibrio cholerae & $\begin{array}{l}\text { Azithromycin } 10 \mathrm{mg} / \mathrm{kg} \mathrm{KG} / \mathrm{d} \text { für } 3 \text { Tage, Cotrimoxazol 6-12 mg } \\
\text { TMP/kg KG/d in } 2 \mathrm{ED}\end{array}$ & $\begin{array}{l}\text { bei Dehydration, verringert Flüssigkeits- } \\
\text { verlust und weitere Ausbreitung }\end{array}$ \\
\hline Yersinia enterocolitica & Cotrimoxazol s. o., Drittgenerations-Cephalosporine & $\begin{array}{l}\text { bei Bakteriämie oder ggf. bei extraintes- } \\
\text { tinalen Symptomen }\end{array}$ \\
\hline
\end{tabular}

Bakteriämie ist bei Säuglingen bis zum 36. Lebensmonat erhöht [160]. Bei klinischem Verdacht auf eine Sepsis oder extraintestinaler fokaler Infektion wird eine antibiotische Behandlung empfohlen [6]. Toxin-bildende Clostridoides difficile sind bei der antibiotikaassoziierten Diarrhoe und nicht selten bei Patienten mit chronisch-entzündlichen Darmerkrankungen ursächlich für schwere Diarrhoen [151]. Eine antibiotikaassoziierte Diarrhoe durch C. difficile sistiert häufig nach Absetzen der Antibiose [151]. Dennoch sollten schwere Diarrhoen und Kolitiden mit Nachweis von C. difficile oral mit Metronidazol (30 mg/kg KG) und bei Metronidazol-Resistenz mit Vancomycin behandelt werden [151]. Bei Säuglingen und Kindern bis zu 3 Jahren ohne Vorerkrankungen oder vorangegangene antibiotische Therapie ist die Bedeutung des Clostridoides- Nachweises unklar. Ferraris et al. konnten bei über $75 \%$ der untersuchten Neonaten eine asymptomatische Kolonisation mit C. difficile nachweisen [97]. Eine antibiotische Therapie ist in diesen Fällen meist nicht erforderlich. Eine Diagnostik auf Clostridoides difficile sollte daher bei asymptomatischen Säuglingen ohne Immunsuppression oder Kindern ohne Zeichen einer Enteritis nicht erfolgen (siehe Kapitel I.6.1.1 und I.6.1.5) [101]

\section{II.3.5.4 EMPFEHLUNG}

Eine antimikrobielle Therapie der AGE sollte außerdem bei folgenden Erregern und Situationen erfolgen:

- schwere Infektion durch Lamblien,

- schwere Infektion mit enterotoxischen E. coli (ETEC) sowie

- Infektion durch Amöben.

Konsensstärke: $100 \%$, starker Konsens

Lamblien sind in Deutschland, Österreich und der Schweiz selten ursächlich für eine akute Gastroenteritis. Werden sie jedoch bei entsprechender klinischer Symptomatik nachgewiesen, sollten sie antibiotisch behandelt werden. Neben Metronidazol wird derzeit auch Albendazol als Mittel der ersten Wahl aufgrund geringerer Nebenwirkungen und einfachem Behandlungsregime in Betracht gezogen ( $\triangleright$ Tab. II-2) [6, 161]. Alternativ kann Tinidazol in schweren Fällen eingesetzt werden, Nitaxoxanid erscheint weniger effektiv zu sein $[6,161]$.

Enteropathogene E. coli (EPEC), enteroaggregative E. coli (EAEC) und enterotoxische E. coli (ETEC) gehören in Europa neben Campylobacter, Clostridium difficile und Salmonellen zu den 6 häufigsten bakteriellen Pathogenen [162]. Darüber hinaus finden sich EIEC-enteroinvasive E. coli (EIEC), Shiga-Toxin-bildende E. coli (STEC) oder auch als enterohämorrhagische E. coli bezeichnet (EHEC)), diffus adhärente E. coli (DAEC) und adhärent invasive E. coli (AIEC) $[162,163]$. Eine regelhafte antibiotische Behandlung 
der AGE durch E. coli wird nicht empfohlen [6]. Problematisch sind insbesondere die Selektion von antibiotikaresistenten Stämmen sowie weitere unerwünschte Wirkungen der Behandlung [163]. Eine antibiotische Therapie kann bei EPEC und ETEC die Keimausscheidung und die Dauer der Diarrhoe signifikant verringern und wird deshalb für ETEC empfohlen [6]. Im Gegensatz hierzu hat eine antibiotische Therapie keinen Einfluss auf den selbstlimitierenden Verlauf der Infektion mit STEC und verhindert nicht das Auftreten eines hämolytisch-urämischen Syndroms (HUS) [163]. Tatsächlich wurde in einer Studie eine antibiotische Therapie auch mit dem Auftreten eines HUS assoziiert [164]. Rifaximin, ein nicht resorbierbares Breitspektrum-Antibiotikum, kann bei Kindern über 12 Jahren bei der afebrilen, wässrigen, nicht dysenterischen AGE verwendet werden, bei der eine ETEC- oder EAECInfektion vermutet wird [6, 152].

Die AGE mit Campylobacter jejuni ist meist selbstlimitierend und benötigt keine antiinfektiöse Therapie. Bei schwerem dysenterischem Verlauf einer Campylobacter-jejuni-Infektion kann jedoch eine antibiotische Behandlung erwogen werden [151]. Eine Metaanalyse der Campylobacter-assoziierten AGE von 11 kleinen RCTs ergab, dass die Dauer der intestinalen Symptome mittels Antibiotikagaben um 1,3 Tage verringert werden konnte [165]. Dieser Effekt zeigte sich jedoch insbesondere, wenn die Therapie bereits in den ersten 3 Krankheitstagen eingeleitet wurde. In den 4 Studien aus den Jahren 1983 bis 1986, die ausschließlich Kinder $(n=91)$ im Alter von 3 Monaten bis 12 Jahren eingeschlossen haben, wurde $40-50 \mathrm{mg} / \mathrm{kg}$ KG Erythromycin für 5 bis 7 Tage verabreicht [165]. Derzeit wird aufgrund der Resistenzlage eine antibiotische Therapie mit Azithromycin empfohlen; diese reduziert auch die Ausscheidung von Campylobacter und somit die Infektiosität und kann die Übertragung in Gemeinschaftseinrichtungen verringern [151]. Zusammengefasst wird aufgrund des Problems der Resistenzentwicklung der Einsatz von Antibiotika bei Campylobacter-Infektionen bei unkomplizierten Fällen und Patienten ohne erhöhtes Komplikationsrisiko nicht empfohlen [165].

\section{II.3.6 Zinksupplementation}

Zink ist ein essenzielles Spurenelement mit multiplen Funktionen, u. a. bei der Mukosa-Regeneration, Immunregulation und Wundheilung. Im Darm verbessert Zink die Integrität der Mukosa-Barriere, die Enzyme der Bürstensaummembran und die Produktion von Antiköpern gegen Darmpathogene. Es gibt keine Zinkspeicher im Körper. Zinkmangel kann assoziiert sein mit chronischer Diarrhoe, sekundären Immundefekten oder Dermatitis [166]. Malnutrition und Diarrhoe können zu einem Zinkmangel führen [167]. Aufgrund der nachgewiesenen Verkürzung der Dauer der Diarrhoe empfiehlt die WHO eine Supplementation von Zink zusammen mit der ORL, wenn ein Zinkmangel vorliegt oder wahrscheinlich erscheint [28]. Dies gilt insbesondere für Kinder mit Malnutrition und für Länder mit niedrigem Grundeinkommen [168]. Auch die Inzidenz der Diarrhoe wird durch eine Zinksupplementation reduziert $[169,170]$.

Kinder ohne Vorerkrankungen in Industrieländern haben eine niedrige Prävalenz eines Zinkmangels von unter $10 \%$ [171].

\section{II.3.6.1 EMPFEHLUNG}

Eine Supplementation mit Zink sollte bei Kindern in gutem Ernährungszustand nicht durchgeführt werden.

Konsensstärke: $100 \%$, starker Konsens

Die Supplementation von Zink bei AGE wurde in zahlreichen RCTs bei Kindern untersucht (33 Studien mit 10481 Kindern); die meisten Studien erfolgten in asiatischen Ländern mit hohem Risiko für einen Zinkmangel [168], aber nur 6 Studien beziehen sich auf Hochlohnländer in Europa oder Australien [172]. In 4 dieser 6 Studien zeigte sich ein Benefit der Zinksupplementation und keine Studie berichtete negative Auswirkungen [172]. Insgesamt sind die Daten jedoch für eine generelle Empfehlung zur Zinksupplementation bei AGE in Europa nicht ausreichend. Aufgrund der guten Versorgung mit Zink wird in Kanada derzeit keine Supplementation bei AGE empfohlen [173].

\section{II.3.6.2 EMPFEHLUNG}

Eine Zinksubstitution kann jedoch bei Säuglingen oder bei Malnutrition erwogen werden.

Konsensstärke: $90 \%$, Konsens

Die WHO empfiehlt eine orale Supplementation mit $10 \mathrm{mg} / \mathrm{d}$ für Säuglinge bis zum 6. Lebensmonat und anschließend $20 \mathrm{mg} / \mathrm{d}$ eines Zinksalzes (z. B. Zinksulfat, Zinkglukonat, Zinkazetat) für 10 bis 14 Tage in der Behandlung der akuten AGE. Für Kinder mit relevanter Malnutrition gelten auch in Ländern mit hohem Einkommen die gleichen Überlegungen wie für Kinder aus Regionen mit verbreiteter Mangelernährung. Hierzu zählen alle Kinder mit chronischen Malabsorptionssyndromen, Maldigestion, Gedeihstörung, mangelnder oraler Zufuhr oder wenn eine akute Gastroenteritis kurz zuvor bestanden hat. Durch die Behandlung verringert sich bei Patienten mit Malnutrition die Dauer der Diarrhoe um rund 1 Tag [168]. Außerdem verkürzt die Zinksupplementation die Dauer einer persistierenden Diarrhoe um 16 Stunden [168]. Schwere Nebenwirkungen der Zinksupplementation wurden nicht berichtet, aber es gibt Hinweise, dass sie vermehrt zu Erbrechen führt [168].

\section{II.3.7 EMPFEHLUNG:}

Smektit (dioktaedrisch) kann zur Senkung der Durchfalldauer erwogen werden.

Konsensstärke: $80 \%$, Konsens

Dioktaedrisches Smektit ist eine natürliche Aluminium-Magnesium-Silikat- Verbindung, die auch in Ton vorkommt, und zählt zu den intestinalen Adsorbenzien. Es bindet an die intestinale Mukosa und adsorbiert Endotoxine, Exotoxine, Rotaviren und Bakterien. Nachdem Studien einen Nutzen nachweisen konnten, wird es 
zunehmend angewendet [174]. Eine aktuelle Metaanalyse berücksichtigt Daten von 2164 Kindern aus 13 Studien hauptsächlich aus Entwicklungsländern wie Malaysia, Peru und Indien [175]. Die Durchfalldauer wird im Mittel um 23,4 Stunden verkürzt und die Wahrscheinlichkeit der Gesundung an Tag 5 ist signifikant höher (OR 4,4). Es wurden keine relevanten Nebenwirkungen beobachtet. Aufgrund der Heterogenität der Studien (zumeist „open label“) wird die Qualität der Evidenz aber als niedrig bewertet, weshalb noch zurückhaltende Empfehlungen ausgesprochen werden [6]. Smektit in Kombination mit LGG ist im Vergleich zu LGG ebenso effektiv, sodass eine kombinierte Behandlung mit LGG nicht sinnvoll erscheint [176]. Die Substanz ist bisher im deutschsprachigen Raum als Begleitmedikation zur Rehydration wenig gebräuchlich, ist jedoch zur Verwendung bei Kindern erhältlich.

\section{II.4 Realimentation}

\section{II.4.1 EMPFEHLUNG}

Bei Stillkindern soll Muttermilch von Anfang an parallel zur ORL-Lösung verabreicht werden.

Konsensstärke: $100 \%$, starker Konsens

Gestillte Kinder zeigen von sich aus zumeist eine gute Regulation ihres Trinkverhaltens hinsichtlich Häufigkeit und Menge. Insofern sind häufigeres Trinken kleinerer Mengen Muttermilch im Rahmen einer Gastroenteritis neben der ORL auch therapeutisch sehr sinnvoll. In Studien konnte außerdem gezeigt werden, dass eine Stillpause das Risiko für eine Dehydration signifikant erhöht [7]. Eine Unterbrechung des Stillens könnte als Konsequenz auch Stillprobleme nach der Erkrankung haben, sodass auch aus diesem Grund das Stillen beibehalten werden sollte. Insgesamt 12 von 15 Leitlinien tragen daher diese Empfehlung [1].

\section{II.4.2 EMPFEHLUNG}

Die Realimentation mit altersentsprechender normaler Kost soll möglichst frühzeitig (noch während oder nach den ersten 4-6 Stunden der initialen Rehydrationsphase) begonnen werden.

Konsensstärke: $100 \%$, starker Konsens

Unter früher Realimentation versteht man die Nahrungszufuhr innerhalb von 12 Stunden nach Beginn der Rehydration. Es wird aus ernährungsphysiologischer Sicht insbesondere bei unterernährten Kindern zu einer frühen Realimentation geraten. Sie soll die Regeneration der Enterozyten und der Bürstensaumenzyme fördern. Eine Metaanalyse aus 12 Studien ergibt kein erhöhtes Risiko für eine erneute intravenöse Therapie, häufigeres Erbrechen oder persistierende Diarrhoe durch frühzeitige Realimentation und keinen Unterschied zur Durchfalldauer [177].

\section{II.4.3 EMPFEHLUNG}

Spezielle Diäten sollen zum Kostaufbau nicht eingesetzt werden.

Konsensstärke: $100 \%$, starker Konsens

Die aktuellen WHO-Leitlinien zur Therapie der akuten Diarrhoe bei Kindern empfiehlt zusätzlich zu den oralen Rehydrationslösungen die Fortführung einer altersgemäßen Ernährung [28]. Inwiefern dabei spezifische Nahrungsbestandteile oder spezielle Diäten für Kinder mit Durchfall besser verträglich sind, wird fortwährend diskutiert. Für die meisten speziellen Kostformen oder Diäten im Nahrungsaufbau, wie z. B. vegane oder glutenfreie Kost, gibt es keine Evidenz für positive Effekte. Eine vorübergehende Laktoseintoleranz kann als Komplikation der AGE auftreten. Eine laktosefreie Ernährung kann laut Metaanalyse von 33 Studien bei nicht gestillten, meist hospitalisierten (29 Studien) Kindern die Diarrhoe-Dauer verkürzen [178]. Dieser Effekt wird jedoch nicht in den 2 Studien mit ambulanten Patienten beobachtet, sodass in der ESPGHAN-Leitlinie für die ambulante AGE-Behandlung keine laktosefreie Kost empfohlen wird [6]. In China, Botswana und Peru wird laktosefreie Milch jedoch zur Verkürzung der Durchfalldauer empfohlen [1]. Ein aktueller Behandlungsalgorithmus sieht eine laktosefreie Diät bei persistierender Diarrhoe vor [48]. Die NICE-Leitlinie sieht keine speziellen Kostformen zur Realimentation nach AGE vor, rät jedoch von festen Nahrungsmitteln während der ORT oder intravenösen Rehydration ab [179].

\section{Kapitel III: Prävention und Hygiene ambulant erwor- bener und nosokomialer akuter Gastroenteritis im Säuglings-, Kindes- und Jugendalter (AG 3)}

AG-Leiter: B. Gruber, Osnabrück; C. Posovszky, Ulm AG-Mitglieder: V. Backendorf, Trier; J. Hübner, München; S. Koletzko, München; A. Stallmach, Jena

\section{III.1 Primärprävention von AGE}

\section{III.1.1 EMPFEHLUNG}

Säuglinge sollten zur Reduktion des Risikos infektiöser AGE gestillt werden.

Konsensstärke: $100 \%$, starker Konsens

In Entwicklungsländern haben nicht gestillte Säuglinge ein höheres Risiko für persistierende Diarrhoe [16]. Die Evidenz des protektiven Effekts des Stillens mit einer signifikanten Reduktion der Morbidität und Mortalität durch infektiöse Durchfallerkrankungen wird durch zahlreiche Studien belegt [180]. Stillen wirkt nicht nur in Entwicklungsländern protektiv, sondern auch in Europa [181, 182]. So hatten spanische Säuglinge, die in den ersten 46 Monaten überwiegend gestillt wurden, in den ersten 6 Lebensmonaten ein niedrigeres Risiko, an einer Gastroenteritis zu erkranken (adj. OR 0,34; $95 \%-K I$ 0,18-0,64) [182]. Der protektive Effekt ist bei teilgestillten Säuglingen geringer und endet mit dem 
Abstillen [181]. Glykane in der Muttermilch sind für diesen protektiven Effekt mitverantwortlich. Sie können Pathogene wie z. B. Campylobacter oder Caliciviren sowie Toxine von ETEC binden und gestillte Kinder vor einer Infektion schützen [183]. Aufgrund des beträchtlichen protektiven Nutzens der Muttermilchernährung in Bezug auf infektiöse Durchfall- und Atemwegserkrankungen sowie die Allergieentwicklung sollte insbesondere in den ersten 6 Lebensmonaten zum Stillen geraten werden.

\section{II.1.2 EMPFEHLUNG}

Monovalente und pentavalente Rotavirus-Impfungen sollen zur Prävention von akuten Gastroenteritiden durch Rotaviren durchgeführt werden. Sie sind sicher und effektiv und verhindern insbesondere schwere Verläufe.

Konsensstärke: $100 \%$, starker Konsens (bei Abstimmung mit und ohne die Teilnehmer mit Interessenkonflikt)

2 orale Lebendvakzine, Rotarix ${ }^{\circledR}$ (RV1; humane monovalente Vakzine mit Genotyp G1P(8), GlaxoSmithKline Biologicals) und RotaTeq $^{\circledR}$ (RV5; human-bovine pentavalente Vakzine mit G1-4 und P (8), Merck \& Co. Inc.), wurden 2006 zur Impfung in Europa zugelassen und sind in Deutschland verfügbar $[184,185]$. In den RCTs an jeweils mehr als 30000 Kindern, die zur Zulassung führten, wurde gezeigt, dass beide Vakzine effektiv sind, um RotavirusEnteritiden und deren schwere Verläufe zu verhindern, und sicher sind [184, 185]. Zwischenzeitlich wurden 2 systematische Reviews und 21 bzw. 12 weitere RCTs für RV1 und RV2 veröffentlicht, die diese Ergebnisse bestätigen [145, 186]. Im Vergleich zu Placebo erscheint die Impfung effizient eine durchfallbedingte Hospitalisierung zu reduzieren [145]. In der Schweiz ist diese Impfung bisher nicht im Impfplan vorgesehen und die Kosten werden von den Krankenkassen nicht übernommen. Seit 2008 zeigt sich ein rückläufiger Trend der gemeldeten Rotavirus-Infektionen in Deutschland [2]. Der deutliche Rückgang von 32 \% der RotavirusGastroenteritis im Jahr 2016 in Deutschland bei unter 2-jährigen Kindern wird der zunehmenden Inanspruchnahme der seit Sommer 2013 von der Ständigen Impfkommission am RKI (STIKO) empfohlenen Impfung für Säuglinge zugeschrieben [2, 187]. Dieser Trend wurde auch in den Vereinigten Staaten nach Einführung der Impfung 2006 berichtet [188]. Dort wurde auch ein Rückgang der Vorstellungen in den Notfallambulanzen aufgrund von Rotavirus-Gastroenteritiden beobachtet [189]. Vakzinierte Kinder wurden in Deutschland signifikant weniger häufig hospitalisiert [4, 190]. Lebensbedrohliche unerwünschte Ereignisse und Hospitalisierungen aus anderen Gründen scheinen im Vergleich zur Placebo-Gruppe geringer (niedrige Evidenzqualität) [145, 184]. Auch gastrointestinale Symptome wie Durchfall, Erbrechen, blutige Stühle oder Appetitlosigkeit (moderate Evidenzqualität) oder Fieber (hohe Evidenzqualität) werden nach der Impfung im Vergleich zu Placebo nicht gehäuft beobachtet [145]. Die Rotavirus-Impfung erscheint nicht mit einem erhöhten Risiko für Invaginationen assoziiert (moderate Evidenzqualität) [145, 184-186].
Laut ESPED wird von einer Risikoerhöhung von 1-2 Fällen pro 100000 Säuglingen pro Jahr durch die Impfung ausgegangen. Die Invagination ist eine insgesamt seltene Erkrankung, die insbesondere bei Kindern innerhalb des ersten Lebensjahres vorkommt. Die Häufigkeit (Inzidenz) der Invagination beträgt in Deutschland ca. 60 Fälle auf 100000 Säuglinge innerhalb des ersten Lebensjahres und erreicht in einem Alter von 6,4-12,5 Monaten einen Gipfel [191]. Um das Risiko für eine Invagination gering zu halten, sollte daher das in den jeweiligen Fachinformationen empfohlene Alter für die Impfungen unbedingt eingehalten werden (siehe Empfehlung 1.2).

Das Paul-Ehrlich-Institut (PEI) hat zu einem erhöhten Risiko einer Invagination nach Rotavirus-Impfung am 11.05.2015 eine Stellungnahme herausgegeben (Zitat):

Daten aus Beobachtungsstudien zur Sicherheit, die in mehreren Ländern durchgeführt wurden, zeigen, dass Rotavirus-Impfstoffe mit einem erhöhten Risiko für eine Invagination hauptsächlich innerhalb von sieben Tagen nach der Impfung verbunden sind. In den USA und Australien wurden bis zu 6 zusätzliche Fälle pro 100000 Säuglingen pro Jahr bei einer Hintergrundinzidenz von 33 bis 101 Fällen pro 100000 Säuglingen (unter einem Alter von 1 Jahr) pro Jahr beobachtet. Es gibt nur begrenzte Hinweise darauf, dass es ein gering erhöhtes Risiko nach der zweiten Dosis gibt. Es bleibt unklar, ob Rotavirus-Impfstoffe die Gesamtinzidenz der Invagination basierend auf längeren Nachbeobachtungszeiten beeinflussen.

Dem Paul-Ehrlich-Institut sind bis heute aus Deutschland 82 Meldungen einer bestätigten Invagination in unterschiedlichem zeitlichem Zusammenhang mit einer Rotavirus-Impfung berichtet worden. In 68 Fällen konnte der Gesundheitszustand wiederhergestellt werden. Bei 12 Kindern (9 männlich, 3 weiblich) musste im Rahmen einer Operation eine partielle Darmresektion vorgenommen werden (ein Stück des Darms operativ entfernt werden). Bei 5 dieser Kinder lagen neben der vorausgegangenen Rotavirus-Impfung Risikofaktoren für eine Invagination vor: 2-mal ein Meckel-Divertikel, 1-mal eine kongenitale mesenteriale Lücke, 1-mal ein Lymphom und 1-mal ein Tumor an der Bauhin'schen Klappe. 7 Patienten entwickelten typische Zeichen und Symptome einer Invagination innerhalb von 7 Tagen nach der Impfung, 2 Kinder zwischen dem 8. und dem 14. Tag nach der Impfung und je 1 Kind 29, 37 und 48 Tage nach der Impfung.

In 2 weiteren Fällen war zum Zeitpunkt der Meldung der Gesundheitszustand noch nicht wiederhergestellt bzw. lagen keine Informationen über den Ausgang vor. Eine Invagination mit tödlichem Ausgang wurde nicht berichtet.

Darüber hinaus sollten Kinderärzte Eltern unbedingt darüber aufklären, dass eine Invagination im zeitlichen Zusammenhang mit einer Rotavirus-Impfung auftreten kann und wie man diese frühzeitig erkennt. Zu den Symptomen einer Invagination gehören krampfartige Bauschmerzen, Nahrungsverweigerung, Erbrechen, ungewöhnliches Schreien und vor allem Absetzen von blutigem Stuhl. Schwere Verläufe können durch eine möglichst frühzeitige Behandlung vermieden werden. 


\section{III.1.3 EMPFEHLUNG}

Die Rotavirus-Impfserie soll möglichst frühzeitig bis zum Alter von 12 Wochen begonnen werden und bis zur vollendeten 24 . bzw. 32. Lebenswoche abgeschlossen sein. Abhängig vom verwendeten Impfstoff sind 2 bzw. 3 Impfungen notwendig, die jeweils in 4-wöchigen Abständen verabreicht werden. Konsensstärke: $100 \%$, starker Konsens (bei Abstimmung mit und ohne die Teilnehmer mit Interessenkonflikt)

Die STIKO empfiehlt seit 2013 die allgemeine Rotavirus (RV) -Schluckimpfung für Säuglinge [187]. Das PEI hat hierfür seit 2015 folgendes Vorgehen veröffentlicht (siehe auch Kommentar zu 1.1):

Für Rotarix (RV1) besteht die Grundimmunisierung aus zwei Dosen. Die erste Dosis kann ab einem Alter von sechs Wochen gegeben werden. Zwischen den einzelnen Dosen ist ein Zeitabstand von mindestens vier Wochen einzuhalten. Die Impfserie sollte vorzugsweise vor dem Alter von 16 Wochen verabreicht werden, muss aber auf jeden Fall bis zum Alter von 24 Wochen abgeschlossen sein.

Für Rotateq (RV5) besteht die Impfserie aus drei Dosen. Die erste Dosis kann ab Vollendung der 6. Lebenswoche, sollte jedoch nicht später als vor Vollendung der 12. Lebenswoche verabreicht werden. Ein Abstand von mindestens vier Wochen zwischen den einzelnen Dosen sollte eingehalten werden. Die Grundimmunisierung mit drei Dosen sollte vorzugsweise bis zur Vollendung der 20. bis 22. Lebenswoche abgeschlossen sein, jedoch nicht später als bis zur Vollendung der 32. Lebenswoche.

Auch Frühgeborene, die mit einem Gestationsalter von mindestens 25 Wochen (RotaTeq ${ }^{\circledR}$ ) bzw. mindestens 27 Wochen (Rotarix ${ }^{\circledR}$ ) geboren wurden, können gegen RV geimpft werden [187, 192]. Die Impfserie kann bei ihnen auch ab dem postnatalen Alter von 6 Wochen begonnen werden [187, 192]. Das direkte Zusammentreffen von Impfstoff und Muttermilch sollte vermieden werden, da ein möglicher Zusammenhang mit Impfdurchbrüchen bestehen könnte [187]. Die gleichzeitige Gabe der RV-Impfung mit anderen Standardimpfungen des Säuglingsalters ist möglich [187, 192].

\section{III.1.4 EMPFEHLUNG}

Eine orale Immunglobulingabe zur Prävention von RotavirusInfektionen soll weder bei Neugeborenen mit niedrigem Geburtsgewicht unter 2500 Gramm noch bei älteren Kindern erfolgen.

Konsensstärke: $100 \%$, starker Konsens

Rotavirus-Infektionen können zu nosokomialen Infektionsausbrüchen bei Neugeborenen in neonatologischen Abteilungen mit schweren und tödlichen Verläufen führen [27, 193, 194]. In einem RCT an 75 Neugeborenen mit einem Gewicht von 20002500 Gramm mit endemischen Rotavirus-Infektionen war die orale Immunglobulingabe zur Prävention von Rotavirus-Infek- tionen nicht effektiv bezüglich Infektionsrate und RotavirusAusscheidungsdauer im Vergleich zu Placebo; unerwünschte Ereignisse wurden nicht berichtet $[194,195]$. Die Studienlage zu anti-rotaviralen Immunglobulinen (z. B. bovines Kolostrum von immunisierten Rindern oder Eidotter von geimpften Hennen) zur Rotavirus- Infektionsprävention bei Frühgeborenen ist weiterhin unzureichend [194]. Alternativ kann eine frühzeitige Immunisierung der hospitalisierten Frühgeborenen durchgeführt werden, ohne dass ein erhöhtes Transmissionsrisiko auf nicht geimpfte Neonaten besteht (siehe 1.2.) [192].

\section{III.2 Infektionsprävention und Management bei infektiöser Gastroenteritis unklarer Genese in der Klinik}

\section{III.2.1 EMPFEHLUNG}

Ein Hygieneteam entsprechend der KRINKO-Empfehlung [196], ein Antibiotic-Stewardship-Team [197] und eine ausreichende Anzahl von Zimmern, in denen Patienten kontaktisoliert werden können, sollten vorhanden sein. Konsensstärke: $100 \%$, starker Konsens

\section{III.2.2 EMPFEHLUNG}

Bei Verdacht auf eine infektiöse Gastroenteritis sollen zusätzlich zu den Standardhygienemaßnahmen entsprechende Maßnahmen zur Verhinderung der Ausbreitung der Infektion erfolgen (z. B. Kontaktisolation). Konsensstärke: $100 \%$, starker Konsens

\section{III.2.3 EMPFEHLUNG}

Eine Kohortierung von Patienten mit unterschiedlichen Enteritis-Erregern sollte vermieden werden. Ist eine Kohortierung oder Einzelunterbringung nicht möglich, kann bei strikter Barrierepflege eine Unterbringung in Mehrbettzimmern erfolgen.

Konsensstärke: $92 \%$, Konsens

\section{Kommentar zu den Empfehlungen III.2.1-2.3:}

Stationäre Patienten sollen so weit möglich im Einzelzimmer untergebracht werden und eine separate Toilette benutzen. Sollte eine Einzelunterbringung nicht möglich sein, ist bei strikter patientenbezogener Kittel- und Handschuhpflege auch eine Unterbringung im Mehrbettzimmer möglich (sogenannte „Barrierepflege“ (engl. „barrier nursing“)). Diese beinhaltet das generelle Tragen von erregerdichten Schutzkitteln und Untersuchungshandschuhen bei direktem Kontakt und in der patientennahen Umgebung, sowie bei Erbrechen zusätzlich auch Mund-NasenSchutz.

Geräte wie z. B. Stethoskop, Fieberthermometer etc. sollen patientenbezogen eingesetzt werden. Die Kontaktisolation und die besonderen Desinfektionsmaßnahmen sollten in der Regel 
bis $48 \mathrm{~h}$ nach Sistieren der Symptomatik fortgesetzt werden. Die besonderen Desinfektionsmaßnahmen sollen für die Dauer der Erregerausscheidungen weiter durchgeführt werden (Dauer in Tagen, Einschränken auf spezielle Bereiche (WC, Wickeltische etc.)).

Eine gastrointestinale Koinfektion durch mehrere Erreger ist mit einer schwereren klinischen Präsentation (starke Dehydration und Durchfall) und einer längeren Dauer des Erbrechens und Durchfalls assoziiert [70]. Koinfektionen mit Rotaviren und Toxinbildenden C. difficile sind häufig [70]. Stationär behandelte Kinder in Deutschland haben mit bis zu $30 \%$ eine hohe Rate an mittels RT-PCR nachweisbaren Koinfektionen [198]. Hierbei handelt es sich meist um duale Infektionen mit Rota- und Noroviren [198]. Insofern ist eine weitgehende Kontaktisolation dieser Patienten sinnvoll (siehe III.2.2). Bei Aufnahme des Patienten in die Klinik ist in der Regel der Erreger noch unbekannt und eine Kohortierung der an Gastroenteritis erkrankten Kinder nach Erregern noch nicht möglich. Sollte eine Einzelunterbringung nicht möglich sein, ist eine Unterbringung in Mehrbettzimmern bei strikter „Barrierepflege“ möglich (siehe III.2.3).

\section{III.2.4 EMPFEHLUNG}

Das medizinische Personal soll über Hygienemaßnahmen zur Prävention von Krankheitsübertragung geschult werden und Patienten, Eltern bzw. Besucher sollen hierzu informiert werden, da hierdurch die Transmissionsraten deutlich reduziert werden.

Konsensstärke: $92 \%$, Konsens

Hygienemaßnahmen verhindern effektiv die Krankheitsübertragung und Ausbreitung. Verschiedene Studien konnten zeigen, dass sich die Transmissionsraten durch Informationen zur Krankheitsübertragung sowie Hygieneschulungen (Händedesinfektion, Händewaschen, Windelwechsel) von Eltern und Betreuern in Kindertagesstätten deutlich reduzieren lassen [199-201]. Insofern sollten neben dem Personal in Krankenhäusern und Kinderarztpraxen auch Eltern und Kinder informiert und geschult werden (siehe auch 5. Allgemeine Hygieneanweisungen für Eltern und Betreuer in Gemeinschaftseinrichtungen). Mit entsprechenden Informationsblättern und Hygieneanleitungen kann dies zeitnah erfolgen.

\section{III.2.5 EMPFEHLUNG}

Bei 2 oder mehr gleichartigen Erkrankungen soll geprüft werden, ob der Verdacht „einer mikrobiell bedingten Lebensmittelvergiftung oder einer infektiösen Gastroenteritis“ mit „epidemischem Zusammenhang wahrscheinlich ist oder vermutet wird“ und nach dem Infektionsschutzgesetz §6 Absatz $2 \mathrm{~b}$ eine nichtnamentliche Meldung erfolgen muss. Konsensstärke: $100 \%$, starker Konsens

Bei Ausbrüchen ist es wichtig, die Infektionsquelle bzw. das übertragende Vehikel schnell zu erkennen, um eine Ausbreitung zu verhindern. In Deutschland führt das Gesetz zur Verhütung und Bekämpfung von Infektionskrankheiten beim Menschen (Infektionsschutzgesetz - IfSG) in § 6 alle meldepflichtigen Erkrankungen auf. Ein vermuteter oder wahrscheinlicher Verdacht eines epidemischen Auftretens von mikrobiell bedingten Lebensmittelvergiftungen oder infektiösen Enteritiden ist bei 2 oder mehr gleichartigen Erkrankungen dem Gesundheitsamt (§ 10) vom feststellenden Arzt oder der Einrichtung ( $(8)$ innerhalb von 24 Stunden nach erlangter Erkenntnis nichtnamentlich zu melden (Link: Infektionsschutzgesetz) [202]. Das Auftreten von 2 oder mehr nosokomialen Infektionen, bei denen ein epidemischer Zusammenhang wahrscheinlich oder vermutet wird, ist nach IfSG $\S 6$ Absatz 3 ebenfalls nichtnamentlich zu melden.

In Österreich besteht Meldepflicht gemäß Epidemie-Gesetz nur in lebensmittelassoziierten Fällen. In der Schweiz müssen nur laborchemisch nachgewiesene Fälle dem Bundesamt für Gesundheit (BAG) gemeldet werden.

\section{III.3 Hygienemaßnahmen bei nachgewiesenem Erreger der infektiösen Enteritis}

\section{III.3.1 EMPFEHLUNG}

Die Hygienemaßnahmen zur Desinfektion, persönlichen Schutzausrüstung und Isolation sollen für virale und bakterielle Enteritis-Erreger im krankenhausspezifischen Hygieneplan festgelegt werden.

Konsensstärke: $100 \%$, starker Konsens

\section{III.3.2 EMPFEHLUNG}

Neben Einzelzimmerisolation kann auch eine Kohortenisolation von Patienten mit gleichen Erregern erfolgen.

Konsensstärke: $100 \%$, starker Konsens

Bei Hygieneplänen handelt es sich um Maßnahmen zur Umsetzung des IfSG §36 Abs. 1. Einrichtungen des Gesundheitswesens legen in Hygieneplänen innerbetriebliche Verfahrensanweisungen zur Infektionshygiene fest. Die Hygienemaßnahmen unterscheiden sich sowohl hinsichtlich der Erreger als auch in den jeweiligen Versorgungsbereichen (ambulant, stationär, Neonatologie, Intensivstation). Erregerspezifische Hygienemaßnahmen finden sich im Anhang.

\section{III.4 Nosokomiale Diarrhoe und C. difficile}

Aus $§ 23$ des Infektionsschutzgesetzes (IfSG) leitet sich die gesetzliche Verpflichtung in Deutschland ab, eine lokale Surveillance von nosokomialen Infektionen in medizinischen Einrichtungen in Deutschland durchzuführen. In Deutschland liefert das Krankenhaus-Infektions-Surveillance-System (KISS) diese Vergleichsdaten für nosokomiale Infektionen. 


\section{III.4.1 EMPFEHLUNG}

Eine nosokomiale Durchfallerkrankung soll diagnostiziert werden, wenn die akute Symptomatik frühestens am 3. Tag des Krankenhausaufenthalts auftritt und eine infektiöse Ursache sehr wahrscheinlich ist bzw. ein Erregernachweis mit entsprechenden Symptomen vorliegt.

Konsensstärke: 83 \%, Konsens

Die CDC-Definition einer nosokomialen Infektion wurde zum 01.01.2017 von den neuen „KISS-Definitionen“ abgelöst (www. rki.de/kiss-definitionen). Eine Infektion wird demnach als nosokomiale Infektion klassifiziert, wenn das Infektionsdatum (Tag mit dem ersten Symptom) frühestens Tag 3 des Krankenhausaufenthalts ist. Bei Infektionen mit einem Infektionsdatum vor Aufnahme, an Tag 1 (Aufnahmetag) oder Tag 2 des Krankenhausaufenthalts handelt es sich demnach um mitgebrachte Infektionen. Die RKI-Definition einer akuten, nosokomial erworbenen Gastroenteritis unterscheidet sich jedoch von der in der Leitliniengruppe formulierten Definition (siehe I.1.1). Eine akute infektiöse Gastroenteritis liegt laut „KISS-Definition“ vor, wenn eine akute Diarrhoe mit flüssigen Stühlen über mehr als 12 Stunden auftritt und eine nichtinfektiöse Ursache unwahrscheinlich ist, oder Gastroenteritis-Erreger nachgewiesen werden und mindestens 2 Krankheitsanzeichen (wie Fieber $>38^{\circ} \mathrm{C}$, Übelkeit, Erbrechen, Abdominal- oder Kopfschmerz ohne andere erkennbare Ursachen) vorliegen [10]. Der Erregernachweis kann hier aus kulturellen oder nichtkulturellen Verfahren aus dem Stuhl oder Rektalabstrich, dem mikroskopischen Nachweis enteropathogener Erreger, Antigen-Nachweis oder Immun-Assay von enteropathogenen Mikroorganismen aus Blut oder Stuhl oder deren zytopathischer Effekte, diagnostischem Einzeltiter (IgM) oder 4-fachem Titeranstieg ( $\mathrm{lgG}$ ) in wiederholten Serumproben für den Krankheitserreger stammen [10].

\section{III.4.2 EMPFEHLUNG}

Als Ursachen nosokomialer infektiöser Durchfallerkrankungen sollen in erster Linie Noro- und Rotaviren sowie Clostridoides difficile in Betracht gezogen werden und zeitnah eine Erregerdiagnostik zur Vermeidung von Ausbruchssituationen erfolgen. Konsensstärke: $100 \%$, starker Konsens

Nosokomiale Gastroenteritisausbrüche werden in Deutschland hauptsächlich durch Noro- (76\%) und Rotaviren $(6,4 \%)$ verursacht [2]. C. difficile gehört zu den häufigsten Erregern nosokomialer Infektionen, die Datenlage zur Epidemiologie der C.-difficile-Infektionen bei Kindern ist jedoch insgesamt schlecht (siehe Kapitel I.3.5). Einige Studien berichten über eine Zunahme von C.-difficile-Kolonisationen bei hospitalisierten Kindern um bis zu $25 \%$ [203]. Darüber hinaus zeigen Studien auch eine Zunahme von C.-difficile-Infektionen im Kindesalter und es werden auch schwere Infektionsverläufe berichtet [203]. Zusätzlich zu diesen Entwicklungen wurden Ausbrüche mit einem Fluoroquinogen- resistenten massiv Toxin-bildenden C.-diff.-Stamm (NAP1) berichtet [203]. Deshalb soll eine aktive und zeitnahe Ursachensuche zur Vermeidung von Ausbruchsituationen erfolgen.

\section{III.4.3 EMPFEHLUNG}

Bei Norovirus-Ausbrüchen soll nach dem ersten positiven Norovirus-Nachweis bereits bei weiteren Verdachtsfällen aufgrund der typischen Symptomatik (mit initial heftigem Erbrechen) eine entsprechende Kohortierung veranlasst werden. Konsensstärke: $100 \%$, starker Konsens

Der Erregernachweis bei Einzeluntersuchungen erfolgt mittels PCR (Polymerase-Chain-Reaction) aus dem Stuhl oder evtl. Erbrochenem. Bei Ausbrüchen kann laut S1-Leitlinie der AWMF zu Hygienemaßnahmen bei Gastroenteritis-Ausbrüchen ein Antigen-ELISA zur Anwendung kommen und nach dem ersten positiven Norovirus-Nachweis die Diagnose anhand der klinischen Symptome gestellt werden [202]. Ein akuter Verlauf und das initial starke Erbrechen sind typisch für Norovirus-Infektionen. Weitere molekularbiologische Einzelnachweise sind dann nicht mehr erforderlich [202].

\section{III.4.4 STATEMENT}

Eine allgemeine Empfehlung für den prophylaktische Einsatz von Probiotika kann aufgrund der unzureichenden Datenlage und der Heterogenität der eingesetzten Bakterienspezies nicht gegeben werden.

Konsensstärke: 92\%, Konsens (bei Abstimmung mit und ohne die Teilnehmer mit Interessenkonflikt)

Durch eine Antibiotikatherapie wird die normale Darmflora zurückgedrängt und es können sich $C$. difficile vermehren und Toxine bilden, die zu einer Durchfallerkrankung (Clostridien-assoziierten Diarrhoe (CDAD)) bis hin zur lebensbedrohlichen pseudomembranösen Kolitis führen können. Eine Metaanalyse von 31 RCTs mit 8672 Patienten zeigt mit moderater Evidenz an, dass eine präventive Probiotika-Verabreichung sicher und effektiv eine CDAD, aber nicht eine Infektion verhindern kann [204]. Diese Metaanalyse zeigt in einer Subgruppenanalyse, dass dieser schützende Effekt insbesondere bei Patienten mit hohem Risiko für eine CDAD signifikant ist [204]. In den 3 rein pädiatrischen Studien wurden L. rhamnosus GG [205, 206] und S. boulardii [207] verwendet, während in den Studien mit Erwachsenen auch andere Probiotika, sowohl einzeln als auch in Kombination, zur Anwendung kamen (z. B. L. plantarum, L. acidophilus mit L. casei). In der Metaanalyse zeigte sich ein Subgruppeneffekt im Vergleich pädiatrischer und adulter Studien, sodass die Ergebnisse bei Erwachsenen nicht unbedingt auf Kinder übertragbar sind und weitere pädiatrische Studien notwendig sind. Unerwünschte Ereignisse traten häufiger bei Patienten in den Kontrollgruppen auf. Die Autoren schließen daraus, dass die kurzzeitige prophylaktische 
Anwendung von Probiotika zusätzlich zu Antibiotikagabe bei immunkompetenten Patienten sicher ist [204].

\section{III.5 Allgemeine Hygieneanweisungen für Eltern und} Betreuer in Gemeinschaftseinrichtungen

\section{III.5.1 EMPFEHLUNG}

Eltern und Personal von Gemeinschaftseinrichtungen sollen über die Übertragung von infektiösen Darmerkrankungen sowie zur Händereinigung und -desinfektion informiert bzw. geschult werden.

Konsensstärke: $84 \%$, Konsens

\section{II.5.2 EMPFEHLUNG}

Zur effektiven Prävention von Infektionen soll eine konsequente Händereinigung durchgeführt werden. Hierbei sollen die Hände möglichst mit Flüssigseife und warmem fließendem Wasser gewaschen und anschließend gut abgetrocknet werden.

Konsensstärke: $84 \%$, Konsens

\section{III.5.3 EMPFEHLUNG}

Eine gründliche Händereinigung soll bei Kindern und Erwachsenen nach jedem Toilettengang und vor Verzehr von Nahrung, sowie bei Eltern und Personal von Gemeinschaftseinrichtungen nach jedem Windelwechsel und vor Zubereitung und Servieren jeder Nahrung erfolgen.

Konsensstärke: $100 \%$, Starker Konsens

\section{III.5.4 EMPFEHLUNG}

Handtücher von infizierten Kindern sollen nicht mit anderen Kindern geteilt werden.

Konsensstärke: $100 \%$, Starker Konsens

\section{III.5.5 EMPFEHLUNG:}

Erkrankte Kinder sollen keine Gemeinschaftseinrichtung (z. B. Kindergärten oder Schulen) besuchen. 48 Stunden nach dem letzten Erbrechen oder Durchfall kann eine Gemeinschaftseinrichtung wieder besucht werden.

Konsensstärke: $92 \%$, Konsens

\section{III.5.6 EMPFEHLUNG}

Kinder sollten die ersten 2 Wochen nach der letzten Durchfallepisode, insbesondere bei Infektionen mit Cryptosporidien und Giardia, nicht in ein öffentliches Schwimmbad. Konsensstärke: $91 \%$, Konsens

\section{Kommentar zu den Empfehlungen III.5.1-5.6:}

Diese Empfehlungen dienen im Wesentlichen der primären Prävention einer Ausbreitung der akuten infektiösen Gastroenteritis in der Öffentlichkeit. Sie basieren auf Empfehlungen des National Institutes of Health and Care Excellence (NICE) aus dem Jahr 2009 und richten sich an Eltern, Betreuer und Kinder [7].

Hygienemaßnahmen verhindern effektiv die Krankheitsübertragung und Ausbreitung (siehe 2.4). Verschiedene Studien konnten zeigen, dass sich die Transmissionsraten durch Informationen zur Krankheitsübertragung sowie Hygieneschulungen (Händedesinfektion, Händewaschen, Windelwechsel) von Eltern und Betreuern in Kindertagesstätten deutlich reduzieren lassen [199-201]. Gründliches und vermehrtes Händewaschen spielt hierbei eine zentrale Rolle [201]. Diese Maßnahmen sollten langfristig beibehalten werden, da die Ausscheidung von Krankheitserregern meist deutlich länger anhält als die Symptomatik. So besteht bei mehr als der Hälfte der Kinder mit schwerer, hospitalisierungspflichtiger Rotavirus-Enteritis noch nach 10 Tagen eine nachweisbare Virusausscheidung und in $30 \%$ der Fälle eine verlängerte Ausscheidung von 25 bis 57 Tagen [208]. Ebenso werden auch andere Erreger wie Cryptosporidium und Giardia lamblia noch mehrere Wochen nach Ende der Symptomatik ausgeschieden.

Im Allgemeinen wird empfohlen, erst 48 Stunden nach dem letzten Erbrechen oder Durchfall eine Gemeinschaftseinrichtung zu besuchen [209].

Immer wieder wird über Gastroenteritis-Ausbrüche nach Besuch von öffentlichen Schwimm- oder Freizeitbädern berichtet, häufig handelt es sich hierbei um Infektionen mit Kryptosporidien und Lamblien [210]. Kinder gelten als besonders gefährdet, da sie während ihrer Schwimmbadaktivitäten ungefähr das 4-fache an Wasser schlucken (durchschnittlich ca. $125 \mathrm{ml}$ in 1 Stunde) und in der Regel doppelt so lang im Wasser sind wie Erwachsene [211]. Wasser- und Filteruntersuchungen konnten nachweisen, dass relevante fäkale Mengen durch die Badegäste in das Schwimmwasser eingebracht werden [212]. Das Center for Disease Control and Prevention (CDC) empfiehlt deshalb, dass sich Badegäste vor dem Baden gründlich abduschen und bei Durchfallerkrankungen nicht zum Schwimmen gehen [212]. Aufgrund der langanhaltenden Ausscheidung von infektiösen Erregern, insbesondere bei Infektionen durch Kryptosporidien oder Lamblien, wird empfohlen, 2 Wochen nach Sistieren der Symptome nicht schwimmen zu gehen [7, 210]. Ärzte werden außerdem aufgefordert, Patienten proaktiv über Präventionsmaßnahmen beim Schwimmbadbesuch zu informieren (Link: CDC Schwimmbadprävention). 
- Interessenkonflikt-Erklärungen - Tabellarische Zusammenfassung.

\section{Leitlinienkoordination: Posovszky, Carsten Leitlinie: Akute infektiöse Gastroenteritis Registernummer: 068/003}

\begin{tabular}{|c|c|c|c|c|c|}
\hline & & Backendorf, Verena & $\begin{array}{l}\text { Buderus, } \\
\text { Stephan }\end{array}$ & Claßen, Martin & $\begin{array}{l}\text { Epple, } \\
\text { Hans-Jörg }\end{array}$ \\
\hline 1 & $\begin{array}{l}\text { Berater- bzw. Gutachtertätigkeit oder bezahlte Mitar- } \\
\text { beit in einem wissenschaftlichen Beirat eines Unterneh- } \\
\text { mens der Gesundheitswirtschaft (z. B. Arzneimittelin- } \\
\text { dustrie, Medizinproduktindustrie), eines kommerziell } \\
\text { orientierten Auftragsinstituts oder einer Versicherung }\end{array}$ & nein & ja & ja & nein \\
\hline 2 & $\begin{array}{l}\text { Honorare für Vortrags- und Schulungstätigkeiten oder } \\
\text { bezahlte Autoren- oder Co-Autorenschaften im Auf- } \\
\text { trag eines Unternehmens der Gesundheitswirtschaft, } \\
\text { eines kommerziell orientierten Auftragsinstituts oder } \\
\text { einer Versicherung }\end{array}$ & nein & ja & ja & ja \\
\hline 3 & $\begin{array}{l}\text { Finanzielle Zuwendungen (Drittmittel) für For- } \\
\text { schungsvorhaben oder direkte Finanzierung von Mit- } \\
\text { arbeitern der Einrichtung von Seiten eines Unterneh- } \\
\text { mens der Gesundheitswirtschaft, eines kommerziell } \\
\text { orientierten Auftragsinstituts oder einer Versicherung }\end{array}$ & nein & nein & ja & nein \\
\hline 4 & $\begin{array}{l}\text { Eigentümerinteresse an Arzneimitteln/Medizinpro- } \\
\text { dukten (z. B. Patent, Urheberrecht, Verkaufslizenz) }\end{array}$ & nein & nein & nein & nein \\
\hline 5 & $\begin{array}{l}\text { Besitz von Geschäftsanteilen, Aktien, Fonds mit Betei- } \\
\text { ligung von Unternehmen der Gesundheitswirtschaft }\end{array}$ & nein & nein & nein & nein \\
\hline 6 & $\begin{array}{l}\text { Persönliche Beziehungen zu einem Vertretungsberech- } \\
\text { tigten eines Unternehmens Gesundheitswirtschaft }\end{array}$ & nein & nein & nein & nein \\
\hline 7 & $\begin{array}{l}\text { Mitglied von in Zusammenhang mit der Leitlinienent- } \\
\text { wicklung relevanten Fachgesellschaften/Berufsver- } \\
\text { bänden, Mandatsträger im Rahmen der Leitlinienent- } \\
\text { wicklung }\end{array}$ & nein & ja & ja & ja \\
\hline 8 & $\begin{array}{l}\text { Politische, akademische (z. B. Zugehörigkeit zu be- } \\
\text { stimmten „Schulen“), wissenschaftliche oder persön- } \\
\text { liche Interessen, die mögliche Konflikte begründen } \\
\text { könnten }\end{array}$ & nein & nein & nein & nein \\
\hline 9 & $\begin{array}{l}\text { Gegenwärtiger Arbeitgeber, relevante frühere Arbeit- } \\
\text { geber der letzten } 3 \text { Jahre }\end{array}$ & $\begin{array}{l}\text { Klinikum Mutterhaus } \\
\text { der Borromäerinnen } \\
\text { Trier bis Juni 2016: } \\
\text { Universitätsmedizin } \\
\text { der Johannes-Guten- } \\
\text { berg-Universität Mainz }\end{array}$ & $\begin{array}{l}\text { GFo Kliniken } \\
\text { Bonn, St. Marien- } \\
\text { Hospital }\end{array}$ & $\begin{array}{l}\text { Gesundheit Nord } \\
\text { gGmbH Bremen }\end{array}$ & $\begin{array}{l}\text { Charité Universi- } \\
\text { tätsmedizin Berlin }\end{array}$ \\
\hline \multirow[t]{2}{*}{10} & $\begin{array}{l}\text { Stimmenthaltung aufgrund von Interessenkonflikt bei } \\
\text { folgenden Themen }\end{array}$ & keine & $\begin{array}{l}\text { Orale Rehydrati- } \\
\text { on, Probiotika, } \\
\text { Impfung }\end{array}$ & $\begin{array}{l}\text { Orale Rehydra- } \\
\text { tion, Impfung }\end{array}$ & \\
\hline & & Gruber, Bernd & Hauer, Almuthe & $\begin{array}{l}\text { Hübner, } \\
\text { Johannes }\end{array}$ & $\begin{array}{l}\text { Keller, } \\
\text { Klaus-Michael }\end{array}$ \\
\hline 1 & $\begin{array}{l}\text { Berater- bzw. Gutachtertätigkeit oder bezahlte Mitar- } \\
\text { beit in einem wissenschaftlichen Beirat eines Unterneh- } \\
\text { mens der Gesundheitswirtschaft (z. B. Arzneimittelin- } \\
\text { dustrie, Medizinproduktindustrie), eines kommerziell } \\
\text { orientierten Auftragsinstituts oder einer Versicherung }\end{array}$ & nein & nein & ja & ja \\
\hline 2 & $\begin{array}{l}\text { Honorare für Vortrags- und Schulungstätigkeiten oder } \\
\text { bezahlte Autoren- oder Co-Autorenschaften im Auf- } \\
\text { trag eines Unternehmens der Gesundheitswirtschaft, } \\
\text { eines kommerziell orientierten Auftragsinstituts oder } \\
\text { einer Versicherung }\end{array}$ & nein & ja & ja & ja \\
\hline
\end{tabular}




\section{- Interessenkonflikt-Erklärungen (Fortsetzung)}

\section{Leitlinienkoordination: Posovszky, Carsten Leitlinie: Akute infektiöse Gastroenteritis Registernummer: 068/003}

3 Finanzielle Zuwendungen (Drittmittel) für Forschungsvorhaben oder direkte Finanzierung von Mitarbeitern der Einrichtung von Seiten eines Unternehmens der Gesundheitswirtschaft, eines kommerziell orientierten Auftragsinstituts oder einer Versicherung

\begin{tabular}{|c|l|}
\hline 4 & $\begin{array}{l}\text { Eigentümerinteresse an Arzneimitteln/Medizinpro- } \\
\text { dukten (z. B. Patent, Urheberrecht, Verkaufslizenz) }\end{array}$ \\
\hline 5 & $\begin{array}{l}\text { Besitz von Geschäftsanteilen, Aktien, Fonds mit Betei- } \\
\text { ligung von Unternehmen der Gesundheitswirtschaft }\end{array}$ \\
\hline 6 & $\begin{array}{l}\text { Persönliche Beziehungen zu einem Vertretungsberech- } \\
\text { tigten eines Unternehmens Gesundheitswirtschaft }\end{array}$ \\
\hline 7 & $\begin{array}{l}\text { Mitglied von in Zusammenhang mit der Leitlinienent- } \\
\text { wicklung relevanten Fachgesellschaften/ Berufsver- } \\
\text { bänden, Mandatsträger im Rahmen der Leitlinienent- } \\
\text { wicklung }\end{array}$ \\
\hline 8 & $\begin{array}{l}\text { Politische, akademische (z. B. Zugehörigkeit zu be- } \\
\text { stimmten „Schulen“), wissenschaftliche oder persön- } \\
\text { liche Interessen, die mögliche Konflikte begründen } \\
\text { könnten }\end{array}$ \\
\hline 9 & $\begin{array}{l}\text { Gegenwärtiger Arbeitgeber, relevante frühere Arbeit- } \\
\text { geber der letzten 3 jahre }\end{array}$ \\
\hline
\end{tabular}

(n)

10 Stimmenthaltung aufgrund von Interessenkonflikt bei folgenden Themen

\begin{tabular}{|c|c|c|c|c|c|}
\hline & & Koletzko, Sibylle & $\begin{array}{l}\text { Lawrenz, } \\
\text { Burkhard }\end{array}$ & $\begin{array}{l}\text { Posovszky, } \\
\text { Carsten }\end{array}$ & $\begin{array}{l}\text { Schmidt-Choud- } \\
\text { hury, Anjona }\end{array}$ \\
\hline 1 & $\begin{array}{l}\text { Berater- bzw. Gutachtertätigkeit oder bezahlte Mitar- } \\
\text { beit in einem wissenschaftlichen Beirat eines Unterneh- } \\
\text { mens der Gesundheitswirtschaft (z. B. Arzneimittelin- } \\
\text { dustrie, Medizinproduktindustrie), eines kommerziell } \\
\text { orientierten Auftragsinstituts oder einer Versicherung }\end{array}$ & ja & ja & ja & nein \\
\hline 2 & $\begin{array}{l}\text { Honorare für Vortrags- und Schulungstätigkeiten oder } \\
\text { bezahlte Autoren- oder Co-Autorenschaften im Auf- } \\
\text { trag eines Unternehmens der Gesundheitswirtschaft, } \\
\text { eines kommerziell orientierten Auftragsinstituts oder } \\
\text { einer Versicherung }\end{array}$ & ja & ja & ja & ja \\
\hline 3 & $\begin{array}{l}\text { Finanzielle Zuwendungen (Drittmittel) für For- } \\
\text { schungsvorhaben oder direkte Finanzierung von Mit- } \\
\text { arbeitern der Einrichtung von Seiten eines Unterneh- } \\
\text { mens der Gesundheitswirtschaft, eines kommerziell } \\
\text { orientierten Auftragsinstituts oder einer Versicherung }\end{array}$ & ja & nein & ja & nein \\
\hline 4 & $\begin{array}{l}\text { Eigentümerinteresse an Arzneimitteln/Medizinpro- } \\
\text { dukten (z. B. Patent, Urheberrecht, Verkaufslizenz) }\end{array}$ & nein & nein & nein & nein \\
\hline 5 & $\begin{array}{l}\text { Besitz von Geschäftsanteilen, Aktien, Fonds mit Betei- } \\
\text { ligung von Unternehmen der Gesundheitswirtschaft }\end{array}$ & nein & nein & nein & nein \\
\hline 6 & $\begin{array}{l}\text { Persönliche Beziehungen zu einem Vertretungsberech- } \\
\text { tigten eines Unternehmens Gesundheitswirtschaft }\end{array}$ & nein & nein & nein & nein \\
\hline
\end{tabular}

\begin{tabular}{|c|c|c|c|}
\hline nein & ja & nein & ja \\
\hline nein & nein & ja & nein \\
\hline nein & nein & ja & nein \\
\hline nein & nein & nein & nein \\
\hline ja & ja & ja & ja \\
\hline nein & nein & nein & nein \\
\hline $\begin{array}{l}\text { Niels-Stensen-Kliniken } \\
\text { Marienhospital Osna- } \\
\text { brück Bischofstr. } 1 \\
49074 \text { Osnabrück seid } \\
01.01 .1990\end{array}$ & $\begin{array}{l}\text { Medizinische Uni- } \\
\text { versität Graz }\end{array}$ & $\begin{array}{l}\text { Klinikum der Uni- } \\
\text { versität München } \\
\text { (seit 2011) seit } \\
1987 \text { Klinikum } \\
\text { der Universität } \\
\text { Freiburg (dort } \\
\text { seit } 2011 \text { Reduk- } \\
\text { tion auf } 10 \% \text { ) }\end{array}$ & $\begin{array}{l}\text { DKD Helios Klinik } \\
\text { Wiesbaden, früher } \\
\text { Rhönkliniken AG }\end{array}$ \\
\hline \multicolumn{4}{|l|}{ keine } \\
\hline Koletzko, Sibylle & $\begin{array}{l}\text { Lawrenz, } \\
\text { Burkhard }\end{array}$ & $\begin{array}{l}\text { Posovszky, } \\
\text { Carsten }\end{array}$ & $\begin{array}{l}\text { Schmidt-Choud- } \\
\text { hury, Anjona }\end{array}$ \\
\hline ja & ja & ja & nein \\
\hline ja & ja & ja & ja \\
\hline ja & nein & ja & nein \\
\hline nein & nein & nein & nein \\
\hline nein & nein & nein & nein \\
\hline nein & nein & nein & nein \\
\hline
\end{tabular}




\section{- Interessenkonflikt-Erklärungen (Fortsetzung)}

\section{Leitlinienkoordination: Posovszky, Carsten Leitlinie: Akute infektiöse Gastroenteritis Registernummer: 068/003}

7 Mitglied von in Zusammenhang mit der Leitlinienentwicklung relevanten Fachgesellschaften/ Berufsverbänden, Mandatsträger im Rahmen der Leitlinienentwicklung

8 Politische, akademische (z. B. Zugehörigkeit zu bestimmten „Schulen“), wissenschaftliche oder persönliche Interessen, die mögliche Konflikte begründen könnten

9 Gegenwärtiger Arbeitgeber, relevante frühere Arbeitgeber der letzten 3 Jahre

\begin{tabular}{|l|l|l|l|}
\hline ja & ja & ja \\
\hline nein & nein & nein & nein \\
\hline $\begin{array}{l}\text { Klinikum der Ludwig- } \\
\text { Maximilians-Universi- } \\
\text { tät München }\end{array}$ & $\begin{array}{l}\text { Selbstständig seit } \\
1999\end{array}$ & $\begin{array}{l}\text { Universitätsklini- } \\
\text { kum Ulm }\end{array}$ & $\begin{array}{l}\text { Klinik für Kinder- } \\
\text { und Jugendmedi- } \\
\text { zin der Ruhr-Uni- } \\
\text { Bochum }\end{array}$ \\
\hline
\end{tabular}

10 Stimmenthaltung aufgrund von Interessenkonflikt bei folgenden Themen

\begin{tabular}{|l|l|}
\hline & folgenden Themen \\
\hline 1 & $\begin{array}{l}\text { Berater- bzw. Gutachtertätigkeit oder bezahlte Mitar- } \\
\text { beit in einem wissenschaftlichen Beirat eines Unterneh- } \\
\text { mens der Gesundheitswirtschaft (z. B. Arzneimittelin- } \\
\text { dustrie, Medizinproduktindustrie), eines kommerziell } \\
\text { orientierten Auftragsinstituts oder einer Versicherung }\end{array}$ \\
\hline
\end{tabular}

2 Honorare für Vortrags- und Schulungstätigkeiten oder bezahlte Autoren- oder Co-Autorenschaften im Auftrag eines Unternehmens der Gesundheitswirtschaft, eines kommerziell orientierten Auftragsinstituts oder einer Versicherung

3 Finanzielle Zuwendungen (Drittmittel) für Forschungsvorhaben oder direkte Finanzierung von Mitarbeitern der Einrichtung von Seiten eines Unternehmens der Gesundheitswirtschaft, eines kommerziell orientierten Auftragsinstituts oder einer Versicherung

4 Eigentümerinteresse an Arzneimitteln/Medizinprodukten (z. B. Patent, Urheberrecht, Verkaufslizenz)

5 Besitz von Geschäftsanteilen, Aktien, Fonds mit Beteiligung von Unternehmen der Gesundheitswirtschaft

6 Persönliche Beziehungen zu einem Vertretungsberechtigten eines Unternehmens Gesundheitswirtschaft

7 Mitglied von in Zusammenhang mit der Leitlinienentwicklung relevanten Fachgesellschaften/ Berufsverbänden, Mandatsträger im Rahmen der Leitlinienentwicklung

8 Politische, akademische (z. B. Zugehörigkeit zu bestimmten „Schulen“), wissenschaftliche oder persönliche Interessen, die mögliche Konflikte begründen könnten

\begin{tabular}{|l|l|l|l|}
\hline ja & nein \\
\hline nein & nein & \\
\hline nein & nein & \\
\hline nein & nein & \\
\hline nein & nein & \\
\hline ja & ja & \\
\hline nein & & \\
\hline & \\
\hline
\end{tabular}


> Interessenkonflikt-Erklärungen (Fortsetzung)

\section{Leitlinienkoordination: Posovszky, Carsten Leitlinie: Akute infektiöse Gastroenteritis Registernummer: 068/003}

9 Gegenwärtiger Arbeitgeber, relevante frühere Arbeitgeber der letzten 3 Jahre
Universitätsklinikum Jena Am Klinikum 1 07743 Jena

10 Stimmenthaltung aufgrund von Interessenkonflikt bei folgenden Themen

\section{Interessenkonflikt}

Erklärungen siehe Tabelle.

\section{Literatur}

[1] Lo Vecchio A et al. Comparison of Recommendations in Clinical Practice Guidelines for Acute Gastroenteritis in Children. J Pediatr Gastroenterol Nutr 2016; 63: 226-235

[2] Robert-Koch-Institut. Infektionsepidemiologisches Jahrbuch meldepflichtiger Erkrankungen 2016. R.K. Institut, Editor. 2017

[3] Wiegering V et al. Gastroenteritis in childhood: a retrospective study of 650 hospitalized pediatric patients. Int J Infect Dis 2011; 15: e401-e407

[4] Kowalzik F et al. Disease Burden of Rotavirus Gastroenteritis in Children Residing in Germany: A Retrospective, Hospital-based Surveillance. Pediatr Infect Dis J 2016; 35: 97-103

[5] Guarino A et al. European Society for Paediatric Gastroenterology, Hepatology, and Nutrition/European Society for Paediatric Infectious Diseases Evidence-based Guidelines for the Management of Acute Gastroenteritis in Children in Europe. JPGN 2008; 46: S81-S122

[6] Guarino A et al. European Society for Pediatric Gastroenterology, Hepatology, and Nutrition/European Society for Pediatric Infectious Diseases evidence-based guidelines for the management of acute gastroenteritis in children in Europe: update 2014. J Pediatr Gastroenterol Nutr 2014; 59: $132-152$

[7] NICE-guideline Diarrhoea and vomiting caused by gastroenteritis in under 5s diagnosis and management 2009.

[8] S1-Handlungsempfehlung Akuter Durchfall (DEGAM). AWMF 2013.

[9] Weaver LT. Bowel habit from birth to old age. J Pediatr Gastroenterol Nutr 1988; 7: 637-640

[10] Nationales_Referenzzentrum_fr_Surveillance_von_nosokomialen_Infektionen, Definitionen nosokomialer Infektionen für die Surveillance im Krankenhaus-Infektions- Surveillance-System (KISS-Definitionen), Editor. Berlin: RKI. 2017
[11] Guarino A, De Marco G. Peristent diarrhea. In: Walker WA, Kleinman RE, Sherman PM, et al., Editor Pediatric Gastrointestinal Disease.2004: 180193

[12] Kliegman RM, Behrman RE, Jenson HB et al. Nelson Textbook of Pediatrics. $18^{\text {th }}$ edition. Part XVII: The Digestive System: 338 Chronic Diarrhea. Saunders; 2007. ISBN: 1416024506/978-1416024507

[13] Mor SM et al. Microsporidiosis and malnutrition in children with persistent diarrhea, Uganda. Emerg Infect Dis 2009; 15: 49-52

[14] Iannotti LL et al. Diagnosis and treatment of severely malnourished children with diarrhoea. J Paediatr Child Health 2015; 51: 387-395

[15] Giannattasio A, Guarino A, Lo Vecchio A. Management of children with prolonged diarrhea. F1000Res 2016; 5: 1-11

[16] Strand TA et al. Risk factors for extended duration of acute diarrhea in young children. PLoS One 2012; 7: e36436

[17] Moore SR et al. Prolonged episodes of acute diarrhea reduce growth and increase risk of persistent diarrhea in children. Gastroenterology 2010; 139: 1156-1164

[18] Fleck J. Diarrhea. Practical Strategies in pediatric Diagnosis and Therapy. ed. N.M. Kliegman RM, Super DM Philadelphia: Elsevier Saunders; 1996: 279-300

[19] Ogilvie I et al. Burden of community-acquired and nosocomial rotavirus gastroenteritis in the pediatric population of Western Europe: a scoping review. BMC Infect Dis 2012; 12: 62

[20] Payne DC et al. Norovirus and medically attended gastroenteritis in U.S. children. N Engl J Med 2013; 368: 1121-1130

[21] Hemming $M$ et al. Major reduction of rotavirus, but not norovirus, gastroenteritis in children seen in hospital after the introduction of RotaTeq vaccine into the National Immunization Programme in Finland. Eur ] Pediatr 2013; 172: 739-746

[22] Belliot $G$ et al. Evidence of emergence of new GGll.4 norovirus variants from gastroenteritis outbreak survey in France during the 2007-to-2008 and 2008-to-2009 winter seasons. J Clin Microbiol 2010; 48: 994-998

[23] Hall AJ et al. Incidence of acute gastroenteritis and role of norovirus, Georgia, USA, 2004-2005. Emerg Infect Dis 2011; 17: 1381-1388 
[24] Ajami N et al. Characterization of norovirus-associated traveler's diarrhea. Clin Infect Dis 2010; 51: 123-130

[25] Wasserman D et al. Molecular analysis of the fructose transporter gene (GLUT5) in isolated fructose malabsorption. J Clin Invest 1996; 98: 2398-2402

[26] Zimmer KP. Laktose- und Fruktosemalabsorption. Monatsschr Kinderheilkd 2007; 155: 565-576

[27] Ciccarelli S, Stolfi I, Caramia G. Management strategies in the treatment of neonatal and pediatric gastroenteritis. Infect Drug Resist 2013; 6: 133-161

[28] THE TREATMENT OF DIARRHOEA. W.H. Organisation, Editor. 2005

[29] Operario DJ et al. Etiology of Severe Acute Watery Diarrhea in Children in the Global Rotavirus Surveillance Network Using Quantitative Polymerase Chain Reaction. J Infect Dis 2017; 216: 220-227

[30] Walker CL et al. Global burden of childhood pneumonia and diarrhoea. Lancet 2013; 381: 1405-1416

[31] Enserink R et al. Gastroenteritis attributable to 16 enteropathogens in children attending day care: significant effects of rotavirus, norovirus, astrovirus, Cryptosporidium and Giardia. Pediatr Infect Dis J 2015; 34: $5-10$

[32] Fletcher SM, McLaws ML, Ellis JT. Prevalence of gastrointestinal pathogens in developed and developing countries: systematic review andmeta-analysis. J Public Health Res 2013; 2: 42-53

[33] Karsten C et al. Incidence and risk factors for community-acquired acute gastroenteritis in north-west Germany in 2004. Eur J Clin Microbiol Infect Dis 2009; 28: 935-943

[34] Garcia Vera C et al. Acute bacterial gastroenteritis: 729 cases recruited by a Primary Care national network. An Pediatr (Barc) 2017; 87: 128134

[35] Tam CC et al. Changes in causes of acute gastroenteritis in the United Kingdom over 15 years: microbiologic findings from 2 prospective, population-based studies of infectious intestinal disease. Clin Infect Dis 2012; 54: 1275-1286

[36] Wadl M et al. Easy-to-use rapid test for direct detection of Campylobacter spp. in chicken feces. J Food Prot 2009; 72: 2483-2488

[37] Febriani $Y$ et al. Association between indicators of livestock farming intensity and hospitalization rate for acute gastroenteritis. Epidemiol Infect 2009; 137: 1073-1085

[38] Bruijning-Verhagen P, Quach C, Bonten M. Nosocomial rotavirus infections: a meta-analysis. Pediatrics 2012; 129: e1011-e1019

[39] Valentini D et al. Hospital-acquired rotavirus and norovirus acute gastroenteritis in a pediatric unit, in 2014-2015. J Med Virol 2017; 89: 1768-1774

[40] Guarino A, Lo Vecchio A, Berni Canani R. Chronic diarrhoea in children. Best Pract Res Clin Gastroenterol 2012; 26: 649-661

[41] Lee KS et al. How to do in persistent diarrhea of children?: concepts and treatments of chronic diarrhea. Pediatr Gastroenterol Hepatol Nutr 2012; 15: 229-236

[42] Widdowson MA et al. Global rotavirus surveillance: determining the need and measuring the impact of rotavirus vaccines. J Infect Dis 2009; 200 (Suppl. 1): S1-S8

[43] Shai S et al. Rotavirus disease in Germany-a prospective survey of very severe cases. Pediatr Infect Dis J 2013; 32: e62-e67

[44] Mathai J et al. Chronic and persistent diarrhea in infants and young children: status statement. Indian Pediatr 2011; 48: 37-42

[45] Rahman AE et al. Childhood diarrhoeal deaths in seven low- and middleincome countries. Bull World Health Organ 2014; 92: 664-671

[46] Abba $\mathrm{K}$ et al. Pathogens associated with persistent diarrhoea in children in low and middle income countries: systematic review. BMC Infect Dis 2009; 9: 88
[47] Whyte LA, Al-Araji RA, McLoughlin LM. Guidelines for the management of acute gastroenteritis in children in Europe. Arch Dis Child Educ Pract Ed 2015; 100: 308-312

[48] Lo Vecchio A et al. An international consensus report on a new algorithm for the management of infant diarrhoea. Acta Paediatr 2016; 105 : e384-e389

[49] Lorrot $\mathrm{M}$ et al. Epidemiology and clinical features of gastroenteritis in hospitalised children: prospective survey during a 2-year period in a Parisian hospital, France. Eur J Clin Microbiol Infect Dis 2011; 30: 361-368

[50] Kobrynski L], Mayer L. Diagnosis and treatment of primary immunodeficiency disease in patients with gastrointestinal symptoms. Clin Immunol 2011; 139: 238-248

[51] Krones E, Hogenauer C. Diarrhea in the immunocompromised patient. Gastroenterol Clin North Am 2012; 41: 677-701

[52] Munir N et al. Norovirus infection in immunocompromised children and children with hospital-acquired acute gastroenteritis. J Med Virol 2014; 86: 1203-1209

[53] Hagel S et al. S2k-guideline gastrointestinal infectious diseases and Whipple's disease. Z Gastroenterol 2015; 53: 418-459

[54] Rosenfeld L et al. Life-threatening systemic rotavirus infection after vaccination in Severe Combined Immunodeficiency (SCID). Pediatr Allergy Immunol 2017; 28: 841-843

[55] Patel NC et al. Vaccine-acquired rotavirus in infants with severe combi ned immunodeficiency. N Engl J Med 2010; 362: 314-319

[56] Agarwal S, Mayer L. Diagnosis and treatment of gastrointestinal disorders in patients with primary immunodeficiency. Clin Gastroenterol Hepatol 2013; 11: 1050-1063

[57] Agarwal S, Mayer L. Pathogenesis and treatment of gastrointestinal disease in antibody deficiency syndromes. J Allergy Clin Immunol 2009; 124: 658-664

[58] Lawson PA et al. Reclassification of Clostridium difficile as Clostridioides difficile (Hall and O'Toole 1935) Prevot 1938. Anaerobe 2016; 40: 95-99

[59] Nicholson MR et al. Novel Risk Factors for Recurrent Clostridium difficile Infection in Children. J Pediatr Gastroenterol Nutr 2014; 60: 18-22

[60] Samady W, Pong A, Fisher E. Risk factors for the development of Clostridium difficile infection in hospitalized children. Curr Opin Pediatr 2014; 26: 568-572

[61] Nylund CM et al. Clostridium difficile infection in hospitalized children in the United States. Arch Pediatr Adolesc Med 2011; 165: 451-457

[62] Zilberberg MD, Tillotson GS, McDonald C. Clostridium difficile infections among hospitalized children, United States, 1997-2006. Emerg Infect Dis 2010; 16: 604-609

[63] Trifan A et al. Impact of Clostridium difficile infection on inflammatory bowel disease outcome: a review. World J Gastroenterol 2014; 20: 11736-11742

[64] Turner D et al. Management of Paediatric Ulcerative Colitis, Part 2. Journal of Pediatric Gastroenterology and Nutrition 2018; 67: 292-310

[65] Barker HC et al. Clostridium difficile pancolitis in adults with cystic fibrosis. J Cyst Fibros 2008; 7: 444-447

[66] Egressy K, Jansen M, Meyer KC. Recurrent Clostridium difficile colitis in cystic fibrosis: an emerging problem. J Cyst Fibros 2013; 12: 92-96

[67] Mc Laughlin D, Friedmacher F, Puri P. The impact of Clostridium difficile on paediatric surgical practice: a systematic review. Pediatr Surg Int 2014: $30: 853-859$

[68] McFarland LV et al. Comparison of pediatric and adult antibiotic-associated diarrhea and Clostridium difficile infections. World ] Gastroenterol 2016; 22: 3078-3104

[69] Tschudin-Sutter $S$ et al. Distinguishing community-associated from hospital- associated Clostridium difficile infections in children: implications for public health surveillance. Clin Infect Dis 2013; 57: 1665-1672 
[70] Valentini D et al. Coinfection in acute gastroenteritis predicts a more severe clinical course in children. Eur J Clin Microbiol Infect Dis 2013; 32: 909-915

[71] Zhang SX et al. Impact of co-infections with enteric pathogens on children suffering from acute diarrhea in southwest China. Infect Dis Poverty 2016; 5: 64

[72] Shrivastava AK et al. Multiple etiologies of infectious diarrhea and concurrent infections in a pediatric outpatient-based screening study in Odisha, India. Gut Pathog 2017; 9: 16

[73] Enserink R et al. High detection rates of enteropathogens inasymptomatic children attending day care. PLoS One 2014; 9: e89496

[74] Heusinkveld $M$ et al. Potential causative agents of acute gastroenteritis in households with preschool children: prevalence, risk factors, clinical relevance and household transmission. Eur J Clin Microbiol Infect Dis 2016; 35: 1691-1700

[75] Guarino A et al. The management of acute diarrhea in children in developed and developing areas: from evidence base to clinical practice. Expert Opin Pharmacother 2012; 13: 17-26

[76] (DGPI), D.G.f.P.I. DGPI-Handbuch - Infektionen bei Kindern und Jugendlichen. 6. Auflage ed. Stuttgart - New York: Georg-Thieme-Verlag; 2013

[77] Bailey B et al. External validation of the clinical dehydration scale for children with acute gastroenteritis. Acad Emerg Med 2010; 17: 583-588

[78] Goldman RD, Friedman JN, Parkin PC. Validation of the clinical dehydration scale for children with acute gastroenteritis. Pediatrics 2008; 122: $545-549$

[79] Kinlin LM, Freedman SB. Evaluation of a clinical dehydration scale in children requiring intravenous rehydration. Pediatrics 2012; 129: e1211-e1219

[80] Pruvost I et al. The value of body weight measurement to assess dehydration in children. PLoS One 2013; 8: e55063

[81] Schnadower D et al. Validation of the modified Vesikari score in children with gastroenteritis in 5 US emergency departments. J Pediatr Gastroenterol Nutr 2013; 57: 514-519

[82] Fleming $S$ et al. The Diagnostic Value of Capillary Refill Time for Detecting Serious Illness in Children: A Systematic Review and MetaAnalysis. PLoS One 2015; 10: e0138155

[83] Shavit I et al. A novel imaging technique to measure capillary-refill time: improving diagnostic accuracy for dehydration in young children with gastroenteritis. Pediatrics 2006; 118: 2402-2408

[84] Forman $S$ et al. The epidemiology of hypernatraemia in hospitalised children in Lothian: a 10-year study showing differences between dehydration, osmoregulatory dysfunction and salt poisoning. Arch Dis Child 2012; 97: 502-507

[85] Kaiser $\mathrm{P}$ et al. Complications in hospitalized children with acute gastroenteritis caused by rotavirus: a retrospective analysis. Eur J Pediatr 2012; 171: $337-345$

[86] Shahrin L et al. Clinical Manifestations of Hyponatremia and Hypernatremia in Under-Five Diarrheal Children in a Diarrhea Hospital. J Trop Pediatr 2016; 62: 206-212

[87] van den Berg J, Berger MY. Guidelines on acute gastroenteritis in children: a critical appraisal of their quality and applicability in primary care. BMC Fam Pract 2011; 12: 134

[88] Friedman JN et al. Development of a clinical dehydration scale for use in children between 1 and 36 months of age. The Journal of Pediatrics 2004; 145: 201-207

[89] Falszewska A, Dziechciarz P, Szajewska H. The diagnostic accuracy of Clinical Dehydration Scale in identifying dehydration in children with acute gastroenteritis: a systematic review. Clin Pediatr (Phila) 2014; 53 : $1181-1188$
[90] Parkin PC et al. Clinical and laboratory assessment of dehydration severity in children with acute gastroenteritis. Clin Pediatr (Phila) 2010; 49: $235-239$

[91] Geurts D et al. How to Predict Oral Rehydration Failure in Children With Gastroenteritis. J Pediatr Gastroenterol Nutr 2017; 5: 503-508

[92] Dennehy PH. Viral gastroenteritis in children. Pediatr Infect Dis ] 2011; 30: 63-64

[93] Lee RM et al. Incubation periods of viral gastroenteritis: a systematic review. BMC Infect Dis 2013; 13: 446

[94] Kochen M, Scherer M. DEGAM S1-Leitlinie EHEC / HUS. AWMF 2011.

[95] Turck D et al. Incidence and risk factors of oral antibiotic-associated diarrhea in an outpatient pediatric population. J Pediatr Gastroenterol Nutr 2003; 37: 22-26

[96] Bryant K, McDonald LC. Clostridium difficile infections in children. Pediatr Infect Dis J 2009; 28: 145-146

[97] Ferraris L et al. Clostridia in premature neonates' gut: incidence, antibiotic susceptibility, and perinatal determinants influencing colonization. PLoS One 2012; 7: e30594

[98] Pascarella F et al. Impact of Clostridium difficile infection on pediatric inflammatory bowel disease. J Pediatr 2009; 154: 854-858

[99] Sandberg KC et al. Disproportionate rise in Clostridium difficile-associated hospitalizations among US youth with inflammatory bowel disease, 1997-2011. J Pediatr Gastroenterol Nutr 2015; 60: 486-492

[100] Martinelli $\mathrm{M}$ et al. Clostridium difficile and pediatric inflammatory bowel disease: a prospective, comparative, multicenter, ESPGHAN study. Inflamm Bowel Dis 2014; 20: 2219-2225

[101] Schutze GE et al. Clostridium difficile infection in infants and children. Pediatrics 2013; 131: 196-200

[102] Baron EJ et al. A guide to utilization of the microbiology laboratory for diagnosis of infectious diseases: 2013 recommendations by the Infectious Diseases Society of America (IDSA) and the American Society for Microbiology (ASM)(a). Clin Infect Dis 2013; 57: e22-e121

[103] Miller JM et al. A Guide to Utilization of the Microbiology Laboratory for Diagnosis of Infectious Diseases: 2018 Update by the Infectious Diseases Society of America and the American Society for Microbiology. Clin Infect Dis 2018; 67: 813-816

[104] Hayajneh WA et al. Comparison of clinical associations and laboratory abnormalities in children with moderate and severe dehydration. J Pediatr Gastroenterol Nutr 2010; 50: 290-294

[105] Kuge R, Morikawa Y, Hasegawa Y. Uric acid and dehydration in children with gastroenteritis. Pediatrics International 2017; 59: 1151-1156

[106] Hoxha TF et al. The usefulness of clinical and laboratory parameters for predicting severity of dehydration in children with acute gastroenteritis. Med Arch 2014; 68: 304-307

[107] Yilmaz $\mathrm{K}$ et al. Evaluation of laboratory tests in dehydrated children with acute gastroenteritis. J Paediatr Child Health 2002; 38: 226-228

[108] Mansour AM et al. Enteric viral infections as potential risk factors for intussusception. J Infect Dev Ctries 2013; 7: 28-35

[109] Arbizu RA et al. Intussusception associated with adenovirus. J Pediatr Gastroenterol Nutr 2014; 59: e41

[110] Nylund CM, Denson LA, Noel JM. Bacterial enteritis as a risk factor for childhood intussusception: a retrospective cohort study. J Pediatr 2010; 156: 761-765

[111] Gluckman $S$ et al. Management for intussusception in children. Cochrane Database Syst Rev 2017; 6: CD006476

[112] Carroll AG et al. Comparative Effectiveness of Imaging Modalities for the Diagnosis and Treatment of Intussusception: A Critically Appraised Topic. Acad Radiol 2017; 24: 521-529

[113] Xie $X$ et al. A randomized trial of pneumatic reduction versus hydrostatic reduction for intussusception in pediatric patients. J Pediatr Surg 2018; 53: 1464-1468 
[114] Fonseca BK, Holdgate A, Craig JC. Enteral vs intravenous rehydration therapy for children with gastroenteritis: a meta-analysis of randomized controlled trials. Arch Pediatr Adolesc Med 2004; 158: 483-490

[115] Gerste R. Verdünnter Apfelsaft statt Elektrolytlösung reicht aus. Deutsches Ärzteblatt 2016; 113: 1317

[116] Hoekstra JH et al. Oral rehydration solution containing a mixture of non- digestible carbohydrates in the treatment of acute diarrhea: a multicenter randomized placebo controlled study on behalf of the ESPGHAN working group on intestinal infections. J Pediatr Gastroenterol Nutr 2004; 39: 239-245

[117] Freedman SB et al. Treatment of acute gastroenteritis in children: an overview of systematic reviews of interventions commonly used in developed countries. Evid Based Child Health 2013; 8: 1123-1137

[118] Bellemare $S$ et al. Oral rehydration versus intravenous therapy for treating dehydration due to gastroenteritis in children: a meta-analysis of randomised controlled trials. BMC Med 2004; 2: 11

[119] Gregorio GV et al. Polymer-based oral rehydration solution for treating acute watery diarrhoea. Cochrane Database Syst Rev 2016; 12: CD006519

[120] Farthing M]. Oral rehydration: an evolving solution. J Pediatr Gastroenterol Nutr 2002; 34 (Suppl. 1): S64-S67

[121] Guarino A et al. Oral rehydration: toward a real solution. J Pediatr Gastroenterol Nutr 2001; 33 (Suppl. 2): S2-S12

[122] Sentongo TA. The use of oral rehydration solutions in children and adults. Curr Gastroenterol Rep 2004; 6: 307-313

[123] Passariello A et al. Acceptability and efficacy of a gel hypotonic oral rehydration solution in children with acute gastroenteritis. Eur ] Gastroenterol Hepatol 2015; 27: 523-526

[124] King CK et al. Managing acute gastroenteritis among children: oral rehydration, maintenance, and nutritional therapy. MMWR Recomm Rep 2003; 52: 1-16

[125] Nager AL, Wang V]. Comparison of nasogastric and intravenous methods of rehydration in pediatric patients with acute dehydration. Pediatrics 2002; 109: 566-572

[126] Hartling L et al. Oral versus intravenous rehydration for treating dehydration due to gastroenteritis in children. Cochrane Database Syst Rev 2006(3); CD004390

[127] Spandorfer PR et al. Oral versus intravenous rehydration of moderately dehydrated children: a randomized, controlled trial. Pediatrics 2005; 115: 295-301

[128] Kartha GB, Rameshkumar R, Mahadevan S. Randomized Double-blind Trial of Ringer Lactate Versus Normal Saline in Pediatric Acute Severe Diarrheal Dehydration. J Pediatr Gastroenterol Nutr 2017; 65: 621-626

[129] Toaimah FH, Mohammad HM. Rapid Intravenous Rehydration Therapy in Children With Acute Gastroenteritis: A Systematic Review. Pediatr Emerg Care 2016; 32: 131-135

[130] Freedman SB et al. Rapid versus standard intravenous rehydration in paediatric gastroenteritis: pragmatic blinded randomised clinical trial. BMJ 2011; 343: d6976

[131] El-Bayoumi MA et al. Normal saline is a safe initial rehydration fluid in children with diarrhea-related hypernatremia. Eur J Pediatr 2012; 171: 383-388

[132] Robertson G et al. Relationship between fluid management, changes in serum sodium and outcome in hypernatraemia associated with gastroenteritis. J Paediatr Child Health 2007; 43: 291-296

[133] Zieg J. Pathophysiology of Hyponatremia in Children. Front Pediatr 2017; 5: 213

[134] Hanna M, Saberi MS. Incidence of hyponatremia in children with gastroenteritis treated with hypotonic intravenous fluids. Pediatr Nephro 2010; 25: 1471-1475

[135] Moritz ML, Ayus JC. Improving intravenous fluid therapy in children with gastroenteritis. Pediatr Nephrol 2010; 25: 1383-1384
[136] Moritz ML, Ayus JC. 100 cc 3\% sodium chloride bolus: a novel treatment for hyponatremic encephalopathy. Metab Brain Dis 2010; 25: 91-96

[137] Neville KA et al. Isotonic is better than hypotonic saline for intravenous rehydration of children with gastroenteritis: a prospective randomised study. Arch Dis Child 2006; 91: 226-232

[138] Wang J, Xu E, Xiao Y. Isotonic versus hypotonic maintenance IV fluids in hospitalized children: a meta-analysis. Pediatrics 2014; 133: 105-113

[139] Holliday MA, Ray PE, Friedman AL. Fluid therapy for children: facts, fashions and questions. Arch Dis Child 2007; 92: 546-550

[140] Szajewska $\mathrm{H}$ et al. Use of probiotics for management of acute gastroenteritis: a position paper by the ESPGHAN Working Group for Probiotics and Prebiotics. J Pediatr Gastroenterol Nutr 2014; 58: 531-539

[141] Urbanska M, Gieruszczak-Bialek D, Szajewska H. Systematic review with meta-analysis: Lactobacillus reuteri DSM 17938 for diarrhoeal diseases in children. Aliment Pharmacol Ther 2016; 43: 1025-1034

[142] Schnadower D et al. Lactobacillus rhamnosus GG versus Placebo for Acute Gastroenteritis in Children. N Engl J Med 2018; 379: 2002-2014

[143] Freedman SB et al. Multicenter Trial of a Combination Probiotic for Children with Gastroenteritis. N Engl ] Med 2018; 379: 2015-2026

[144] Das JK et al. The effect of antiemetics in childhood gastroenteritis. BMC Public Health 2013; 13 (Suppl. 3): S9

[145] Dalby-Payne JR, Elliott EJ. Gastroenteritis in children. Clinical Evidence 2011; 7: 1-64

[146] Marchetti F et al. Oral Ondansetron versus Domperidone for Acute Gastroenteritis in Pediatric Emergency Departments: Multicenter Double Blind Randomized Controlled Trial. PLoS One 2016; 11: e0165441

[147] Hoffman RJ, Alansari K. Effect of intravenous ondansetron on QTc interval in children with gastroenteritis. Am J Emerg Med 2017; 5: 754-757

[148] Uhlig U et al. Dimenhydrinate in children with infectious gastroenteritis: a prospective, RCT. Pediatrics 2009; 124: e622-e632

[149] Gordon M, Akobeng A. Racecadotril for acute diarrhoea in children: systematic review and meta-analyses. Arch Dis Child 2016; 101: 234240

[150] Li ST, Grossman DC, Cummings P. Loperamide therapy for acute diarrhea in children: systematic review and meta-analysis. PLoS Med 2007: 4: e98

[151] Bruzzese E, Giannattasio A, Guarino A. Antibiotic treatment of acute gastroenteritis in children. F1000Res 2018; 7: 193

[152] Riddle MS et al. Guidelines for the prevention and treatment of travelers' diarrhea: a graded expert panel report. Journal of Travel Medicine 2017; 24 (Suppl. 1): S63-S80

[153] WHO. Guidelines for the control of shigellosis, including epidemics due to Shigella dysenteriae type 1. Geneva: W.H. Organisation, Editor. 2005

[154] Christopher PR et al. Antibiotic therapy for Shigella dysentery. Cochrane Database Syst Rev 2010(8); CD006784

[155] Bennish ML et al. Low risk of hemolytic uremic syndrome after early effective antimicrobial therapy for Shigella dysenteriae type 1 infection in Bangladesh. Clin Infect Dis 2006; 42: 356-362

[156] Basualdo W, Arbo A. Randomized comparison of azithromycin versus cefixime for treatment of shigellosis in children. Pediatr Infect Dis ] 2003; 22: 374-377

[157] Williams PCM, Berkley JA. Guidelines for the management of paediatric cholera infection: a systematic review of the evidence. Paediatrics and International Child Health 2018; 38 (Suppl. 1): S16-S31

[158] Kaushik JS et al. Single dose azithromycin versus ciprofloxacin for cholera in children: a randomized controlled trial. Indian Pediatr 2010; 47: 309-315 
[159] Onwuezobe IA, Oshun PO, Odigwe CC. Antimicrobials for treating symptomatic non-typhoidal Salmonella infection. Cochrane Database Syst Rev 2012; 11: CD001167

[160] Shkalim V et al. Characteristics of non-typhi Salmonella gastroenteritis associated with bacteremia in infants and young children. Infection 2012; 40: 285-289

[161] Granados CE et al. Drugs for treating giardiasis. Cochrane Database Syst Rev 2012; 12: CD007787

[162] Spina A et al. Spectrum of enteropathogens detected by the FilmArray GI Panel in a multicentre study of community-acquired gastroenteritis. Clin Microbiol Infect 2015; 21: 719-728

[163] Croxen MA et al. Recent advances in understanding enteric pathogenic Escherichia coli. Clin Microbiol Rev 2013; 26: 822-880

[164] Wong CS et al. Risk factors for the hemolytic uremic syndrome in children infected with Escherichia coli 0157:H7: a multivariable analysis. Clin Infect Dis 2012; 55: 33-41

[165] Ternhag A et al. A meta-analysis on the effects of antibiotic treatment on duration of symptoms caused by infection with Campylobacter species. Clin Infect Dis 2007; 44: 696-700

[166] Hess SY et al. Recent advances in knowledge of zinc nutrition andhuman health. Food Nutr Bull 2009; 30: S5-S11

[167] Berni Canani R, Buccigrossi V, Passariello A. Mechanisms of action ofzinc in acute diarrhea. Curr Opin Gastroenterol 2011; 27: 8-12

[168] Lazzerini M, Wanzira H. Oral zinc for treating diarrhoea in children. Cochrane Database Syst Rev 2016; 12: CD005436

[169] Brown KH et al. Preventive zinc supplementation among infants, preschoolers, and older prepubertal children. Food and Nutrition Bulletin 2009; 30: S12-S40

[170] Liberato SC, Singh G, Mulholland K. Zinc supplementation in young children: A review of the literature focusing on diarrhoea prevention and treatment. Clin Nutr 2015; 34: 181-188

[171] Wessells KR, Brown KH. Estimating the global prevalence of zinc deficiency: results based on zinc availability in national food supplies and the prevalence of stunting. PLoS One 2012; 7: e50568

[172] Creasy W, Stebbings C. Question 1: Does zinc enhance recovery time from gastroenteritis in high-income countries? Arch Dis Child 2018; 103: $297-300$

[173] Goldman RD. Zinc supplementation for acute gastroenteritis. Can Fam Physician 2013; 59: 363-364

[174] Szajewska H, Dziechciarz P, Mrukowicz ]. Meta-analysis: Smectite in the treatment of acute infectious diarrhoea in children. Aliment Pharmacol Ther 2006; 23: 217-227

[175] Das RR, Sankar ], Naik SS. Efficacy and safety of diosmectite in acute childhood diarrhoea: a meta-analysis. Arch Dis Child 2015; 100: 704-712

[176] Piescik-Lech M, Urbanska M, Szajewska H. Lactobacillus GG (LGG) and smectite versus LGG alone for acute gastroenteritis: a double-blind, randomized controlled trial. Eur J Pediatr 2013; 172: 247-253

[177] Gregorio GV, Dans LF, Silvestre MA. Early versus Delayed Refeeding for Children with Acute Diarrhoea. Cochrane Database Syst Rev 2011(7); CD00729

[178] MacGillivray S, Fahey T, McGuire W. Lactose avoidance for young children with acute diarrhoea. Cochrane Database Syst Rev 2013(10); CD005433

[179] NICE-pathways: Fluid and nutritional management in children with diarrhoea and vomiting. NICE. 2017

[180] Lamberti LM et al. Breastfeeding and the risk for diarrhea morbidity and mortality. BMC Public Health 2011; 11 (Suppl. 3): S15

[181] Quigley MA, Kelly YJ, Sacker A. Breastfeeding and hospitalization for diarrheal and respiratory infection in the United Kingdom Millennium Cohort Study. Pediatrics 2007; 119: e837-e842
[182] Morales E et al. Effects of prolonged breastfeeding and colostrum fatty acids on allergic manifestations and infections in infancy. Clin Exp Allergy 2012; 42: 918-928

[183] Morrow AL et al. Human-milk glycans that inhibit pathogen binding protect breast-feeding infants against infectious diarrhea. J Nutr 2005; 135: 1304-1307

[184] Ruiz-Palacios GM et al. Safety and efficacy of an attenuated vaccine against severe rotavirus gastroenteritis. N Engl J Med 2006; 354: 11-22

[185] Vesikari T et al. Safety and efficacy of a pentavalent human-bovine (WC3) reassortant rotavirus vaccine. N Engl ] Med 2006; 354: 23-33

[186] Soares-Weiser K, Maclehose H. Vaccines for preventing rotavirus diarrhoea: vaccines in use. Cochrane Database Syst Rev 2012; 11 : CD008521. doi:10.1002/14651858.CD008521.pub3

[187] Neuerungen in den aktuellen Empfehlungen der Stä ndigen Impfkommission (STIKO) am RKI vom August 2013. Epidemiologisches Bulletin. 2013; 35

[188] Rha B et al. Effectiveness and impact of rotavirus vaccines in the United States - 2006-2012. Expert Rev Vaccines 2014; 13: 365-376

[189] Shah MP et al. Decline in Emergency Department Visits for Acute Gastroenteritis Among Children in 10 US States After Implementation of Rotavirus Vaccination, 2003 to 2013. Pediatr Infect Dis J 2016; 35 : 782-786

[190] Adlhoch C et al. Rotavirus vaccine effectiveness and case-control study on risk factors for breakthrough infections in Germany, 2010-2011. Pediatr Infect Dis J 2013; 32: e82-e89

[191] Weiss $S$ et al. Incidence of intussusception in early infancy: a capturerecapture estimate for Germany. Klin Padiatr 2011; 223: 419-423

[192] Monk HM, Motsney AJ, Wade KC. Safety of rotavirus vaccine in the NICU. Pediatrics 2014; 133: e1555-e1560

[193] Civardi E et al. Viral outbreaks in neonatal intensive care units: what we do not know. Am J Infect Control 2013; 41: 854-856

[194] Pammi M, Haque KN. Oral immunoglobulin for the prevention of rotavirus infection in low birth weight infants. Cochrane Database Syst Rev 2011(11); CD003740

[195] Barnes GL et al. A randomised trial of oral gammaglobulin in low-birthweight infants infected with rotavirus. Lancet 1982; 1: 1371-1373

[196] Empfehlung der Kommission für Krankenhaushygiene und Infektionsprävention Personelle und organisatorische Voraussetzungen zur Prävention nosokomialer Infektionen. Bundesgesundheitsblatt Gesundheitsforschung Gesundheitsschutz 2009; 52: 951-962

[197] S3-Leitlinie Strategien zur Sicherung rationaler Antibiotika-Anwendung im Krankenhaus. AWMF 2013; 092-001.

[198] Oh DY, Gaedicke G, Schreier E. Viral agents of acute gastroenteritis in German children: prevalence and molecular diversity. J Med Virol 2003; 71: 82-93

[199] Roberts L et al. Effect of infection control measures on the frequency of diarrheal episodes in child care: a randomized, controlled trial. Pediatrics 2000: 105 : 743-746

[200] Kotch JB et al. Hand-washing and diapering equipment reduces disease among children in out-of-home child care centers. Pediatrics 2007; 120: e29-e36

[201] Ejemot-Nwadiaro RI et al. Hand washing promotion for preventing diarrhoea. Cochrane Database Syst Rev 2015(9); CD004265

[202] Hygienemaßnahmen bei Gastroenteritis Ausbrüchen durch Noroviren Leitlinie zur Hygiene in Klinik und Praxis AWMF 2013. AWMF-Leitlinien Register Nr. 029/037.

[203] Sammons JS, Toltzis P, Zaoutis TE. Clostridium difficile Infection in children. JAMA Pediatr 2013; 167: 567-573

[204] Goldenberg JZ et al. Probiotics for the prevention of Clostridium difficile-associated diarrhea in adults and children. Cochrane Database Syst Rev 2017; 12: CD006095 
[205] Arvola T et al. Prophylactic Lactobacillus GG reduces antibiotic-associated diarrhea in children with respiratory infections: a randomized study. Pediatrics 1999; 104: e64

[206] Ruszczynski M, Radzikowski A, Szajewska H. Clinical trial: effectiveness of Lactobacillus rhamnosus (strains E/N, Oxy and Pen) in the prevention of antibiotic- associated diarrhoea in children. Aliment Pharmacol Ther 2008; 28: 154-161

[207] Kotowska M, Albrecht P, Szajewska H. Saccharomyces boulardii in the prevention of antibiotic-associated diarrhoea in children: a randomized double-blind placebo-controlled trial. Aliment Pharmacol Ther 2005; 21: $583-590$

[208] Richardson S et al. Extended excretion of rotavirus after severe diarrhoea in young children. Lancet 1998; 351: 1844-1848

[209] Guidance on Infection Control in Schools and other Childcare Settings. Public Health England. 2016

[210] Castor ML, Beach M]. Reducing illness transmission from disinfected recreational water venues: swimming, diarrhea and the emergence of a new public health concern. Pediatr Infect Dis J 2004; 23: 866-870
[211] Dufour AP et al. Ingestion of swimming pool water by recreational swimmers. J Water Health 2017; 15: 429-437

[212] Centers for Disease, C. and Prevention. Microbes in pool filter backwash as evidence of the need for improved swimmer hygiene - metroAtlanta, Georgia, 2012. MMWR Morb Mortal Wkly Rep. 2013; 62: 385-388

[213] TRBA 250 Biologische Arbeitsstoffe im Gesundheitswesen und in der Wohlfahrtspflege. GMBI, 2014. Ausgabe März 2014, 3. Änderung vom Oktober 2016 (Nr. 10/11).

[214] Martin M et al. National European guidelines for the prevention of Clostridium difficile infection: a systematic qualitative review. J Hosp Infect 2014; 87: 212-219

[215] Robert-Koch-Institut. Ausbruchmanagement und strukturiertes Vorgehen bei gehäuftem Auftreten nosokomialer Infektionen. Bundesgesundheitsbl 2002; 45: 180-186 